Linköping Studies in Science and Technology

Dissertation No. 1889

\title{
Deposition of Al-doped ZnO films by high power impulse magnetron sputtering
}

\author{
Martin Mickan \\ 1.1 LINKÖPING \\ UNIVERSITY

\author{
Plasma \& Coatings Physics \\ Department of Physics, Chemistry and Biology \\ Linköping University, Sweden
}

\begin{abstract}
Part of
Joint European Doctoral program in Materials Science and Engineering (DocMASE) in collaboration with Institut Jean Lamour,

University of Lorraine, France
\end{abstract}


CMartin Mickan, unless otherwise stated

ISBN: 978-91-7685-418-1

ISSN: 0345-7524

Printed by LiU-Tryck, Linköping, Sweden 2017 


\section{Abstract}

Transparent conducting oxides (TCOs) are an important class of materials with many applications such as low emissivity coatings, or transparent electrodes for photovoltaics and flat panel displays. Among the possible TCO materials, Al-doped $\mathrm{ZnO}$ (AZO) is studied due to its relatively low cost and abundance of the raw materials. Thin films of AZO are commonly produced using physical vapour deposition techniques such as magnetron sputtering. However, there is a problem with the homogeneity of the films using reactive direct current magnetron sputtering (DCMS). This homogeneity problem can be related to the bombardment of the growing film with negative oxygen ions, that can cause additional acceptor defects and the formation of insulating secondary phases. In this work AZO films are deposited by high power impulse magnetron sputtering (HiPIMS), a technique in which high instantaneous current densities are achieved by short pulses of low duty cycle.

In the first part of this thesis, the possibility to improve the homogeneity of the deposited AZO films by using HiPIMS is demonstrated. This improvement can be related to the high instantaneous sputtering rate during the HiPIMS pulses, so the process can take place in the metal mode. This allows for a lower oxygen ion bombardment of the growing film, which can help to avoid the formation of secondary phases. Another problem of AZO is the stability of the properties in humid environments. To assess this problem, the degradation of the electrical properties after an aging procedure was investigated for films deposited by both DCMS and by HiPIMS. A method was proposed, to restore the properties of the films, using a low temperature annealing under $\mathrm{N}_{2}$ atmosphere. The improvement of the electrical properties of the films could be related to a diffusion process, where water is diffusing out of the films. Then, the influence of the substrate temperature on the properties of AZO films deposited by HiPIMS was studied. The electrical, optical and structural properties were found to improve with increasing substrate temperature up to $600^{\circ} \mathrm{C}$. This improvement can be mostly explained by the increase 
in crystalline quality and the annealing of defects. Finally, the deposition of AZO films on flexible PET substrates was investigated. The films are growing as a thick porous layer of preferentially c-axis oriented columns on top of a thin dense seed layer. The evolution of the sheet resistance of the films after bending the films with different radii was studied. There is an increase in the sheet resistance of the films with decreasing bending radius, that is less pronounced for thicker films. 


\section{Populärvetenskaplig sammanfattning}

För många viktiga tillämpningar i vårt moderna liv, såsom skärmar till mobiltelefoner eller solceller, är det nödvändigt att ha ett transparent material som har en elektrisk ledningsförmåga. Att både vara transparent och vara elektriskt ledande är en ovanlig materialegenskap. Material som är elektriskt ledande, såsom metaller, är vanligtvis inte transparenta, medan transparenta material, såsom glas, vanligen inte är ledande. Att producera transparenta ledande material är därför en utmaning. Flera metoder för att lösa detta problem är kända och den viktigaste materielgruppen är keramiska material som benämns transparenta ledande oxider. Det vanligaste materialet, som idag används i de flesta bildskärmar, är indiumtennoxid. Indium är emellertid ett dyrt material, så det finns ett intresse att ersätta detta med andra material.

Ett alternativt material är aluminiumdopad zinkoxid (AZO), det vill säga zinkoxid med en liten mängd aluminium inuti. Den transparanta ledaren används oftast i form av en tunn film med en tjocklek mellan 0,1 och $1 \mu \mathrm{m}$ som beläggs på ett substrat. Substratet kan vara av glas, en solcell eller en bildskärm. Flera metoder används för att belägga AZO-tunnfilmer. En vanlig teknik kallas reaktiv magnetron-sputtering. I denna teknik skapas ett plasma i en vakuumkammare, som tillåter att förånga zink och aluminium som kondenserar på substratet. Dessutom tillsätts syre. Detta leder till en kemisk reaktion mellan syre-, zink- och aluminiumatomerna, så att AZO bildas på substratet.

Det har dock visat sig att det är svårt att erhålla filmer med en jämn kvalitet på stora substrat. Det är därför ofta nödvändigt att värma substraten till högre temperaturer. Högre temperaturer gör processen dyrare men framförallt så begränsas valet av möjliga substratmaterial. Vissa material som används i solceller tål inte höga temperaturer. Det finns också intresse för att deponera AZO-filmer på plastsubstrat, vilket också kräver låga temperaturer. För att lösa detta problem används en special- 
teknik som kallas High Power Impulse Magnetron Sputtering (HiPIMS) i arbetet i denna avhandling. I HiPIMS skapas inte plasma kontinuerligt utan koncentreras i korta pulser.

Resultaten presenterade i denna avhandling visar att med användning av HiPIMS-processen gör det möjligt att deponera AZO-tunnfilmer av god kvalitet utan att behöva värma substratet. Detta kan förklaras, i avhandlingen, och beror på hur syre växelverkar med metallerna och hur detta i sin tur påverkar beläggningsprocessen.

Det finns ett annat problem med materialet AZO. Om det utsätts för fukt under lång tid, kommer dess elektriska ledningsförmåga degenereras. Detta beteende har också studerats i denna avhandling och det visas att elektrisk ledningsförmåga kan återställas genom att värma AZO-filmerna i en kväveatmosfär till $180^{\circ} \mathrm{C}$. Dessutom har effekterna av upphettning av substratet vid HiPIMS-deponering undersökts. Resultaten visar att det är möjligt att ytterligare öka filmens kvalitet vid högre beläggningstemperaturer.

Slutligen har AZO-filmer belagts på plastsubstrat. Plasten är böjlig vilket är intressant för utvecklingen av, till exempel, flexibla bildskärmar. Böjning av substratet kan dock bryta AZO-filmerna, så de blir mindre ledande. I denna avhandling böjs plastsubstrat med AZO-filmer för att se hur mycket filmens kvalitet minskar på grund av böjningen. 


\section{Résumé étendu}

Les oxydes conducteurs transparents ou TCO sont une classe de matériaux, à la fois transparents dans le visible et conducteurs électriques. Ces matériaux peuvent être utilisés dans de nombreuses applications, par exemple comme électrodes transparentes dans des cellules solaires, des écrans plats, des écrans tactiles ou des dispositifs électrochromes, ainsi que des dispositifs de chauffage transparents, des films antistatiques ou des fenêtres à faible émissivité. Le TCO le plus courant est $\operatorname{In}_{2} \mathrm{O}_{3}$ dopé Sn (ITO). Cependant, l'indium est un élément coûteux, dont l'approvisionnement fluctue et qui peut s'avérer nocif pour l'être humain. Ainsi, des matériaux alternatifs sont en cours de recherche. Un de ces matériaux est l'oxyde de zinc ( $\mathrm{ZnO})$ dopé à l'Al (AZO), qui est le matériau étudié dans ce travail.

Pour la plupart des applications, les TCO sont nécessaires sous la forme de films minces qui doivent présenter des propriétés homogènes sur de grandes surfaces. Une méthode de dépôt communément utilisée pour déposer des films d'AZO est la pulvérisation cathodique magnétron réactive, qui utilise un plasma pour pulvériser des atomes à partir d'une cible et pour réaliser la croissance d'un film mince sur un substrat par condensation de ces atomes. Cependant, pour le dépôt de films de haute qualité, des températures élevées du substrat sont habituellement nécessaires. Les températures élevées sont un problème pour certains dispositifs tels que les cellules solaires, dont les composants sont sensibles aux températures élevées. C'est également le cas pour certains supports organiques utilisés pour la réalisation de dispositifs flexibles. De plus, lors de la synthèse de films à partir de la pulvérisation réactive conventionnelle, les propriétés des films peuvent se dégrader à cause $\mathrm{du}$ bombardement en ions négatifs d'oxygène pendant la croissance du film.

Dans cette thèse, une forme spéciale de la pulvérisation cathodique magnétron, appelée pulvérisation magnétron en régime d'impulsions de haute puissance (HiPIMS), est utilisée pour déposer des films d'AZO. Avec 
la pulvérisation HiPIMS, des densités de courant instantanées élevées peuvent être atteintes en utilisant des impulsions courtes mais intenses pour créer le plasma. Le but de cette thèse est d'étudier la possibilité de déposer des films d'AZO en utilisant la méthode HiPIMS à basse température. La stabilité des films dans des environnements humides est également évaluée. Ensuite, l'effet de la température du substrat sur les propriétés des films d'AZO déposés par HiPIMS est étudié en détail. Enfin, des films d'AZO auto-nanostructurés sont déposés sur des substrats flexibles, sensibles à la température, afin de leur conférer une fonctionnalité électrique.

Cette thèse est organisée comme suit : Après une introduction correspondant au chapitre 1, les concepts théoriques des TCO sont décrits avec un accent particulier sur les propriétés de $\mathrm{ZnO}$ dans le chapitre 2. Dans le chapitre 3 est décrite la procédure de synthèse des films d'AZO après une introduction des concepts de base de la pulvérisation cathodique magnétron. Les techniques de caractérisation utilisées dans ce travail sont présentées au chapitre 4 . Un résumé des résultats, ainsi que des suggestions pour les travaux futurs figurent aux chapitres 5 et 6 . Enfin, les résultats détaillés sont présentés sous la forme des articles jointes.

Dans l'article 1, des films d'AZO ont été déposés en utilisant la méthode HiPIMS en mode réactif sans assistance thermique. Les propriétés de ces films ont été étudiées et comparées à celles de films d'AZO déposés en utilisant la pulvérisation cathodique à courant continu dans le même réacteur et dans des conditions proches. Les films d'AZO ont été déposés en utilisant trois tensions de décharge différentes entre 540 et 570 V. Les meilleurs films ont été déposés en utilisant l'HiPIMS à la plus haute tension de décharge de $570 \mathrm{~V}$. Dans ce cas, une résistivité optimale de $4 \times 10^{-4} \Omega \mathrm{cm}$ a été trouvée. La concentration de porteurs de charge atteint des valeurs allant jusqu'à $11 \times 10^{20} \mathrm{~cm}^{-3}$. Ceci suggère que la diffusion d'impuretés ionisées est le mécanisme de diffusion dominant dans les films colonnaires.

L’amélioration des propriétés électrique par l'utilisation de la méthode HiPIMS peut être résumé comme suit. En passant du mode continu au mode HiPIMS, et avec une tension de décharge croissante dans le cas de HiPIMS, la résistivité des films et la transmittance dans le proche infrarouge diminuent, le gap augmente et la qualité cristalline diminue. Ces résultats suggèrent que les films deviennent de plus en plus sous-stœchiométriques. De plus, les propriétés électriques et optiques 
mettent en évidence une plus faible hétérogénéité spatiale des propriétés de conduction électrique dans le cas du film déposé par HiPIMS à $570 \mathrm{~V}$. Nous proposons que ce résultat est lié à un moindre bombardement des films par des ions oxygène rapides.

Un bombardement moins prononcé des films par les ions oxygène et le dépôt de films sous-stœchiométriques indiquent que le processus de pulvérisation cathodique se déroule dans le mode métallique. Des films d'AZO ont également été déposés en utilisant des longueurs d'impulsion comprises entre 80 et $120 \mu$ s. Les propriétés optiques et structurales de ces films montrent que les films deviennent plus sous-stœchiométriques avec une largeur d'impulsion croissante et donc une augmentation de la dose d'ions reçue par les cibles au cours d'une impulsion.

Ces résultats suggèrent qu'avec la pulvérisation HiPIMS le processus est décalé vers le mode métallique, en raison de l'augmentation de la vitesse de pulvérisation instantanée, qui empêchent la formation d'une couche d'oxyde à la surface de la cible. À partir de la dose d'ions par impulsion et du profil de la zone d'érosion, la distribution locale du taux de pulvérisation cathodique sur la zone d'érosion a été estimée comme indiqué dans le supplément de l'article 1 . Au centre de la zone d'érosion, le nombre d'atomes pulvérisés est estimé être du même ordre de grandeur que la densité atomique de surface de $\mathrm{ZnO}$. Ceci conforte notre modèle de l'élimination partielle de l'oxygène au centre de la zone d'érosion dans le cas de l'HiPIMS. De plus, la vitesse de dépôt normalisé est plus élevé dans le cas de HiPIMS que dans la pulvérisation cathodique continue.

Dans le deuxième article, des films d'AZO déposés en utilisant la pulvérisation HiPIMS et la pulvérisation DC avec différentes conditions d'élaboration ont été recuits à basse température entre 160 et $180^{\circ} \mathrm{C}$ après un vieillissement dans l'air ambiant. Comme les propriétés électriques de l'AZO sont connues pour se dégrader lors de l'exposition à l'humidité, le procédé de recuit proposé a permis d'améliorer et de restaurer partiellement les propriétés électriques. La dégradation des propriétés électriques a été reliée à l'absorption d'eau et à la formation de groupes hydroxyles dans la littérature. Ces groupes hydroxyle agissent comme des pièges pour les porteurs de charge et peuvent donc diminuer la concentration des porteurs de charge et la mobilité.

Dans ce travail, l'évolution de la résistance et les spectres de transmittance ont été suivis in situ pendant le recuit. Les résultats sont interprétés 
en faisant intervenir un processus de diffusion, lié à la décomposition des groupes hydroxyles et à la diffusion de l'eau vers l'extérieur. Un modèle de diffusion simplifié a été adapté à l'évolution de la résistance des films avec le temps de recuit. Ceci a permis d'obtenir un coefficient de diffusion effectif, qui s'est avéré avoir une valeur la plus élevée pour le film déposé à la pression la plus élevée. Comme une pression de dépôt plus élevée est généralement liée à une microstructure moins dense des films, les résultats suggèrent que les joints de grains servent comme la voie préférentielle de diffusion pour les molécules d'eau. Des preuves supplémentaires pour l'élimination de l'hydrogène des films ont été obtenues par spectrométrie de masse à ionisation secondaire (SIMS), ainsi que par spectrométrie de photoélectrons induits par rayons X (XPS). Les résultats d'XPS pour le pic de niveau de base de $\mathrm{O}$ ls montrent que la quantité de groupes hydroxyles diminue après le recuit.

Dans le troisième article, des films d'AZO ont été déposés à des températures de substrat entre la température ambiante et $600^{\circ} \mathrm{C}$, en utilisant l'HiPIMS réactif. Dans cette étude, les propriétés électriques se sont avérées s'améliorer jusqu'à la température la plus élevée testée de $600^{\circ} \mathrm{C}$ avec une résistivité minimale de $3 \times 10^{-4} \Omega \mathrm{cm}$. L'amélioration de la résistivité des films est principalement liée à une amélioration de la mobilité, due à une qualité cristalline améliorée à température élevée du substrat.

Dans la littérature, les températures de substrat optimales pour le dépôt d'AZO par pulvérisation cathodique réactive sont habituellement comprises entre 200 et $350^{\circ} \mathrm{C}$. Le bombardement du film par les ions d'oxygène provoque la désactivation des porteurs de charge en raison de la formation de phases secondaires et en jouant le rôle d'impureté ionisées qui diffusent les électrons. La formation de phases secondaires est censé être augmenté à des températures élevées du substrat en raison de la désorption préférentielle du $\mathrm{Zn}$. Les résultats de l'article 1 ont montré que les effets inconvénients du bombardement en oxygène peuvent être réduits dans le cas de HiPIMS, ce qui peut expliquer pourquoi il n'y a pas de dégradation des propriétés électriques à température élevée du substrat dans cette étude.

De plus, l'étude de l'effet du vieillissement des films dans l'humidité ambiante, similaire à la procédure décrite dans le papier 2, a été réalisé. Seuls les films déposés à température ambiante ont montré une dégradation significative des propriétés après 9 mois de vieillissement. 
Les films déposés à des températures de substrat de $200^{\circ} \mathrm{C}$ et au delà sont plus stables dans le temps. Ceci peut être relié à la qualité cristalline améliorée des films, qui rend plus difficile la diffusion de l'eau dans les films.

Les résultats du premier article ont montré que l'HiPIMS est une technique appropriée pour déposer des films d'AZO conducteurs transparents à température ambiante. Par conséquent, il est intéressant de déposer des films d'AZO sur des substrats polymères flexibles en utilisant cette technique, car ces substrats sont sensibles aux températures élevées. De plus, les films d'AZO déposés avec des conditions de croissance favorisant une forte vitesse de dépôt consistaient en un réseau poreux de nano-bâtonnets au-dessus d'une couche de départ dense d'une épaisseur d'environ $100 \mathrm{~nm}$. Cette microstructure particulière a permis d'améliorer la fiabilité électrique des films.

La résistance des films a été mesurée après des flexions successives avec un rayon de courbure décroissant. Il a été observé que la résistance augmente avec la diminution du rayon de courbure, cependant, le début de la diminution était décalé vers un rayon de courbure inférieur avec une épaisseur de film croissante. De plus, l'amplitude de la variation de la résistance diminue avec l'épaisseur du film. Cela peut s'expliquer par la nanostructure des films. Lorsque l'échantillon est plat, les nanobâtonnets sont en contact latéral, assurant la conduction dans le film. Lorsque l'échantillon est courbé, les nano-bâtonnets peuvent se séparer sans se rompre et revenir à leur orientation initiale après la flexion. Cette interprétation est soutenue par l'absence de longues fissures dans les films perpendiculaires à la direction de flexion.

D'après les résultats d'analyses par diffraction des rayons $\mathrm{X}$, la couche continue de germination présente une contrainte de compression élevée de près de $3 \mathrm{GPa}$ pour les films déposés sur PET, tandis que pour les films déposés sur $\mathrm{Si}$, la contrainte de compression n'est que de l'ordre de $1 \mathrm{GPa}$. La contrainte de compression élevée dans la couche de germination dans le cas d'un dépôt sur du PET peut être expliquée par la différence élevée des coefficients de dilatation thermique du PET et de l'AZO (respectivement $0.15 \mathrm{~W} \mathrm{~m}^{-1} \mathrm{~K}^{-1}$ et $>30 \mathrm{~W} \mathrm{~m}^{-1} \mathrm{~K}^{-1}$ ). La couche de nano-bâtonnets au dessus de la couche de départ croît avec la même faible contrainte de compression d'environ $1 \mathrm{GPa}$ sur les deux types de substrats. Cette contrainte de compression est proche de la contrainte 
de compression constatée dans les films AZO déposés à température ambiante et à $200^{\circ} \mathrm{C}$ dans l'article 3 .

La formation de la nanostructure des films AZO dans cette étude peut être expliquée par une combinaison d'un effet d'ombrage atomique et d'une diffusion limitée des adatomes due à une vitesse de croissance relativement élevé. L'effet d'ombrage atomique est connu pour conduire à de telles structures poreuses dans le cas d'un dépôt par pulvérisation cathodique sous des angles obliques. La vitesse de croissance dans ce travail était d'environ $40 \mathrm{~nm} / \mathrm{min}$, ce qui est encore plus élevé que la vitesse de croissance le plus élevé dans le cas de de l'article $3(35 \mathrm{~nm} / \mathrm{min}$ à $500^{\circ} \mathrm{C}$ ). Compte tenu de la faible température du substrat dans cette étude, la vitesse de croissance élevé pourrait empêcher la diffusion d'adatomes entre les grains. La ségrégation des phases secondaires aux joints de grains est également susceptible d'empêcher la croissance latérale des grains. 


\section{Preface}

This thesis is the result of my doctoral studies in the Erasmus Mundus joint doctoral program, DocMASE, carried out between 2013 and 2017. During this time, I worked in two research groups, the group Elaboration et Fonctionnalités de Couches Minces at the Institut Jean Lamour (IJL) at the Université de Lorraine (Nancy, France) and the Plasma \& Coatings Physics Division at the Department of Physics, Chemistry and Biology (IFM) at Linköping University (Linköping, Sweden). In addition, the work was supported by the Knut and Alice Wallenberg foundation (KAW 2014.0276).

Martin Mickan

Linköping, October 2017 


\section{Included papers and author's contribution}

\section{Paper 1}

Room temperature deposition of homogeneous, highly transparent and conductive $\mathrm{Al}$-doped $\mathrm{ZnO}$ films by reactive high power impulse magnetron sputtering

M. Mickan, U. Helmersson, H. Rinnert, J. Ghanbaja, D. Muller, and D. Horwat

Sol. Energy Mater. Sol. Cells 157 (2016) 742

\section{Paper 2}

Restoring the properties of transparent Al-Doped $\mathrm{ZnO}$ thin film electrodes exposed to ambient air M. Mickan, M. Stoffel, H. Rinnert, U. Helmersson, and D. Horwat J. Phys. Chem. C 121 (2017) 14426

\section{Paper 3}

Effect of substrate temperature on the deposition of Al-Doped ZnO thin films using high power impulse magnetron sputtering M. Mickan, U. Helmersson, and D. Horwat Submitted

\section{Paper 4}

Improved electrical reliability of flexible transparent electrodes based on bottom-up nanostructured $\mathrm{Al}$-doped $\mathrm{ZnO}$ thin films M. Mickan, S. Ikeda, U. Helmersson, and D. Horwat In manuscript 


\section{My contribution to the papers}

\section{Paper 1}

I was involved in planning the experiments, and performed part of the film synthesis and most of the characterization. I also wrote most of the paper.

\section{Paper 2}

I was involved in planning the experiments, performed part of the film synthesis and most of the characterization. I performed the data analysis and wrote most of the paper.

\section{Paper 3}

I was involved in planning the experiments, performed the film synthesis and characterization. I also wrote the paper.

\section{Paper 4}

I was involved in planning the experiments, performed the film synthesis and part of the characterization. I also wrote the paper.

\section{Related but not included paper}

New strategies for the synthesis of $\mathrm{ZnO}$ and $\mathrm{Al}$-doped $\mathrm{ZnO}$ films by reactive magnetron sputtering at room temperature

D. Horwat, M. Mickan, and W. Chamorro

Phys. Status Solidi C 13 (2016) 951 


\section{Acknowledgements}

First, I would like to thank my supervisor David Horwat for his guidance and support throughout the 4 years of my thesis. Thank you for motivating me and always being available for discussions.

I am also thankful to my co-supervisor Ulf Helmersson for his support and advice, especially during the time of my stays in Linköping.

I would like to thank the members of my committee, especially Aline Rougier for being the opponent for the Swedish part and the reviewer for the French part of this thesis, as well as Gunnar Niklasson for being the second reviewer.

Furthermore, I would like to thank Hervé Rinnert for the interesting discussions and for teaching me how to use the PL setup.

I am also in gratitude to Jean-François Pierson for giving me the opportunity to work as part of his group at IJL.

I would also like to thank the Erasmus Mundus program DocMASE for the funding as well as the opportunity to attend all the interesting summer schools.

I am also thankful to all my collaborators, Jaafar Ghanbaja, Dominique Muller, Mathieu Stoffel, and Shuga Ikeda for their contributions to the manuscripts.

I would also like to thank Flavio Soldera for the preparation of the TEM samples by FIB.

I am also grateful for all the technical and administrative support from the people at IJL, Elodie Boucard, Sylvie Migot and Christine Gendarme for maintaining the SEM, Pascal Boulet for the XRD, Denis Mangin 
for the SIMS measurements, and Valérie Tamburini for all the administrative help organizing my trips to conferences and summer schools.

Special thanks also to their counterparts at IFM, Thomas Lingefelt for the SEM support, Fredrik Eriksson for the XRD support, and Therese Dannetun and Jessica Gidby for the administrative support.

I am very grateful to the people I shared an office with throughout the years in Nancy: Alexis, Alan, Yong, William, Manuel, Katherine, Fahad, Alejandro, Claudia, and Benjamin. Thank you for all the interesting discussions, sharing your chocolate and cookies, and the general good atmosphere. I am also grateful to all the other group members, Alaa, Aurélien D., Aurélien E., Christophe, Daria, David P., Emile, Fabien, Joseph, Nathaniel, Nicole, Silvère, and Stéphanie. Additionally, I would like to thank all the other people that made the pause café and especially the Goûter du Jeudi more enjoyable.

I would also like to thank my colleagues from the Plasma group at IFM, Julien, Nils, Rickard, Robert, Rommel, Sadegh, and Sebastian for providing a good and motivating atmosphere in the lab as well as during the various social activities. Furthermore, thanks to all the people at IFM that I had discussions with or shared fika during the time I spent in Linköping.

Special thanks also to my fellow DocMASE students in Nancy and Linköping: Ana, Aylin, Eric, Fei, Ina, Isabella, Jeni, Jiaqi, Kumar, My, and Nina.

I am also thankful to all my friends from around the world for making life more enjoyable.

Finally, I would like to thank my family for their support throughout my entire life. 


\section{Abbreviations}

\begin{tabular}{ll} 
ALD & Atomic layer deposition \\
AZO & Aluminium doped zinc oxide \\
CVD & Chemical vapour deposition \\
DC & Direct current \\
EDS & Energy dispersive spectroscopy \\
FEG & Field-emission gun \\
FFT & Fast Fourier transform \\
FIB & Focused ion beam \\
FTO & Fluorine doped tin oxide \\
FWHM & Full width at half maximum \\
HiPIMS & High power impulse magnetron sputtering \\
HRTEM & High resolution transmission electron microscopy \\
ITO & Tin doped indium oxide \\
MOCVD & Metal organic chemical vapour deposition \\
OLED & Organic light emitting device \\
PECVD & Plasma enhanced chemical vapour deposition \\
PET & Polyethylene terephthalate \\
PL & Photoluminescence \\
PLD & Pulsed laser deposition \\
PVD & Physical vapour deposition \\
RBS & Rutherford backscattering spectrometry \\
RF & Radio frequency \\
SEM & Scanning electron microscopy \\
SIMS & Secondary ion mass spectrometry \\
TCO & Transparent conducting oxide \\
TEM & Transmission electron microscopy \\
UV & Ultraviolet \\
XANES & X-ray absorption near edge structure \\
XPS & X-ray photoelectron spectroscopy \\
XRD & X-ray diffraction \\
\hline &
\end{tabular}




\section{Contents}

1 Introduction 1

2 Transparent conducting oxides 3

2.1 Physical properties of TCOs $\ldots \ldots \ldots \ldots \ldots \ldots \ldots$

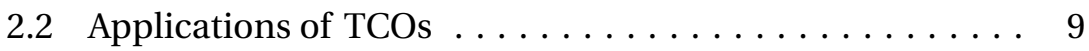

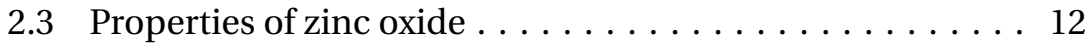

2.4 Deposition methods for AZO thin films $\ldots \ldots \ldots \ldots 16$

3 The sputter deposition process 21

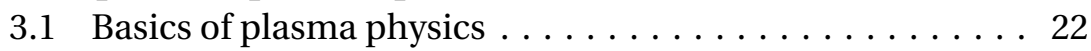

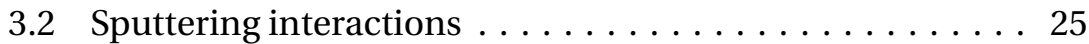

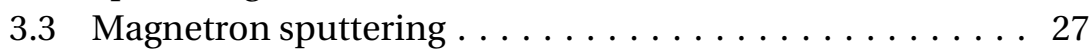

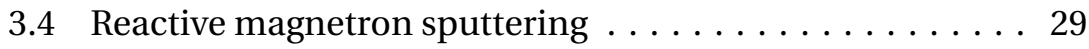

3.5 High power impulse magnetron sputtering . . . . . . 32

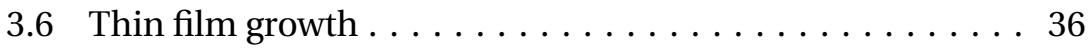

3.7 Sputter deposition of AZO thin films $\ldots \ldots \ldots \ldots \ldots 38$

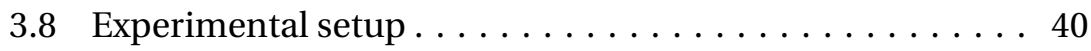

4 Characterization methods 43

4.1 Spectrophotometry.................. 43

4.2 Photoluminescence spectroscopy . . . . . . . . . . 47

4.3 Electrical characterization . . . . . . . . . . . . . 49

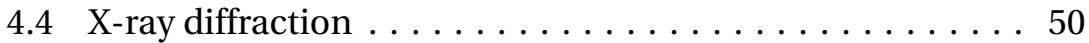

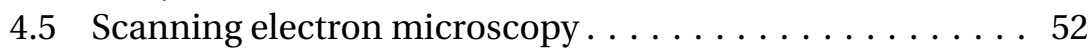

4.6 Transmission electron microscopy . . . . . . . . . . . 54

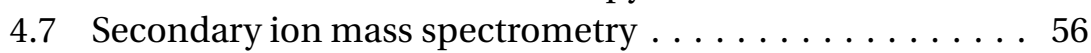

4.8 Rutherford backscattering spectrometry . . . . . . . 57

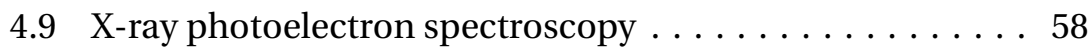

5 Summary of the results 61

6 Contributions and future work 67 


\section{Chapter 1}

\section{Introduction}

Transparent conducting oxides or TCOs are a class of materials, that are both transparent in the visible range as well as electrically conducting. Such materials can be used in many applications for example as transparent electrodes in solar cells, flat panel displays, touchscreens or electrochromic devices, as well as transparent heaters, anti-static films, or low-emissivity windows [1]. The most common TCO is Sn-doped $\mathrm{In}_{2} \mathrm{O}_{3}$ (ITO) [2]. However, as In is an expensive and potentially toxic material with a fluctuating supply, alternative materials are being researched [3]. One such material is Al-doped $\mathrm{ZnO}$ (AZO), which is the material studied in this work.

For most applications, TCOs are needed in the form of thin films that need to show homogeneous properties over large areas. A common deposition method that is used to deposit AZO films is reactive magnetron sputtering, which uses a plasma to sputter atoms from a target and deposit them on a substrate [4]. For the deposition of high quality films, however, elevated substrate temperatures are usually needed [5]. Elevated temperatures are a problem for certain devices such as solar cells, whose components are sensitive towards high temperatures [6, p. 423]. This is also the case for organic polymer substrates that are used for flexible devices [7, p. 5]. Additionally, the properties of the films can degrade due to the bombardment with negative oxygen ions during the film growth $[8,9]$.

In this thesis, a special form of magnetron sputtering, called high power impulse magnetron sputtering (HiPIMS) is used to deposit AZO films. In HiPIMS, high instantaneous current densities can be reached by using short pulses to create the plasma [10]. The goal of this thesis is to investigate the possibility to deposit AZO films at low substrate temperatures using HiPIMS. Additionally, the stability of the films in humid 
environments is assessed. Furthermore, the effect of the substrate temperature on the properties of HiPIMS deposited AZO films is studied in detail. Finally, nanostructured AZO films are deposited on temperature sensitive flexible substrates.

The outline of this thesis is organized as follows: In chapter 2, the theoretical concepts of TCOs are described with a special focus on the properties of $\mathrm{ZnO}$. Then, in chapter 3 the deposition of AZO films is described after an introduction of the basics of magnetron sputtering. The characterization techniques that were used in this work are introduced in chapter 4. A summary of the results and the contributions to the field, as well as suggestions for future work are given in chapters 5 and 6 . Finally, the detailed results are presented in the form of the appended papers. 


\section{Chapter 2}

\section{Transparent conducting oxides}

As already mentioned in chapter 1, TCOs are an interesting type of materials because of their interesting properties, of being simultaneously transparent and conductive. In this chapter more details on this class of materials will be given. The physical properties of TCOs are explained in section 2.1 in order to understand how a material can be both transparent and conductive. The different applications of TCOs are then described in more detail in section 2.2. TCOs can be both n-type as well as p-type conductors. Important $\mathrm{n}$-type TCOs are the already mentioned ITO and AZO, as well as $\mathrm{SnO}_{2}: \mathrm{F}$ (FTO). For p-type TCOs, delafossite materials based on $\mathrm{Cu}_{2} \mathrm{O}$ are commonly used [11]. This chapter will, however, focus mainly on n-type TCOs. Special attention is paid to the TCO material zinc oxide in section 2.3. Finally, a short review of the different deposition methods for Al-doped $\mathrm{ZnO}$ films will be given in section 2.4.

\subsection{Physical properties of TCOs}

In order to be transparent in the visible range, TCOs need to have a band gap that is larger than the energy of photons in the visible range $(\sim 3 \mathrm{eV})$. On the other hand, to be simultaneously conducting, the material needs to have a sufficient charge carrier concentration. The conductivity $\sigma$ of a material is given by

$$
\sigma=n e \mu,
$$

with $n$ the charge carrier concentration, $e$ the elementary charge and $\mu$ the mobility of the charge carriers. To achieve a large charge carrier 
concentration in a wide band gap semiconductor, shallow donor states need to be introduced below the conduction band [12].

When doping semiconductors, additional energy levels are introduced within the band gap close to the valence or conduction band in case of $\mathrm{p}$-type or $\mathrm{n}$-type semiconductors, respectively. These additional states can introduce charge carriers in the valence or conduction band. This causes a shift of the Fermi level $E_{\mathrm{F}}$ that in the case of an n-type semiconductor is given by

$$
E_{\mathrm{C}}-E_{\mathrm{F}}=k_{\mathrm{B}} T \ln \frac{n_{\mathrm{C}}}{n_{\mathrm{D}}},
$$

with $E_{\mathrm{C}}$ the energy level of the conduction band, $n_{\mathrm{C}}$ the effective density of states in the conduction band and $n_{\mathrm{D}}$ the density of donor defects [13, p. 37]. Equation 2.2 shows that the Fermi level increases with increasing $n-$ type doping. This is the case for non-degenerate semiconductors. If the doping is increased so far, that the dopant concentration is higher than the effective density of states in the conduction band, the Fermi level will lie inside the conduction band. In this case the semiconductor is called degenerate [13, p. 151]. In the case of a degenerate semiconductor, the position of the Fermi level is given by

$$
E_{\mathrm{F}}-E_{\mathrm{C}}=\frac{\hbar^{2}}{2 m_{\mathrm{e}}^{*}}\left(3 \pi^{2} n_{\mathrm{e}}\right)^{\frac{2}{3}}
$$

with $m_{\mathrm{e}}^{*}$ the effective mass of an electron, and $n_{\mathrm{e}}$ the concentration of electrons [14].

The fact that the Fermi level lies within the conduction band means that the bottom states of the conduction band are filled. The optical band gap measured by absorption techniques will therefore be shifted towards higher energies. This effect is called the Burstein-Moss effect and is shown in Figure $2.1[14,15]$. To calculate the shift in the optical band gap, Equation 2.3 needs to be multiplied by $\left(1+m_{\mathrm{e}}^{*} / m_{\mathrm{h}}^{*}\right)$, with $m_{\mathrm{h}}^{*}$ the hole effective mass, in order to take the curvature of the bands into account [15]. The Burstein-Moss shift is then given by

$$
\Delta E_{\mathrm{BM}}=\frac{\hbar^{2}}{2}\left(3 \pi^{2} n_{\mathrm{e}}\right)^{\frac{2}{3}}\left(\frac{1}{m_{\mathrm{e}}^{*}}+\frac{1}{m_{\mathrm{h}}^{*}}\right) .
$$

The resulting increase in the band gap due to a large charge carrier concentration is beneficial for the properties of TCOs as it shifts the 

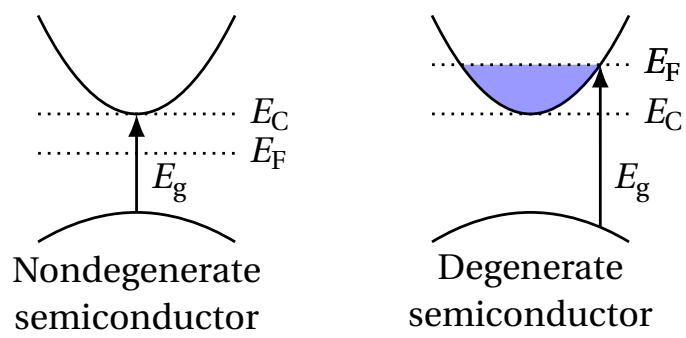

Figure 2.1: Schematic representation of the Burstein-Moss effect in degenerate semiconductors

absorption edge further into the ultraviolet (UV) range and therefore widens the spectral region where the material is transparent.

On the other hand, the transparency in TCOs could be limited by possible transitions of the electrons in the conduction band close to the Fermi level to unoccupied states in higher conduction bands [2]. In order for the material to be transparent, this second band gap also needs to be sufficiently large.

While a high concentration of free charge carriers can increase the band gap of a material due to the Burstein-Moss effect, it also causes absorption of photons in the near-infrared range. This absorption appears at the plasma wavelength of the material and can be explained by the Drude model for free electrons. In the Drude model, the plasma frequency $\omega_{\mathrm{p}}$ is given by

$$
\omega_{\mathrm{p}}=\left(\frac{n e^{2}}{\epsilon_{\infty} \epsilon_{0} m_{\mathrm{e}}^{*}}\right)^{1 / 2},
$$

with $\epsilon_{\infty}$ the high frequency relative permittivity, $\epsilon_{0}$ the vacuum permittivity and $m_{\mathrm{e}}^{*}$ the electron effective mass [12]. Below the plasma frequency (at long wavelengths) the material will be reflective. Above the plasma frequency, the absorption coefficient of the material is given by

$$
\alpha=\frac{n e^{2}}{m_{\mathrm{e}}^{*} \epsilon_{0} N c \tau} \frac{1}{\omega^{2}},
$$

with $N$ the refractive index, $c$ the speed of light and $\tau$ the relaxation time that describes the mean time between scattering events [16, p. 194]. This free charge carrier absorption is represented in the band structure as an 
intraband transition from an occupied state in the conduction band to an unoccupied state in the conduction band above the Fermi level. As the momentum of the electron changes in such a transition, a scattering event needs to happen in order to conserve the momentum [16, p. 194]. The scattering rate is given as the inverse of the relaxation time $\tau$ and is related to the mobility $\mu[17$, p. 235$]$ by

$$
\mu=\frac{e \tau}{m_{\mathrm{e}}^{*}} .
$$

As can be seen from Equation 2.6, the absorption close to the plasma frequency is decreasing with the frequency, but depends on both the charge carrier concentration and the relaxation time. In order to keep this free charge carrier absorption low, there are therefore limits in increasing the charge carrier concentration if the material needs to be transparent [18].

The different mechanisms that limit the transparency of TCOs are summarized in Figure 2.2. At short wavelengths, the transparency is limited by the transitions $T_{1}$ and $T_{2}$. The transition $T_{1}$ corresponds to the transition between the valence band and the conduction band. It is shifted towards higher energy with increasing charge carrier concentration due to the Burstein-Moss effect. The transition $\mathrm{T}_{2}$ corresponds to the transition between the conduction band and the second conduction band and is shifted towards lower energies with increasing charge carrier concentration. Finally, the transition $\mathrm{T}_{3}$ corresponds to the free charge carrier absorption, which limits the transparency for long wavelengths and is shifted towards shorter wavelengths with increasing charge carrier concentration [2].

From these results one can conclude that a compromise needs to be found for the charge carrier concentration as it cannot be increased arbitrarily without detriments to the transparency of the material, which limits the conductivity on the other hand. Instead it is necessary to increase the mobility (i.e. increase the relaxation time $\tau$ ), which would both improve the conductivity and decrease the free charge carrier absorption [7, p. 63]. The mobility is limited by different scattering mechanisms. In polycrystalline TCOs the principal scattering mechanisms are ionized impurity scattering, grain boundary scattering and phonon scattering, which are described in the following.

Ionized impurity scattering is scattering of the free carriers due to the Coulomb interaction with the dopants or other defects [18]. This leads to 


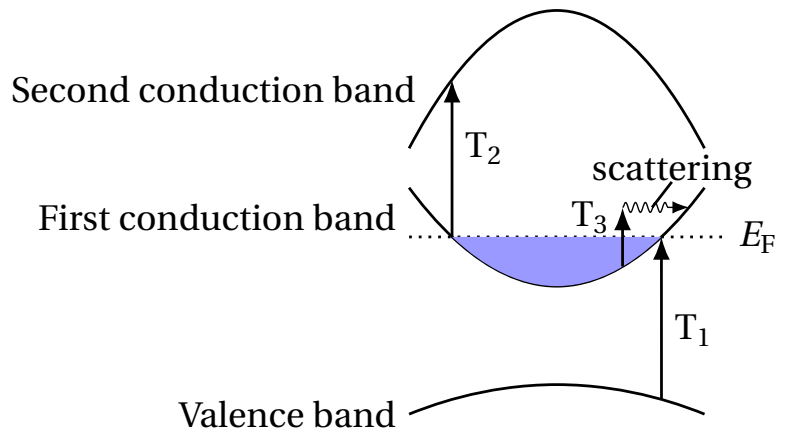

Figure 2.2: Different optical transitions in a TCO [2, 16, p. 195]

a decrease of the mobility at high charge carrier concentrations. Masetti et al. [19] developed a semi-empirical expression for the mobility at high charge carrier concentration in doped $\mathrm{Si}$, which can also be applied to TCOs. This expression is given by

$$
\mu=\mu_{\min }+\frac{\mu_{\max }-\mu_{\min }}{1+\left(\frac{n}{n_{\text {refl }}}\right)^{\alpha_{1}}}-\frac{\mu_{1}}{1+\left(\frac{n_{\text {ref2 }}}{n}\right)^{\alpha_{2}}},
$$

with $\mu_{\max }$ being related to the mobility due to scattering with the lattice at low charge carrier concentrations and $\mu_{\min }$ the mobility limited due to the ionized impurities. At very high charge carrier concentrations, the ionized impurities can form clusters that cause stronger scattering. The mobility due to this clustering process is described by $\mu_{\max }-\mu_{1}$ in Equation 2.8 [6, p. 51]. The fit parameter $n_{\text {ref1 }}$ describes the reference charge carrier concentration for the transition between the lattice scattering regime and the ionized impurity scattering regime, while the parameter $n_{\text {ref2 }}$ describes the transition between the ionized impurity scattering regime to the cluster scattering regime. The parameters $\alpha_{1}$ and $\alpha_{2}$ describe the steepness of these transitions [20]. Typical values for these fit parameters for common TCO materials are shown in Table 2.1.

Grain boundary scattering has been described by Seto [22] for polycrystalline silicon. He attributes it to the formation of trap states at grain boundaries. When these trap states are filled, a potential barrier with height $\Phi_{\mathrm{B}}$ is created which hinders the movement of charge carriers across the grain boundary, as the charge carriers have to overcome the barrier by thermionic emission. The effective mobility due to grain 
Table 2.1: Values for the fit parameters in Equation 2.8 for common TCO materials [21]

\begin{tabular}{lccc}
\hline Fit parameter & $\mathrm{ZnO}$ & $\mathrm{ITO}$ & $\mathrm{SnO}_{2}$ \\
\hline$\mu_{\max }\left(\mathrm{cm}^{2} / \mathrm{Vs}\right)$ & 210 & 210 & 250 \\
$\mu_{\min }\left(\mathrm{cm}^{2} / \mathrm{Vs}\right)$ & 55 & 55 & 50 \\
$\mu_{\max }-\mu_{1}\left(\mathrm{~cm}^{2} / \mathrm{Vs}\right)$ & 5 & 5 & 10 \\
$n_{\mathrm{ref} 1}\left(10^{17} \mathrm{~cm}^{-3}\right)$ & 4 & 15 & 20 \\
$\alpha_{1}$ & 1 & 1 & 1 \\
$n_{\text {ref2 }}\left(10^{20} \mathrm{~cm}^{-3}\right)$ & 6 & 20 & 6 \\
$\alpha_{2}$ & 2 & 2 & 2 \\
\hline
\end{tabular}

boundaries $\mu_{\text {eff }}$ is therefore given by

$$
\mu_{\text {eff }}=\mu_{0} \exp \left(-\frac{\Phi_{\mathrm{B}}}{k_{\mathrm{B}} T}\right),
$$

with $\mu_{0}$ the mobility inside the grain [6, pp. 59-60]. The height of the potential barrier depends on the charge carrier concentration. At low carrier concentration the potential barrier is given by

$$
\Phi_{\mathrm{B}}=\frac{e^{2} L^{2} n}{8 \epsilon_{\mathrm{r}} \epsilon_{0}} \quad \text { for } \quad L n<n_{\mathrm{t}},
$$

with $n_{\mathrm{t}}$ the trap density at the grain boundary, $L$ the grain size and $\epsilon_{\mathrm{r}}$ the static relative permittivity [6, p. 60]. In this case of low charge carrier concentration, the grains are depleted and the trap states are partially filled, leading to an increase in the potential barrier up to a maximum when $L n=n_{\mathrm{t}}$ and all the traps states are filled [22]. At higher charge carrier concentration the potential barrier is given by

$$
\Phi_{\mathrm{B}}=\frac{e^{2} n_{\mathrm{t}}^{2}}{8 \epsilon_{\mathrm{r}} \epsilon_{0} n} \text { for } L n>n_{\mathrm{t}} .
$$

In this case, the trap states are filled, but the grains are only partially depleted, so the barrier height decreases with increasing charge carrier concentration [22]. Additionally, at very high charge carrier concentration, tunneling through the barriers is possible, as the depletion region around the grain boundaries becomes narrower. This tunneling process leads to a further increase in the mobility at high charge carrier concentrations [6, pp. 60-61]. 
Phonon scattering can be divided in optical and acoustical phonon scattering. The displacement of atoms causes both a dipole electric moment and local changes in the band structure, which are responsible for optical and acoustical phonon scattering, respectively [18]. Additional scattering mechanisms include neutral impurity scattering and dislocation scattering [21]. Under the assumption that the different scattering mechanisms are independent of each other, the combined mobility $\mu$ can be calculated from the mobilities due to the different scattering mechanisms $\mu_{i}$ according to Matthiessen's rule [23, p. 323]:

$$
\frac{1}{\mu}=\sum_{i} \frac{1}{\mu_{i}} .
$$

Bikowski and Ellmer [18] have developed an analytical model using this rule to investigate the contribution of the different scattering mechanisms in degenerately doped $\mathrm{ZnO}$ films. Their results show that grain boundary scattering is dominant for charge carrier concentrations up to $2 \times 10^{20} \mathrm{~cm}^{-3}$. At higher charge carrier concentrations, ionized impurity scattering becomes increasingly important and the contribution of grain boundary scattering decreases.

\subsection{Applications of TCOs}

The most important applications of TCOs are architectural window applications, and as transparent electrodes in flat panel displays, touchscreens and photovoltaics [7, p. 3, 24, p. 768]. Other applications include transparent electronics and films for electrochromic devices [7, p. 5], as well as antistatic films [24, pp. 758-759] and electromagnetic shielding $[24$, p. 754$]$. In the following, a short description of the different applications will be given.

For architectural windows, the principal interest in TCOs lies in their low emissivity in the infrared. The emissivity $\epsilon$ is related to the reflectance $R$ and the transmittance $T$ by $\epsilon=1-T-R$ [25]. As TCOs are reflective above the plasma wavelength, their emissivity is low in the infrared. This allows to lower the transfer of heat from the inside to the outside of a building via infrared radiation, while the solar radiation in the nearinfrared can still pass through the window [26]. An ideal material for this application would therefore be fully transparent at wavelengths between 
400 and $3000 \mathrm{~nm}$, and fully reflective at wavelengths above $3000 \mathrm{~nm}$ [25]. Especially important is a low emissivity in the wavelength range between 8000 and $13000 \mathrm{~nm}$ in order to avoid the radiative cooling effect due to the transparency window of the atmosphere in that range [27]. Low emissivity coatings are therefore also useful to prevent frost on car windscreens [27]. The most common material used for these applications is FTO due to its good chemical and mechanical stability [25]. Additionally, it is also possible to use the TCO film as a transparent heater by applying a voltage across the film, in order to defrost car or airplane windscreens [24, p. 753].

In order to be used as a transparent electrode, a material needs to be transparent in a certain wavelength range that depends on the application of the device [28]. For use in flat panel displays, the material needs to be transparent in the range that is visible to the human eye $(400-800 \mathrm{~nm})$ [29]. For use in photovoltaics, the necessary transparency range is given by the solar spectrum $(300-2500 \mathrm{~nm})[30]$ and the band gap of the absorbing material.

In flat panel displays, two transparent electrodes are needed with a layer of liquid crystals in between. Applying a voltage to the device allows to change the orientation of the liquid crystals [31]. For flat panel displays, the most commonly used TCO material is ITO due to its low resistivity [6, p. 24]. However, because of the high cost of In, materials with less or no In are also interesting for use as transparent electrodes. Recently, amorphous TCOs such as indium zinc oxide (IZO) have emerged [32], which offer a better uniformity over large areas [33, p. 157]. These materials are therefore also used in flat panel displays [7, p. 4].

On mobile devices, such as phones and tablets, flat panel displays are usually equipped with a touchscreen. There are generally two types of touchscreens [24, pp. 768-772]. The first type is the resistive type, where one transparent electrode is deposited on a flexible substrate. When this flexible layer is deformed by touching it, a contact with the second transparent electrode is formed. By applying a voltage gradient on each electrode, the position of the contact can be detected. The other type of touchscreen is the capacitive type. In this type, two grids of transparent electrodes, that are perpendicular to each other and separated by a dielectric spacer, form capacitors. When the device is touched at a certain location, the local electric fields change, and the resulting change 
in capacitance can be detected. For such touchscreens, ITO films are usually used.

In solar cells, TCO films can be used as back and front contacts. ITO alternatives such as AZO or FTO are often used [6, p. 24]. For example, sputtered $\mathrm{Al}$-doped $\mathrm{ZnO}$ layers are used as both back and front contacts in solar cells based on amorphous Si. The surface of these layers can be modified by chemical etching to improve the light trapping [34]. Transparent electrodes based on doped zinc oxide are also used in thin film

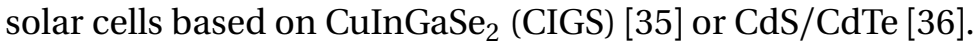

Another application where transparent electrodes are needed, are electrochromic devices [25]. Electrochromic devices experience a change of their optical properties when a voltage is applied. Such electrochromic devices can therefore be used in applications such as "smart windows" which allow to control the onset of reflectivity [37]. This allows to switch the window from a mode, where near-infrared radiation from the sun is reflected, to keep the inside of the building cool, to a mode, where the onset of reflectivity is shifted to longer wavelengths, in order to keep heat from escaping through the window. Electrochromic devices are based on the transport of ions, such as $\mathrm{H}^{+}$or $\mathrm{Li}^{+}$through an ionic conductor from an ion storage film towards the electrochromic film. A typical electrochromic material is $\mathrm{WO}_{3}$. As ionic conductors, both organic and inorganic materials can be used. Finally, transparent electrodes are used on both sides of the device in order to apply a voltage. When a voltage is applied through these electrodes, the ions are transferred into the electrochromic film, thereby increasing the absorption of the material.

In order to evaluate the suitability of a material for use as a transparent electrode, a figure of merit can be defined. Such a figure of merit needs to take into account both the transparency and the conductivity. Different definitions for such a figure of merit have been proposed. Fraser and Cook [38] proposed to simply divide the average transmittance $T$ by the sheet resistance $R_{\mathrm{S}}$. However, Haacke [39] observed that this definition favours a low sheet resistance too much and proposed a different definition of the figure of merit $\Phi$.

$$
\Phi=T^{10} / R_{\mathrm{S}} .
$$

This figure of merit depends on the thickness. Gordon [40] proposed to use the conductivity $\sigma$ and the absorption coefficient $\alpha$ to define a 
figure of merit that does not depend on the thickness and is given by

$$
\Phi=\sigma / \alpha .
$$

For the value of the transmittance or absorption in these equations, the average value in the spectral range that is important for the application should be used. Gordon [1] reported optimum values for the figure of merit for the most common TCOs (FTO, ITO and AZO) in the range of 3-5 $\Omega^{-1}$.

TCOs can also be used in transparent and possibly flexible electronics. Typically used materials in thin film transistors are amorphous $\mathrm{Si}$, which has low field-effect mobility [7, p. 481]. Transparent oxides, on the other hand, can offer advantages such as a higher mobility. In such applications, the TCO is not only used as a passive contact, but as an active part of the device. For example, in organic light emitting devices (OLED) ITO or $\mathrm{ZnO}$ are used for hole injection into the organic conductor [6, p. 25]. However, also for these applications amorphous TCOs present advantages due to the absence of grain boundaries [7, p. 481]. Nomura et al. [41] fabricated a fully transparent TFT on a flexible substrate based on amorphous indium gallium zinc oxide. These devices are all based on n-type transparent oxides. Devices based on p-type TCOs are more difficult to realize as p-type transparent oxides generally have a lower mobility. Nevertheless, advances in p-type TCOs have been made using for example $\mathrm{Cu}_{2} \mathrm{O}$ [42].

\subsection{Properties of zinc oxide}

Zinc oxide $(\mathrm{ZnO})$ is a wide band gap semiconductor. It is used in the chemical industry for rubber production, paints and agricultural usage [6, p. 3]. ZnO is also used in the form of micro- or nanoparticles in sunscreen, as its absorption edge is in the UV [43]. Research on $\mathrm{ZnO}$ as a semiconductor material has started in the 1950s, however since the 1990s there has been a significant increase in the number of publications on $\mathrm{ZnO}$ [6, p. 1]. This increase can be related to the many interesting properties of $\mathrm{ZnO}$, such as its direct band gap, the large exciton binding energy, as well as its piezoelectric and luminescence properties [44]. Other important factors are the possibility to easily fabricate $\mathrm{ZnO}$ nanostructures [45] and the potential of $\mathrm{ZnO}$ to be used as a dilute magnetic 


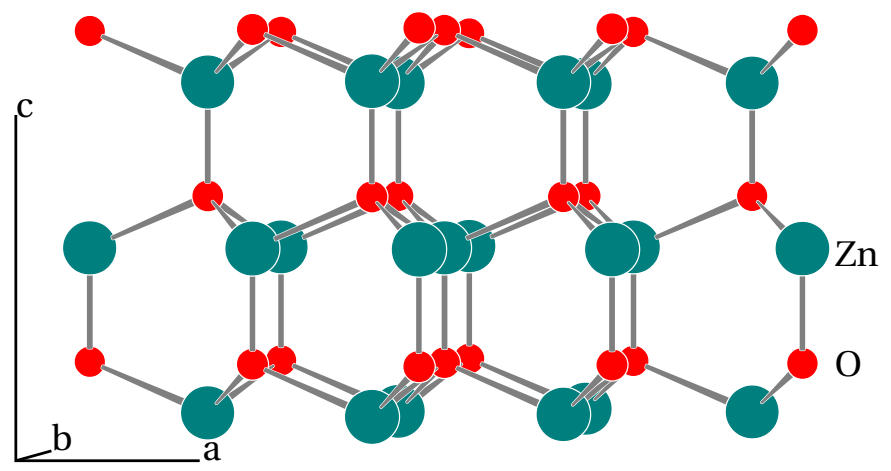

Figure 2.3: Wurtzite crystal structure of $\mathrm{ZnO}$

semiconductor [46]. This section will give an overview on the properties of $\mathrm{ZnO}$ with a focus on the possibility of doping $\mathrm{ZnO}$ with extrinsic impurities in order to use it as an n-type TCO.

$\mathrm{ZnO}$ can occur in several crystal structures, such as the hexagonal wurtzite structure, the cubic zincblende structure and the cubic rocksalt structure [47]. The most stable one of these crystal structures is the wurtzite structure. In the wurtzite structure of $\mathrm{ZnO}$ (Spacegroup $\mathrm{P}_{3} \mathrm{mc}$ ) the hexagonal unit cell has the lattice parameters $a=3.2501 \AA$ and $c=5.2071 \AA$. The structure can be seen as the superposition of two hexagonal closed packed sublattices of $\mathrm{Zn}$ and $\mathrm{O}$ [48, p. 2]. Each $\mathrm{Zn}$ and $\mathrm{O}$ atom is surrounded by the respective other type of atom in a tetrahedral coordination. The crystal structure is shown in Figure 2.3. In $\mathrm{ZnO}$ the (0001) planes are terminated by $\mathrm{Zn}$ atoms, whereas the $(000 \overline{1})$ surfaces are terminated by $\mathrm{O}$ atoms. These planes are therefore polar, which means that $\mathrm{ZnO}$ does not show an inversion symmetry and has piezoelectric properties [47]. It is interesting to note, that thin films of $\mathrm{ZnO}$ often show a preferential orientation along the c-axis [49]. This preferential orientation depends on the deposition method, but is very common especially in sputter deposited films. However, the exact reasons for this preferential orientation are not yet fully understood, but are possibly related to the surface energies of the different planes [49].

$\mathrm{ZnO}$ has a direct band gap of $3.37 \mathrm{eV}$ at room temperature making it transparent in the visible range [44]. Towards longer wavelengths, the transmittance is limited by the free charge carrier absorption as has been described in section 2.1. The valence band maxima and the 
conduction band minima are located at the $\Gamma$ point in the Brillouin zone at $k=0$ [50, p. 4]. The valence band states are given by the $\mathrm{O} 2 \mathrm{p}$ states [6, p. 12]. The chemical bonds in $\mathrm{ZnO}$ have a strong ionic character, so the conduction band is mainly given by the $4 \mathrm{~s}$ states of $\mathrm{Zn}^{2+}$ [51]. When a photon excites an electron from the valence to the conduction band, the resulting electron-hole pair can be bound due to the Coulomb interaction between the electrons. The so formed electron-hole pair is called an exciton [52, p. 276]. Upon recombination of the electron-hole pair, a photon is emitted. The exciton binding energy in $\mathrm{ZnO}$ is $60 \mathrm{meV}$, which is large enough that excitonic emission can be observed at room temperature [44].

A variety of intrinsic point defects are common in $\mathrm{ZnO}[53,54]$. Among these are $\mathrm{Zn}$ and $\mathrm{O}$ vacancies $\left(\mathrm{V}_{\mathrm{Zn}}\right.$ and $\mathrm{V}_{\mathrm{O}}$ in Kröger-Vink notation) and interstitials $\left(\mathrm{Zn}_{\mathrm{i}}\right.$ and $\left.\mathrm{O}_{\mathrm{i}}\right)$. These defects can be ionized and can therefore serve as acceptors $\left(\mathrm{V}_{\mathrm{Zn}}\right.$ and $\left.\mathrm{O}_{\mathrm{i}}\right)$ or donors $\left(\mathrm{V}_{\mathrm{O}}\right.$ and $\left.\mathrm{Zn}_{\mathrm{i}}\right)$. Zinc vacancies introduce states close to the valence band maximum and can take up two electrons [44]. Oxygen interstitials are also considered to be shallow acceptors [55]. Both $\mathrm{V}_{\mathrm{Zn}}$ and $\mathrm{O}_{\mathrm{i}}$ have been reported to be the dominant compensating defect in n-type $\mathrm{ZnO}[44,54]$. Oxygen vacancies have the lowest formation energy among the donor defects, however calculations show that it is a deep donor [44]. Zinc interstitials occupy the octahedral site in the wurtzite structure and act as a shallow donors. However, their formation energy is quite high in n-type $\mathrm{ZnO}$, so they can only be introduced in n-type $\mathrm{ZnO}$ in out-of-equilibrium conditions [44]. The energy levels of these defects are shown in a schematic band structure in Figure 2.4. The donor defects could be a possible explanation for the natural n-type conductivity in $\mathrm{ZnO}$ [44]. Some authors argue, however, that the native defects are not a sufficient explanation for the n-type behaviour of $\mathrm{ZnO}$ and propose extrinsic doping by $\mathrm{H}$ impurities [56].

In order to increase the conductivity of $\mathrm{ZnO}$ extrinsic doping is necessary. The most common dopants are group III elements, such as B, $\mathrm{Al}, \mathrm{Ga}$ or In [55]. But also doping with group IV elements, such as $\mathrm{Si}, \mathrm{Ge}$, $\mathrm{Ti}, \mathrm{Zr}, \mathrm{Hf}, \mathrm{Sn}$ or $\mathrm{Pb}$ has been reported [57]. In these cases, the dopant atom acts as a donor and substitutes a $\mathrm{Zn}$ atom in the crystal lattice [44]. For group III elements, the dopant has an additional valence electron as compared to $\mathrm{Zn}$, so it can become easily ionized and introduce an electron into the conduction band of the material. While group IV elements could theoretically supply two electrons in a substitutional site, it 


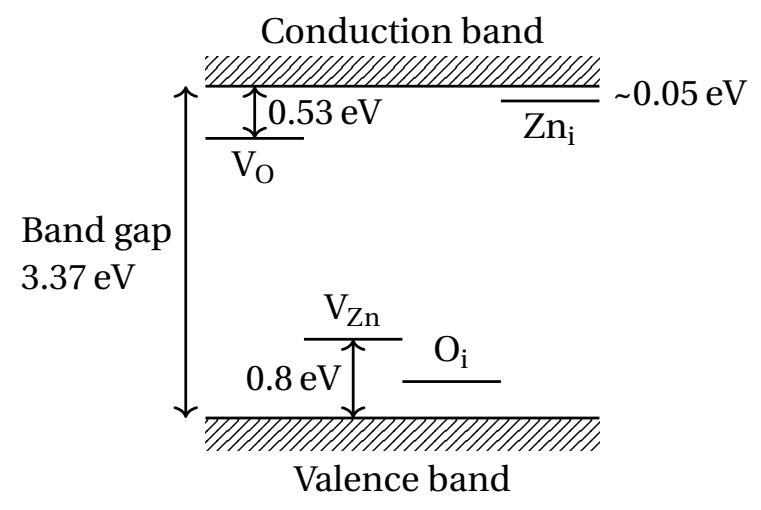

Figure 2.4: Schematic representation of the energy levels of intrinsic point defects in $\mathrm{ZnO}[53,55]$

was found that group IV dopants are present as a trivalent ion and also supply one electron to the conduction band [57]. On the other hand, it is also possible to substitute the oxygen by an group VII element, such as $\mathrm{F}$ [58]. Because $\mathrm{F}$ has one more valence electron than $\mathrm{O}$, it can also supply an electron to the conduction band [55].

Sato et al. [57] deposited $\mathrm{ZnO}$ films doped with different group IV elements by RF magnetron sputtering and found the best properties for Si-doped $\mathrm{ZnO}$ with a resistivity of $4.7 \times 10^{-4} \Omega \mathrm{cm}$. But also other dopant elements, such as $\mathrm{Ge}, \mathrm{Ti}, \mathrm{Zr}$, and $\mathrm{Hf}$, improved the conductivity of the films. Sn and $\mathrm{Pb}$, however, are not efficient dopants and caused an increase in the resistivity due to a decrease in the mobility. Since then, several groups have reported the deposition of $\mathrm{ZnO}$ films doped with group IV elements, such as $\mathrm{ZnO}: \mathrm{Si}$ [59] and $\mathrm{ZnO}: \mathrm{Zr}$ [60].

Doping $\mathrm{ZnO}$ with group III elements is more common and has been studied more intensively than doping with group IV elements. Among these dopants, the lowest resistivities have been achieved using $\mathrm{Al}$ and $\mathrm{Ga}$ [55]. The following discussion will be focused on $\mathrm{Al}$, because it is the most commonly used dopant. Al has only a limited solubility in $\mathrm{ZnO}$ [61], as the thermodynamic solubility limit of $\mathrm{Al}$ in $\mathrm{ZnO}$ has been determined to be only 0.3 at\% [62]. In contrast, typical Al concentrations in transparent conducting $\mathrm{ZnO}$ thin films are between 1 and 4 at\% [5]. This means that out-of-equilibrium growth techniques are needed for the deposition of AZO films, as secondary phases such as $\mathrm{ZnAl}_{2} \mathrm{O}_{4}$ or 
$\mathrm{Al}_{2} \mathrm{O}_{3}$ can be formed [20]. Additionally, the formation of a homologous $\mathrm{Al}_{2} \mathrm{O}_{3}(\mathrm{ZnO})_{m}$ phase has been deduced from X-ray absorption near edge structure (XANES) measurements [8, 63]. These secondary phases cause a deactivation of the dopant atoms and therefore a degradation of the electrical properties. Additional reasons for dopant deactivation are the compensation of donors by acceptor defects such as $\mathrm{O}_{\mathrm{i}}$ or $\mathrm{V}_{\mathrm{Zn}}$, or the formation of neutral defect complexes [55]. Due to these effects, the doping efficiency in AZO films is usually below $100 \%$ and depends on the deposition method and the process conditions [55].

\subsection{Deposition methods for AZO thin films}

There are several methods in order to deposit thin films of ZnO or AZO. These deposition methods can belong to several categories, such as chemical solution based methods, chemical vapour deposition (CVD) and physical vapour deposition (PVD) [7, pp. 201-202].

\section{Chemical solution based methods}

Among the chemical solution based methods are techniques, such as spray pyrolysis $[64,65]$ and sol-gel methods $[66,67]$. In spray pyrolysis, fine droplets of a solution of precursors such as zinc acetate and aluminium chloride are sprayed onto a heated substrate. Typical deposition temperatures are around $450^{\circ} \mathrm{C}$, at which the precursors decompose and $\mathrm{ZnO}$ is formed. In the sol-gel method, a colloidal solution of polymer particles (the "sol") is prepared from precursors [68, pp. 2-8]. This sol can be transferred to the substrate by techniques such as dip coating or spin coating. The colloidal particles can then aggregate and form a polymer network (the "gel"). The substrate then needs to be annealed at temperatures between 400 and $850^{\circ} \mathrm{C}$ in order to remove the solvents and condensate a ceramic compound, that can be crystallized by sintering. Films obtained by these methods are generally polycrystalline and their resistivity is limited to around $1 \times 10^{-3} \Omega \mathrm{cm}$, however there are also reports of resistivities down to $7 \times 10^{-4} \Omega \mathrm{cm}$ in case of spray pyrolysis [64]. The advantage of these methods is their simplicity, as no vacuum system is needed. They also provide a good control over the composition of the films. However, they require quite high process temperatures compared to other techniques. 
Another chemical solution based method is electrochemical deposition [69]. The deposition temperature in this technique is less than $100^{\circ} \mathrm{C}$, as the process takes place in an aqueous solution. The substrate is put into an electrolytic bath and used as a working electrode. The precursors are then electrochemically reduced to form the film. This means, that this technique requires a conductive substrate, so it is not useful for the fabrication of transparent electrodes. However, electrochemical deposition of $\mathrm{ZnO}$ allows to deposit nanostructures, such as nanorods, by decreasing the concentration of the zinc precursor [70, 71].

\section{Chemical vapour deposition}

AZO films can also be deposited using CVD methods. With the exception of atmospheric pressure CVD, CVD methods are usually vacuum techniques, which means, that they are more expensive than chemical solution based methods. On the other hand, working in vacuum reduces the amount of unwanted contamination. Generally, CVD works via a chemical reaction of vapours of the precursors, in which the precursors are decomposed and form a film on the substrate [72, p. 147]. The chemical reaction on the substrate depends strongly on the substrate temperature. There are several types of CVD, that can be used to deposit transparent conducting $\mathrm{ZnO}$ films, such as metal organic CVD (MOCVD) [73], plasma enhanced CVD (PECVD) [74], atmospheric pressure CVD [75] and atomic layer deposition (ALD) [76].

MOCVD uses metal organic precursors, that means metal atoms with organic ligands. The oxygen precursor can be $\mathrm{O}_{2}, \mathrm{H}_{2} \mathrm{O}$ or an alcohol [6, pp. 235-236]. The precursors are evaporated and carried into the vacuum chamber by a carrier gas such as Ar. $\mathrm{O}_{2}$ might be introduced separately into the chamber. The substrate needs to be heated to temperatures of several hundred ${ }^{\circ} \mathrm{C}$. Using MOCVD, AZO films with a resistivity of $6 \times 10^{-4} \Omega \mathrm{cm}$ have been deposited at $275^{\circ} \mathrm{C}$ [73]. The deposition temperature can be reduced by using PECVD. In this technique, a plasma is used to assist in breaking the chemical bonds of the precursors, so lower substrate temperatures can be used [72, p. 181]. This way, AZO films with a resistivity of $7 \times 10^{-4} \Omega \mathrm{cm}$ could be deposited [77]. Another CVD method is atmospheric pressure CVD, which does not require a vacuum system. AZO films with a resistivity in the order of $10^{-4} \Omega \mathrm{cm}$ could be deposited with this technique at a substrate temperature of $400^{\circ} \mathrm{C}$ [75]. 
ALD is another technique that is related to CVD. The main difference is that the metal and oxygen precursors are inserted into the reactor separated in time. This allows to grow films layer by layer, which allows an accurate control over the film thickness. While this technique generally gives lower deposition rates, films deposited by ALD have a great conformity to any substrate shape. However, ALD is sensitive to the chemical nature of the substrate, as the initial growth can be severely hindered if the precursor does not react with the surface of the substrate [78]. AZO films with a resistivity in the order of $9 \times 10^{-4} \Omega \mathrm{cm}$ have been grown at a substrate temperature of $200^{\circ} \mathrm{C}$ using ALD [76].

\section{Physical vapour deposition}

Physical vapour deposition methods are also vacuum processes, leading to a lower contamination of the substrates and the growing films [79, p. 7]. PVD methods for the deposition of AZO films include evaporation [80, 81], pulsed laser deposition (PLD) [6, p. 303], cathodic arc deposition [82] and magnetron sputtering [4].

In thermal evaporation methods, a source of material is heated in vacuum, so it evaporates and the atoms are deposited onto a substrate [79, p. 11]. There are several possible ways to evaporate the material, such as passing an electric current through the material [79, p. 368] or directing an electron beam of several $\mathrm{keV}$ onto the surface of the material [79, p. 400]. Both of these techniques have been used to deposit AZO films with lowest resistivities in the order $10^{-4} \Omega \mathrm{cm}$ using $\mathrm{ZnO}$ powder as a source at temperatures between room temperature and $200^{\circ} \mathrm{C}[80,81]$.

Another PVD technique that allows the growth of high quality AZO films is pulsed laser deposition. In PLD a target is ablated by laser pulses with high energy [6, pp. 305-309]. As the laser pulse interacts with the vaporized target material a plasma plume is formed, that expands towards the substrate. The atoms and ions then condense on the substrate, leading to growth of a thin film. One of the advantages of PLD is the stoichiometric transfer of the compound from the target to the substrate. Additionally, the process is free of contamination and the growth of metastable materials is possible. The main disadvantage of PLD is the limitation to substrate sizes of about $1 \mathrm{~cm}^{2}$ [6, p. 304]. However, in laboratory scale, $\mathrm{PLD}$ allows the deposition of $\mathrm{AZO}$ films with the lowest resistivity known [83]. Using a ceramic $\mathrm{ZnO} / \mathrm{Al}_{2} \mathrm{O}_{3}$ target, Agura et al. 
[84] deposited columnar AZO films with a resistivity of $8.5 \times 10^{-5} \Omega \mathrm{cm}$ at a substrate temperature of $230^{\circ} \mathrm{C}$ on glass substrates.

Cathodic arc deposition is another method for the synthesis of AZO films. It is based on an arc discharge that is used to evaporate a target at so called cathode spots and transform the material into a plasma [85]. In these cathode spots, the current density is very high in the order of $10^{10}$ to $10^{12} \mathrm{~A} / \mathrm{m}^{2}$, while the voltage is low at around $20 \mathrm{~V}$. The high current density leads to large ionized fraction of the target atoms. However, macroparticles are often produced at the cathode spots, that can be incorporated into the growing film. In order to avoid this, a filtering system can be used, such as a magnetic field to steer only the ions towards the substrate. Using pulsed filtered cathode arc deposition, AZO films with a resistivity in the order of $10^{-4} \Omega \mathrm{cm}$ were deposited at a substrate temperature of $200^{\circ} \mathrm{C}$ [82]. In these depositions, $\mathrm{Zn}$ rods with a few percent of $\mathrm{Al}$ were used as targets and oxygen was injected into the vacuum chamber as a reactive gas.

Finally, magnetron sputtering is a PVD method, that is commonly used for the deposition of AZO films [4]. This is due to the advantages of magnetron sputtering, such as the scalability to large areas of up to $20 \mathrm{~m}^{2}$ and the possibility to achieve good film properties at relatively low substrate temperatures due to the plasma assistance [7, p. 202]. This technique is used in this thesis. Therefore, a detailed description of magnetron sputtering will be given in chapter 3 with a focus on the sputtering of AZO films in section 3.7. 


\section{Chapter 3}

\section{The sputter deposition process}

Sputter deposition is a method to deposit thin films on a substrate. It uses ions from a plasma to bombard a target in order to sputter atoms from that target via momentum transfer. These sputtered atoms are then deposited onto the substrate. A schematic representation of a typical sputter deposition setup is shown in Figure 3.1. The plasma is generated by supplying a working gas into a vacuum chamber with the most commonly used working gas being argon. A negative potential of several $100 \mathrm{~V}$ is applied to the target. The Ar atoms in the gas are then ionized by electrons, and accelerated towards the target. The processes in the plasma are explained in more detail in section 3.1. When the Ar ions hit the target, several processes such as sputtering and secondary electron emission occur. The interactions between the ions and the target are explained in section 3.2. In sections 3.3, 3.4 and 3.5 more details about the different techniques of sputter deposition are given. Then, the growth of thin films on the substrate will be detailed in section 3.6. A review of the deposition of AZO thin films using magnetron sputtering is given in section 3.7. Finally, the different experimental setups used in this work will be presented in section 3.8. 


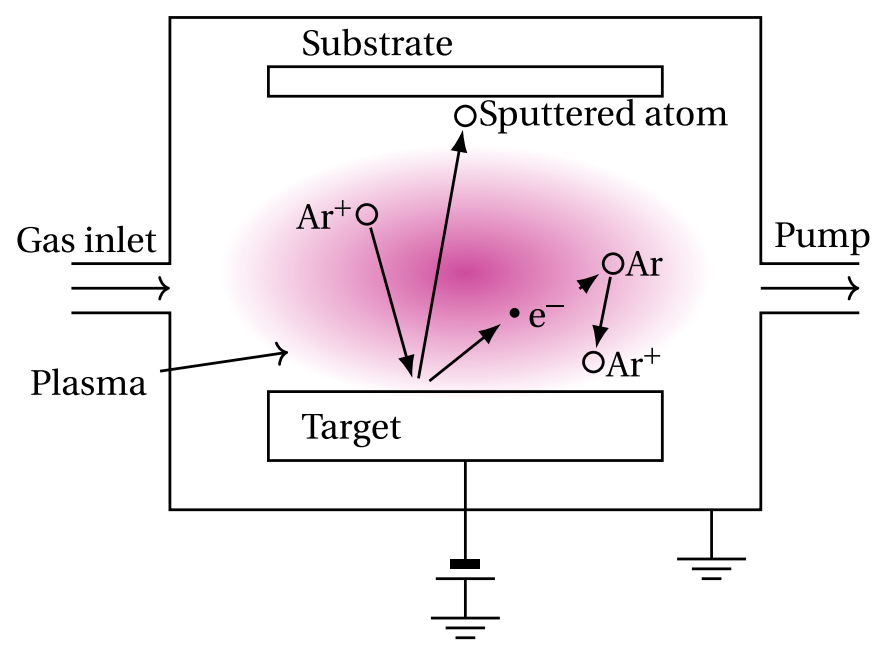

Figure 3.1: Typical sputter deposition experimental setup

\subsection{Basics of plasma physics}

A plasma is an ionized gas, where gas ions, electrons and neutral particles exist in a quasineutral equilibrium, meaning the overall amount of negative and positive charges cancel each other out. Plasmas are often called the forth state of matter after the solid, liquid and gas state, because of the increasing order of energies in these states [86, p. 1]. The energy $E$ of a plasma is given by the average energies of the particles in the plasma. It is often expressed as a temperature $T=E / k_{\mathrm{b}}$, with $k_{\mathrm{b}}$ the Boltzmann constant [72, p. 106]. In a so called non-thermal plasma, the electrons and ions do not have the same temperature. The electron temperature $T_{\mathrm{e}}$ is generally much higher than the temperature of the ions or the neutrals [86, p. 4].

A typical way to ignite a plasma discharge is a simple diode setup, where a potential difference is applied between two electrodes in a gas at low pressure. As there are always a few electrons in a gas due to natural radioactivity, these electrons are accelerated in the potential difference and can ionize gas atoms [79, p. 282]. This creates a direct current (DC) discharge. There are several regimes of plasma that are differentiated by their current-voltage characteristics that are shown in Figure 3.2. At low current, there is the so called Townsend region. When the voltage is increased, electrons are able to ionize more gas molecules and more 


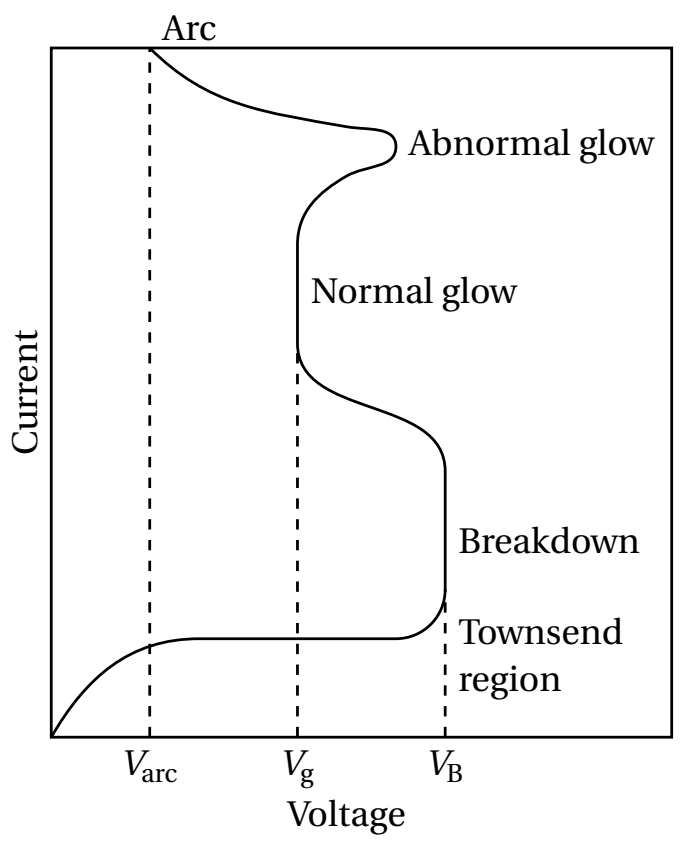

Figure 3.2: Current-voltage of characteristics of a DC discharge [79, p. 282]

electrons are created. If the voltage is high enough, these newly created electrons can gain enough energy to also ionize gas atoms. This electron multiplication leads to an exponential increase in current [79, p. 286].

If the voltage gets increased further to the breakdown voltage $V_{\mathrm{B}}$, the discharge will arrive to the breakdown stage, where the current increases by several orders of magnitude. This breakdown is due to the onset of secondary electron emission at the cathode [79, p. 288]. The mechanisms of secondary electron emission are explained in more detail in section 3.2. After breakdown the voltage drops while the current remains constant. The discharge is now called a glow discharge because it emits visible light due to excited species. In the normal glow regime, the voltage remains constant at $V_{\mathrm{g}}$. Not all of the cathode surface is used in the normal glow regime. Increasing the current increases the part of the surface of the cathode that carries the current. When all of the cathode surface is used, the abnormal glow regime is reached. In the abnormal glow regime the voltage increases with the current. Increasing the discharge 
power further will heat up the cathode. When the temperature is high enough, thermionic emission is possible and the arc regime is reached. The transition to the arc regime is related to a decrease in voltage to the arc voltage $V_{\text {arc }}$ [79, p. 289]. For sputter deposition the discharge is operated in the abnormal glow regime.

Any surface that is introduced in a plasma gives rise to a potential gradient called the plasma sheath [87, p. 70]. This plasma sheath is due to a space charge region close to the surface. The space charge region forms because electrons can move faster than ions towards surfaces. If the surface is electrically insulated, its potential, the so called floating potential $V_{\mathrm{f}}$, is given by

$$
V_{\mathrm{f}}=\frac{k_{\mathrm{B}} T_{\mathrm{e}}}{2 e} \ln \left(\frac{\pi}{2} \frac{m_{\mathrm{e}}}{m}\right),
$$

with $T_{\mathrm{e}}$ the electron temperature, $e$ the elementary charge, $m_{\mathrm{e}}$ the electron mass and $m$ the molecular mass of the gas species. In sputter deposition the anode surface is generally quite large, as the whole chamber is grounded. This large surface leads to a small current density, so the voltage drop at the anode is smaller than the floating potential $V_{\mathrm{f}}[87$, p. 71]. The potential drop at the cathode is approximately equal to the applied discharge voltage. The thickness of the cathode sheath $s$ is given by the Child law [86, p. 144]:

$$
s=\frac{\sqrt{2}}{3} r_{\mathrm{D}}\left(\frac{2 V_{0}}{T_{\mathrm{e}}}\right)^{\frac{3}{4}},
$$

with $V_{0}$ the sheath voltage. The Debye radius $r_{\mathrm{D}}$ describes the screening of electric charges and is given by

$$
r_{\mathrm{D}}=\left(\frac{\epsilon_{0} k_{\mathrm{B}} T_{\mathrm{e}}}{n e^{2}}\right)^{\frac{1}{2}},
$$

with $\epsilon_{0}$ the vacuum permittivity and $n$ the density of electrons [88, p. 10]. Typical values for the sheath thickness in the case of sputter deposition are in the range of a few centimeters [87, p. 302].

The largest potential gradient in a DC discharge is found in the cathode sheath. Electrons are accelerated within this potential gradient and can collide with gas atoms. These collisions can be both elastic and inelastic. In elastic collisions there is only an exchange of the kinetic 
energy of the colliding particles. However, as electrons have a much lower mass than ions, only a small portion of the energy is transferred to the ion, and the electron is just scattered [72, p. 108]. In the case of inelastic collisions gas atoms can get excited or ionized. In case of gas molecules dissociation can also occur. In an excitation reaction, a gas atom such as an Ar atom gets into an excited state and the electron loses the corresponding energy. When the excited state of the molecule decays a photon of a specific wavelength is emitted [79, p. 170]. Atoms can get ionized for example in the case of Ar by the following reaction:

$$
\mathrm{e}^{-}+\mathrm{Ar} \rightarrow \mathrm{Ar}^{+}+2 \mathrm{e}^{-} .
$$

Gas molecules such as $\mathrm{O}_{2}$ can get dissociated into oxygen radicals upon collisions with electrons. Other reactions such as dissociative ionization are also possible.

\subsection{Sputtering interactions}

When ions are accelerated across the cathode sheath towards the target, they gain an energy $E=e V_{\mathrm{T}}$, with $V_{\mathrm{T}}$ the target potential drop, that is approximately equal to the applied voltage. When the ions reach the target several interactions such as implantation, sputtering or secondary electron emission can occur. The sputter yield $Y$ that describes the number of sputtered atoms per incident ion is given by

$$
Y=\frac{3}{4 \pi^{2}} \alpha_{\mathrm{MR}} \frac{\eta E}{U_{\mathrm{S}}} .
$$

In this equation $\alpha_{\mathrm{MR}}$ describes the mass ratio of the incident particle and the target atom, $E$ the energy of the ions and $U_{\mathrm{S}}$ the surface binding energy [89]. The energy transfer factor for an elastic collision $\eta$ depends on the masses of the involved particles $m_{1}$ and $m_{2}$ and is given by

$$
\eta=\frac{4 m_{1} m_{2}}{\left(m_{1}+m_{2}\right)^{2}} .
$$

Sputtering is only possible above a certain threshold energy, as the surface binding energy of the material has to be overcome [79, p. 569]. The threshold energy is given by

$$
E_{\mathrm{th}}=\frac{U_{\mathrm{S}}}{\eta(1-\eta)} .
$$


The threshold energy is typically in the range of 20-40 eV. Equation 3.5 shows that the sputter yield increases linearly with the energy of the incident ions. This is valid for the energy ranges that are typically used in sputtering (100-1000 V) [79, p. 568]. At higher energies, the sputter yield starts to decrease because the ions can reach deeper into the material, and surface atoms are less affected [79, p. 567].

The energy distribution of the atoms sputtered from the target $f(E)$ can be described by the Thompson distribution:

$$
f(E) \propto \frac{E}{\left(E+U_{\mathrm{S}}\right)^{3}},
$$

with $E$ the energy of the sputtered atoms [90]. This energy is usually in the range of a few $\mathrm{eV}$ to a few tens of $\mathrm{eV}$ [91]. The angular distribution of the sputtered atoms is generally approximated by a cosine law [89, p. 23].

The impacting ions also induce emission of secondary electrons that can keep the plasma alive [92]. The emission of secondary electrons is characterized by the secondary electron yield $\gamma_{\mathrm{SE}}$ that is defined as the ratio of the emitted electrons per incoming ion. There are two mechanisms for the emission of secondary electrons, which are potential emission and kinetic emission [93]. Potential emission is the main mechanism in the case of metal targets and is similar to an Auger process, when the incoming ion is neutralized by an electron from the target. The excess energy of this process leads to the emission of a secondary electron. The yield of this mechanism depends on the work function of the target material $W$ and the ionization energy of the incoming ion $E_{\mathrm{i}}$. Several empirical expressions have been proposed to describe the secondary electron yield $\gamma_{\mathrm{SE}}$ in the case of potential emission [93, 94]:

$$
\begin{gathered}
\gamma_{\mathrm{SE}}=0.032\left(0.78 E_{\mathrm{i}}-2 W\right) \\
\gamma_{\mathrm{SE}}=0.016\left(E_{\mathrm{i}}-2 W\right) \\
\gamma_{\mathrm{SE}}=0.2\left(0.8 E_{\mathrm{i}}-2 W\right) / E_{\mathrm{F}}
\end{gathered}
$$

In the case of kinetic emission, electrons are emitted due to the kinetic energy of the impinging ions [93]. This emission process becomes dominant for higher energies than the ones typically found in sputtering processes [95]. Kinetic emission can, however, play a role in the sputtering of insulating materials, such as wide band gap oxides or nitrides [89, p. 208]. 
The plasma is sustained due to the ionization of Ar atoms by the secondary electrons. The minimum voltage required for maintaining the discharge $V_{\mathrm{d}}$ is therefore closely related to the secondary electron yield $\gamma_{\mathrm{SE}}$ and is given by

$$
V_{\mathrm{d}}=\frac{U_{\mathrm{i}}}{e \gamma_{\mathrm{SE}} \epsilon_{\mathrm{i}} \epsilon_{\mathrm{e}} f_{\mathrm{m}} f_{\mathrm{eff}}},
$$

with $U_{\mathrm{i}}$ the average energy loss per ionization which is around $30 \mathrm{eV}$ for an Ar discharge [89, p. 8]. The other coefficients in Equation 3.12 correspond to different loss or multiplication mechanisms. The coefficient $\epsilon_{\mathrm{i}}$ describes the loss due to ions that are created far from the target and the coefficient $\epsilon_{\mathrm{e}}$ is due to electrons being lost at the anode. The coefficient $f_{\mathrm{m}}$ is a multiplication parameter due to electrons that are created in the cathode sheath and gain enough energy to produce more ions. The coefficient $f_{\text {eff }}$ describes the effective ionization probability that takes the recapture of electrons by the target into account. The effective ionization probability depends on the pressure. At low pressure, fewer ionization events are expected, which leads to a higher discharge voltage [89, p. 9].

\subsection{Magnetron sputtering}

In order to keep a plasma alive, electrons need to encounter and ionize the working gas atoms with a sufficient probability. This probability is given by the electron mean free path and depends on the pressure. Therefore, it is necessary to have a sufficiently high pressure in the order of tens of Pa in the case of diode sputtering that has been described so far. Such high pressures lead to a decrease in the deposition rate, as the motion of the sputtered atoms is impeded by collisions with the working gas [87, p. 303]. To increase the sputtering rate and enable sputtering at lower pressures, additional magnetic fields can be used. In a magnetron, permanent magnets are placed behind the target as shown in Figure 3.3. The resulting magnetic field $\boldsymbol{B}$ causes electrons to experience a Lorentzforce and a force due the electric field $\boldsymbol{E}$, which is given by

$$
\boldsymbol{F}=-e(\boldsymbol{E}+\boldsymbol{v} \times \boldsymbol{B}),
$$

with $v$ the velocity of the electron and $e$ the elementary charge [72, p. 123]. The magnetic field will cause electrons to gyrate with the electron 


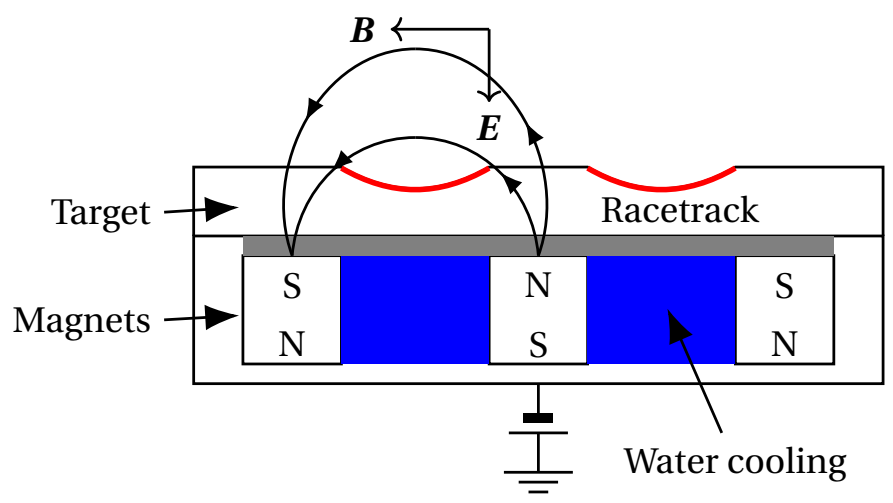

Figure 3.3: Schematic representation of the magnetron sputter process

cyclotron angular frequency,

$$
\omega_{\mathrm{e}}=\frac{e B}{m_{\mathrm{e}}},
$$

with $m_{\mathrm{e}}$ the electron mass [96]. The presence of both the electric and the magnetic field causes a drift of the electrons perpendicular to both fields, that is given by

$$
\boldsymbol{v}_{\mathrm{d}}=\frac{\boldsymbol{E} \times \boldsymbol{B}}{B^{2}} .
$$

This drift causes an azimuthal current, that is called Hall current. These effects trap the electrons in the vicinity of the target, which leads to more ionization of Ar atoms. This means that a stable plasma can be achieved at lower pressure. The distribution of the magnetic field lines leads to the concentration of the ionization in the region of the Hall current. In this region more ions are created, which leads to an enhanced erosion of the target. This erosion zone is called the racetrack.

A sputtering magnetron can use a balanced or an unbalanced configuration [89, pp. 4-5]. In a balanced configuration, the total magnetic flux through the inner magnet is equal to the magnetic flux through the outer magnet, meaning that the magnetic field lines are closed between the outer and inner poles of the magnetron. In an unbalanced magnetron this is not the case and the flux through the outer magnet is larger. This allows the plasma to extend towards the substrate, as stray field lines flow towards the substrate leading to an increased ion flux towards the substrate [97]. 


\subsection{Reactive magnetron sputtering}

With the description of magnetron sputtering so far, it can be readily understood how to deposit a metallic thin film on a substrate by sputtering atoms from a metallic target, which are then deposited onto the substrate. In order to sputter a compound film, such as a metal oxide or nitride, there are two possibilities. The first one is to sputter a ceramic oxide or nitride target and the second possibility is to use reactive sputtering. Sputtering ceramic targets using a DC discharge is not possible if the target is not conductive, as it would cause charge accumulation on the target [87, p. 318]. Instead, it is necessary to use radio-frequency (RF) sputtering. In RF sputtering, an RF signal with a typical frequency of $13.56 \mathrm{MHz}$ is coupled capacitively to the target to generate a discharge, which allows to sputter insulating targets [72, p. 121]. However, ceramic targets are costly and mechanically fragile, which makes it difficult to produce large targets. Additionally, RF power supplies are generally more expensive than DC power supplies [7, p. 204]. Finally, the deposition rate in RF sputtering can often be quite low [98, p. 379].

As an alternative, reactive magnetron sputtering can be used to deposit a compound film by sputtering a metal target and introducing a reactive gas such as oxygen or nitrogen to the gas phase. This reactive gas can then react with the sputtered atoms to form a compound. The target also reacts with the reactive gas and a compound is formed on the target [99]. The formation of the compound leads to a change in the sputtering conditions, because the sputter yield and the secondary electron emission coefficient change. The change in the sputter yield is due to the change in the surface binding energy of the target material. The ionic or covalent bonds in the compound are generally stronger than metallic bonds. Therefore, the sputter yield generally decreases when the compound is formed on the target as can be seen from Equation 3.5. This effect is often referred to as target poisoning.

There is typically a hysteresis behaviour observed when changing the flow rate of the reactive gas as shown in Figure 3.4. When increasing the gas flow rate above a critical point the sputter parameters such as the reactive gas partial pressure, the discharge voltage and the deposition rate change suddenly. Decreasing the gas flow rate below a second, lower critical point will bring the sputter parameters back to their initial values. At low reactive gas flow, the process is in the metallic mode, which means 


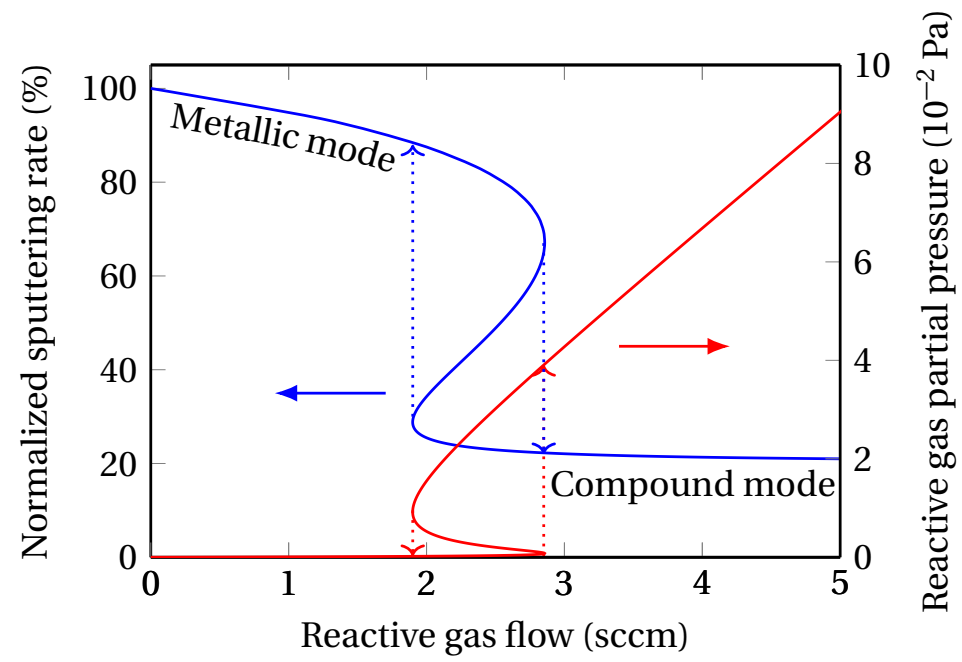

Figure 3.4: Typical hysteresis curves of the sputtering rate and the partial pressure of reactive gas according to Berg's model [100]

that the target surface is metallic leading to a high deposition rate. After the critical point the deposition rate decreases drastically and the process is in the compound mode, where a compound is formed on the target surface.

This hysteresis behaviour can be described by Berg's model of reactive sputtering $[100,101]$. This model takes into account the gettering of the reactive gas by the sputtered atoms, the target and the substrate area (including the chamber walls) as well as the pump using several steady state equations. From these equations, the sputtering rate, and the formed compound fractions on the target and the substrate can be calculated as a function of the partial pressure of the reactive gas or the reactive gas flow. In order to obtain the curves in Figure 3.4, a certain partial pressure of the reactive gas is assumed and the gas flow that is necessary to achieve that partial pressure is calculated. In an experiment, such a curve is only possible to obtain using an active feedback control of the gas flow. Without the feedback control, the process will follow the dotted lines as described in the previous paragraph. In the metallic mode, all the reactive gas is consumed by the target and the substrate, so the partial pressure of the reactive gas is zero. In the compound, the target area is fully covered by the compound and the partial 
pressure of reactive gas increases linearly with the gas flow as the gas is not consumed by the process anymore.

This hysteresis in reactive sputtering is influenced by the different parameters, such as the sputter yields of the metal and the compound. Also the applied current has an influence. By increasing the current the critical flow rates get shifted to higher values. On the other hand, increasing the pumping speed leads to a decrease in the width of the hysteresis. For very high pumping speeds the hysteresis can even disappear.

In reactive sputtering, it is often desirable to work in the transition mode between the metal and compound mode. This mode allows to deposit stoichiometric compound films, while still having a higher deposition rate than the compound mode. Because of the hysteresis behaviour it is difficult to stabilize the transition mode, unless an active feedback control is used. Such a feedback control monitors for example the partial pressure of the reactive gas or some other process parameter and adjusts the flow of reactive gas or the electrical parameters of the discharge to stay at a fixed point in the hysteresis loop [102].

Berg's model of reactive sputtering was extended by Depla et al. to include also the effect of implantation of reactive gas ions on the target [99]. By including ion implantation of reactive gas ions into the target and also knock-on implantation of chemisorbed reactive gas atoms into the target, the extended model allows for compound layers thicker than just a monolayer as in Berg's model.

Another effect of the introduction of a reactive gas is the change in the discharge voltage in case of sputtering with a constant current. For some materials, such as $\mathrm{Al}$ or $\mathrm{Zn}$, the discharge voltage decreases in the oxide mode, whereas for other materials, such as Ti, the discharge voltage increases in the oxide mode [103]. This can be explained by the change in the secondary electron emission yield upon formation of the compound layer. As described in Equation 3.12 the discharge voltage is inversely proportional to the secondary electron yield. For most oxides, the secondary electron yield is larger than for the corresponding metal as kinetic emission becomes dominant, leading to a decrease in the discharge voltage. Other oxides can become substoichiometric as oxygen is preferentially sputtered. The secondary electron yield of the suboxides is smaller or in the same order as the secondary electron yield of the metal leading to an increase in the discharge voltage [103]. 


\subsection{High power impulse magnetron sputtering}

High power impulse magnetron sputtering (HiPIMS) is a special form of pulsed DC magnetron sputtering, that allows to reach large instantaneous current and power densities. While in DC magnetron sputtering a constant current is applied, pulsed DC magnetron sputtering uses pulses with short off times in the order of $\mu$ s, that are repeated with a frequency of several $100 \mathrm{kHz}$. This technique is often used when sputtering materials with a relatively high resistivity in order to allow charges to dissipate during the off times and prevent arcing. HiPIMS on the other hand uses relatively long off times of several $100 \mu$ s between pulses and lower repetition frequencies in the order of 100 to a few $1000 \mathrm{~Hz}$. The difference in the pulsing modes between DC magnetron sputtering, pulsed DC magnetron sputtering and HiPIMS is shown schematically in Figure 3.5. The pulsing in case of HiPIMS allows to keep the average power density at a low enough value to not overheat the target, while the high power density during the pulse leads to a high plasma density, which in turn leads to a large degree of ionization of the sputtered atoms. The technique was first developed in the 1990s [10, 104]. The ratio of the pulse length and the pulse period is called the duty cycle. In HiPIMS the duty cycle is typically in the order of $0.5 \%$ to $5 \%$ [96]. As an alternative name of HiPIMS also high power pulsed magnetron sputtering (HPPMS) is used [105]. HPPMS is also often used as a general term to include HiPIMS and modulated pulse power (MPP), which is a technique that groups several short micropulses into a longer macropulse [106]. Anders proposed two different definitions of the term HiPIMS [107]. His technical definition is that peak power should exceed the time averaged power by typically two orders of magnitude in HiPIMS. The more physical definition is that in HiPIMS a significant fraction of the sputtered atoms becomes ionized.

If a large fraction of the sputtered atoms are ionized, these ions can get back-attracted to the target and participate in the sputtering process. This is called self-sputtering [107]. Models that explain the processes in a HiPIMS discharge were published by several authors [108-110]. These models are based on the relative fractions of sputtered atoms that are ionized and back-attracted to the target, respectively. Increasing the discharge voltage above a critical value will lead to a large increase in the discharge current. This runaway has been primarily attributed to self 


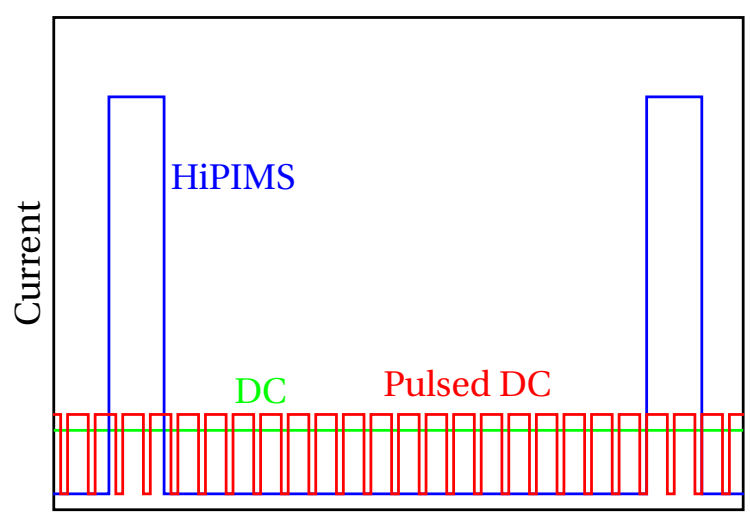

Time

Figure 3.5: Schematic comparison of DC magnetron sputtering, pulsed DC magnetron sputtering and HiPIMS

sputtering and the runaway threshold is characterized by the following condition.

$$
\beta_{\mathrm{i}} \beta_{\mathrm{r}} \gamma_{\mathrm{SS}}>1
$$

with $\beta_{\mathrm{i}}$ the ionization probability of a sputtered atom, $\beta_{\mathrm{r}}$ the probability that an ion returns to the target and $\gamma_{\text {SS }}$ the self-sputter yield [95]. This concept has been more generalized in the so-called recycling trap model, where both target atoms as well as gas atoms are ionized and return to the target to cause further sputtering [110].

The back-attraction of metal ions to the target causes an issue for HiPIMS processes, namely a reduction in the deposition rate as compared to DC sputtering with the same average power. Deposition rates in HiPIMS are typically found to be only $30-85 \%$ of the corresponding deposition rates in DC sputtering [111].

Another effect in HiPIMS is the rarefaction of gas in front of the target [112]. This rarefaction is due to the heating of the gas, which leads to a decrease in gas density according to the ideal gas law. The rarefaction is also due to an effect known as "sputter wind", meaning the transfer of momentum from the sputtered atoms to the gas atoms. This effect is very pronounced in the case of HiPIMS discharges due to the high instantaneous density of sputtered atoms. The rarefaction effect can be observed in the current waveforms as a decrease in the discharge current 


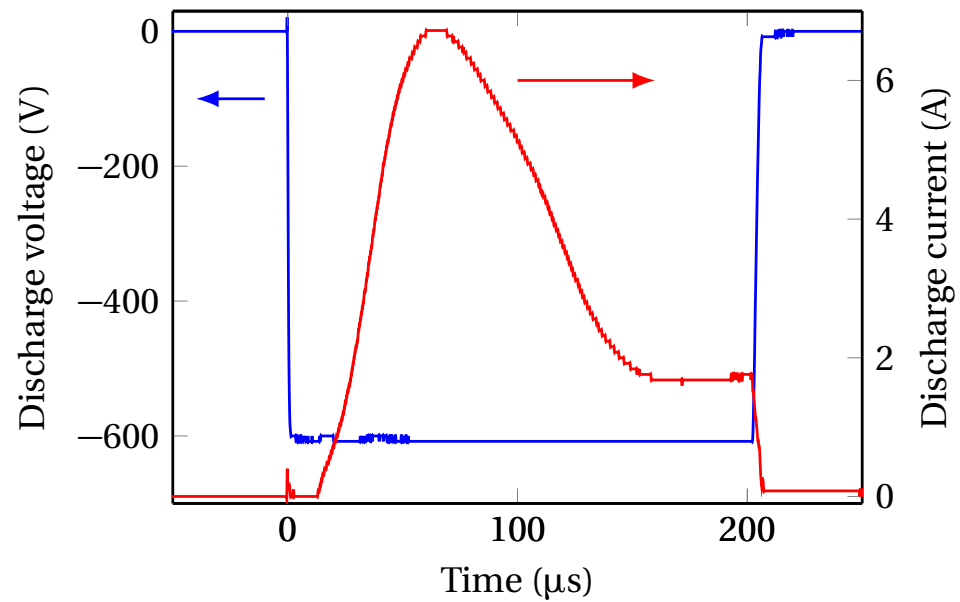

Figure 3.6: Typical current waveform for a $200 \mu$ s HiPIMS pulse

after a peak. Such a typical current waveform is shown for a $200 \mu$ s pulse in Figure 3.6.

HiPIMS discharges were found not to be homogeneous above the racetrack of the target, but rather show regions of increased ionization [113]. These ionization regions are called spokes and drift along the racetrack in a $\boldsymbol{E} \times \boldsymbol{B}$ direction. The ionization zones have been described in the so called ionization region model, that takes into account the reaction rates of the different species in the plasma and also the rarefaction effect [114].

When sputtering in reactive mode, the shape of the current waveform typically changes between the metal and the compound mode. In Figure 3.7, discharge current waveforms are shown for a $\mathrm{Zn} / \mathrm{Al}$ target sputtered in an $\mathrm{Ar} / \mathrm{O}_{2}$ mixture using $50 \mu$ s HiPIMS pulses at different frequencies. At the higher frequency, the process is in the metallic mode, whereas at the lower frequency the process is in the compound mode. In the metallic mode, the current waveform is flat, whereas in the compound mode, the current waveform has a triangular shape and rises to a maximum at the end of the pulse. This evolution of the discharge current waveform is commonly observed in literature [115], and can even be used to control the reactive sputter process [116]. The different shapes in the two modes can be explained by an extension of the ionization region model for reactive sputtering by Gudmundsson et al. [117]. They show 


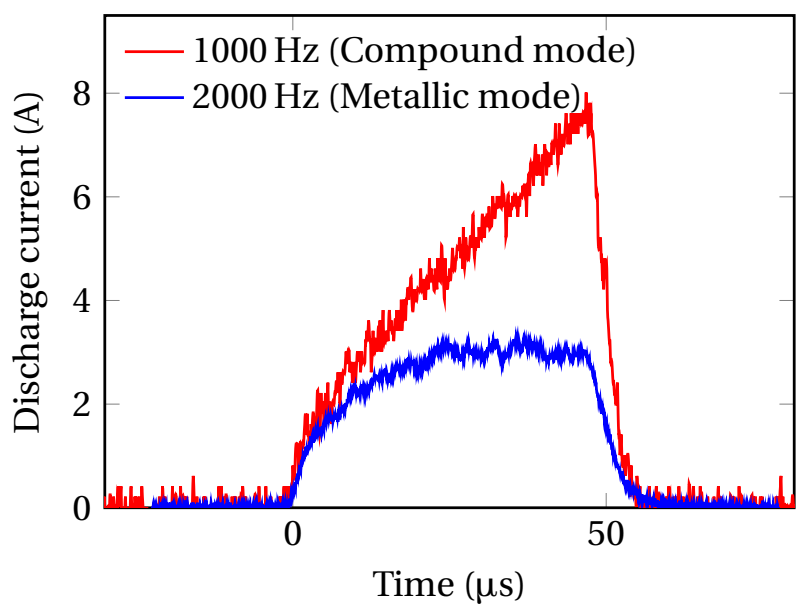

Figure 3.7: Discharge current waveforms of a $\mathrm{Zn} / \mathrm{Al}$ target sputtered in an $\mathrm{Ar} / \mathrm{O}_{2}$ mixture using $50 \mu$ s pulses

that in the compound mode the discharge is dominated by recycling of Ar ions, whereas in the metallic mode, there is a mixture of metal ions and Ar ions.

In reactive sputtering using HiPIMS, it was observed that the hysteresis effect can be avoided in certain cases $[118,119]$. This has been related to the high instantaneous sputtering rate, that might remove the oxide layer during a pulse, and the rarefaction effect, that would decrease the compound formation between the pulses. To account for these effects, Wallin and Helmersson [118] modified Berg's model to use an higher effective current density in the steady state equations for the target. This modification of Berg's model allows to qualitatively describe the behaviour of the hysteresis in the case of HiPIMS as the target coverage of the compound is shifted towards higher reactive gas flow, and the typical S-shape of the sputtering rate that is shown in Figure 3.4 can be avoided. Recently, more advanced models of reactive HiPIMS have been published, that also take into account the implantation of reactive gas ions and back-attracted metal ions [120]. 


\subsection{Thin film growth}

Up to now, the processes on the target and in the plasma have been described. This section will describe what happens on the substrate surface, when the sputtered atoms arrive and condense to form a film. There are three basic growth modes in film formation that depend on the relative strength of the bonds formed between the substrate and the film and between the atoms of the growing film [72, pp. 197-198]. When the atoms from the vapour impinge on the substrate they form nuclei. If the bonds between the atoms of the nuclei are stronger than the bonds towards the substrate, the nuclei will grow into small islands on the substrates. This island growth mode is also called Volmer-Weber growth. On the other hand, if the bonds between the substrate and the film are stronger, the film will form a monolayer on top of the substrate. On top of this first layer, a second layer with slightly weaker bonding can form. This means, that the film can grow layer by layer. This growth mode is called layer growth or Frank-van der Merwe growth. In the third growth mode, a few layers are grown initially, and then island growth occurs on top of these initial layers. This growth mode is called Stranski-Krastanov growth.

The properties of the growing film are also influenced by the deposition parameters such as the pressure and the substrate temperature. The influence of these parameters on the morphology of the films can be described by structure zone models or structure zone diagrams. A first structure zone model was developed by Movchan and Demchishin as a function of the homologous temperature $T / T_{\mathrm{m}}$ [121]. The homologous temperature is the ratio of the substrate temperature divided by the melting temperature of the deposited material. Movchan and Demchishin identified three different zones. For low homologous temperatures $\left(T / T_{\mathrm{m}}<0.3\right)$ the film growth is described by zone 1 . In this zone fibrous grains ending with domed tops are found. This can be explained by the low mobility of the adsorbed atoms (adatoms) at low temperature [122]. At higher temperatures $\left(0.3<T / T_{\mathrm{m}}<0.5\right)$ in zone 2 , uniform, columnar grains are formed due to the surface diffusion. Finally, in zone $3\left(T / T_{\mathrm{m}}>0.5\right)$ dense films with equiaxed grains are formed due to bulk diffusion.

In magnetron sputtering, another important parameter next to the substrate temperature is the pressure in the chamber. As typical pres- 
sures in magnetron sputtering are in the range between 0.1 and $10 \mathrm{~Pa}$, there are collisions between the sputtered atoms and the background gas, which decrease the kinetic energy of the sputtered atoms. With increasing pressure, the mean free path between collisions decreases and the kinetic energy of the sputtered atoms and the deposition rate decrease. It is possible to evaluate this decrease in the kinetic energy and the deposition rate either by analytical calculations or by modelling using Monte-Carlo simulations [123].

In order to include the influence of the pressure on the film growth, Thornton extended the structure zone model by Movchan and Demchishin $[121,124]$. Thornton found a transition zone $\mathrm{T}$ between zones 1 and 2 for low pressures. This transition zone consists of dense, fibrous grains without voids. Barna and Adamik [125] extended the structure zone model further to include the effect of impurities. The segregation of impurities at the grain boundaries can hinder grain growth and lead to smaller grains [126, pp. 23-24].

Another extension of the structure zone model was made by Mahieu et al. [127]. In this structure zone model, adatom diffusion on the surface and between grains is considered separately. A new zone Ic is introduced, where adatoms can only diffuse on the surface of one grain, but not diffuse to another grain. This leads to the growth of faceted columns without a preferential crystallographic orientation. Only at higher temperature the diffusion from one grain to another is possible, which leads to a preferential orientation along the fastest growing crystallographic orientation after initial competition between randomly oriented grains. Mahieu et al. call this zone the zone T.

This structure zone model has to be further extended, if one considers that a significant number of the sputtered atoms are ionized, such as in HiPIMS. Anders [122] proposed an extended structure zone diagram to include the effects of the ion flux on the film growth. He replaced the homologous temperature with a generalized temperature $T^{*}$. This generalized temperature also includes the effect of the potential energy of particles arriving on the substrate. He proposed to replace the pressure axis in the diagram by a normalized energy $E^{*}$, that is related to kinetic energy of the incoming particles. Additionally, Anders introduced the film thickness as a third axis, to show the effects of densification and sputter etching of the growing film. 


\subsection{Sputter deposition of AZO thin films}

As already described in section 3.4, oxide films can be deposited either using RF sputtering of a ceramic target or by reactively sputtering a metal target. Because of the conductivity of AZO, however, it is also possible to sputter an AZO target using a DC discharge [128]. AZO films have been grown using both non-reactive and reactive magnetron sputtering. The best properties of the films are usually achieved by RF sputtering from a ceramic target [129]. For example, Agashe et al. [130] deposited AZO films with a resistivity of $3.5 \times 10^{-4} \Omega \mathrm{cm}$ at a substrate temperature of $100^{\circ} \mathrm{C}$. However, due to the higher cost of ceramic targets there is an interest in using reactive sputtering of metal targets. Even though the hysteresis effect can be relatively small in reactive sputtering of AZO depending on the process parameters [131], a small change in the oxygen partial pressure can cause a large change in the properties of the films [4]. Despite this difficulty of controlling the reactive sputtering process, reactive magnetron sputtering has been used to deposit AZO films with various deposition parameters.

One problem that was reported by several groups studying both nonreactive and reactive sputtering of AZO, is the lateral inhomogeneity of the properties $[132,133]$. The problem was initially found in the deposition of undoped $\mathrm{ZnO}$ by Minami et al. [134]. An increase in the resistivity by several orders of magnitude was found for substrates placed in front of the target. Tominaga et al. [132] confirmed this effect for AZO films prepared by RF magnetron sputtering and related it to the bombardment of the film with negative oxygen ions coming from the target. This negative oxygen ion bombardment can introduce acceptor defects, such as oxygen interstitials into the growing film, and therefore decrease the charge carrier concentration as reported by Bikowski et al. [9]. They observed a minimum in the resistivity for a certain substrate temperature that depends on the sputter method. They postulate that at low substrate temperature the compensation of the carriers by the created oxygen interstitials is dominant. At intermediate temperatures, the acceptor defects get annealed and the resistivity decreases. At high substrate temperatures, phase segregation occurs which increases the resistivity. The formation of secondary phases, such as the homologous $\mathrm{Al}_{2} \mathrm{O}_{3}(\mathrm{ZnO})_{m}$ phase, can also be induced by the oxygen ion bombardment. Using XANES, Horwat et al. [8] deduced a stronger presence of that phase at 
substrate positions in front of the target axis in AZO films, that were reactively sputtered at room temperature. Vinnichenko et al. [63] found that the formation of the homologous phase occurs independently of the substrate temperature, but the volume fraction of the homologous phase increases above an optimum deposition temperature. This increase in the volume fraction can be related to an increase in the $\mathrm{Al}$ concentration in the film due to preferential $\mathrm{Zn}$ desorption, as $\mathrm{Zn}$ has a higher vapour pressure than Al.

There are many studies on the influence of the different process parameters, such as the oxygen partial pressure (or more general the ratio between metal and oxygen flux), the substrate temperature, the $\mathrm{Al}$ concentration in the target or the total pressure, on the properties of sputtered AZO films. Reviews on magnetron sputtering of AZO films have been published by Ellmer [4] and by Szyszka [6, pp. 187-233].

In the case of reactive sputtering, one of the most important process parameters is the oxygen partial pressure. Usually, the resistivity shows an optimum at an intermediate oxygen partial pressure. For example, Brehme et al. [135] studied the deposition of AZO films in reactive DC sputtering at room temperature as a function of the oxygen flow rate and found an optimum resistivity of $6 \times 10^{-4} \Omega \mathrm{cm}$. This behaviour can be related to the influence of stoichiometry on the electrical and optical properties of the films [7, pp. 205-206]. At low oxygen partial pressure, the films have a high charge carrier concentration, which limits the mobility and the transmittance of the films. At high oxygen partial pressure, the dopants become oxidized and therefore inactive, leading to transparent but insulating films.

The substrate temperature also plays an important role as has been already discussed above in terms of the deactivation of dopants by the formation of secondary phases. In many cases, an optimum in resistivity is therefore found for an intermediate substrate temperature. The exact value of that optimum substrate temperature depends on the other deposition parameters, such as the $\mathrm{Al}$ concentration in the target and the oxygen partial pressure [63].

The influence of the $\mathrm{Al}$ concentration in the target on the film properties has been studied by Cornelius and Vinnichenko [5] for concentrations between 0.7 at\% and 8.7 at\%. They found the highest dopant activation and the lowest resistivity for a target $\mathrm{Al}$ concentration of 1.7 at\%. 
Finally, the microstructure of the films is strongly affected by the total pressure as the energy of the arriving atoms is pressure dependent. As described in section 3.6, a higher pressure generally causes a less dense film structure, thereby increasing the grain boundary scattering and therefore the resistivity [7, pp. 206-207].

As reactive and non-reactive magnetron sputtering remains a challenge, new approaches are still being tested. One such new approach is HiPIMS. In the literature, HiPIMS has been used to deposit both doped and undoped $\mathrm{ZnO}$ films from both metal and ceramic targets. The HiPIMS deposition of undoped $\mathrm{ZnO}$ was first reported in 2007 by Konstantinidis et al. [136] and the HiPIMS deposition of AZO was reported in 2008 by Ruske et al. [137].

Ruske et al. [137] deposited AZO films using reactive HiPIMS from alloyed $\mathrm{Zn} / \mathrm{Al}$ targets. They used a prototype HiPIMS power supply providing pulses of 100-150 $\mu$ s [138]. Additionally, they used a feedback control for the reactive sputter process using the oxygen partial pressure as an input signal to regulate the pulse frequency [139]. This allowed them to deposit transparent AZO films with a resistivity of around $2 \times$ $10^{-3} \Omega \mathrm{cm}$ at room temperature and $3.5 \times 10^{-4} \Omega \mathrm{cm}$ at $200^{\circ} \mathrm{C}$. Later, the same group also deposited AZO films using a ceramic AZO target, but these films showed large lateral variations of the resistivity due to the oxygen ion bombardment [140].

Tiron et al. [141] also deposited AZO using HiPIMS with short pulses of $6 \mu \mathrm{s}$. They used a $\mathrm{Zn}$ target and an additional Al electrode that was

placed between the target and the substrate. With this setup, they could control the $\mathrm{Al}$ content in the films by varying the bias voltage on the $\mathrm{Al}$ electrode. They found an optimum resistivity of $3.6 \times 10^{-3} \Omega \mathrm{cm}$ with an $\mathrm{Al}$ concentration of 1.5 at\% for room temperature deposition. There is another report of the deposition of AZO films by Anders and Brown [142], who used a HiPIMS discharge steered towards the substrate by a solenoid in order to filter out the negative oxygen ions. This way, they deposited AZO films with a resistivity of $3.5 \times 10^{-4} \Omega \mathrm{cm}$ at a substrate temperature of $160^{\circ} \mathrm{C}$.

\subsection{Experimental setup}

Different vacuum chamber with different sputter setups were used in this work. In all of the chambers, a rotary vane pump and a turbomolecular 


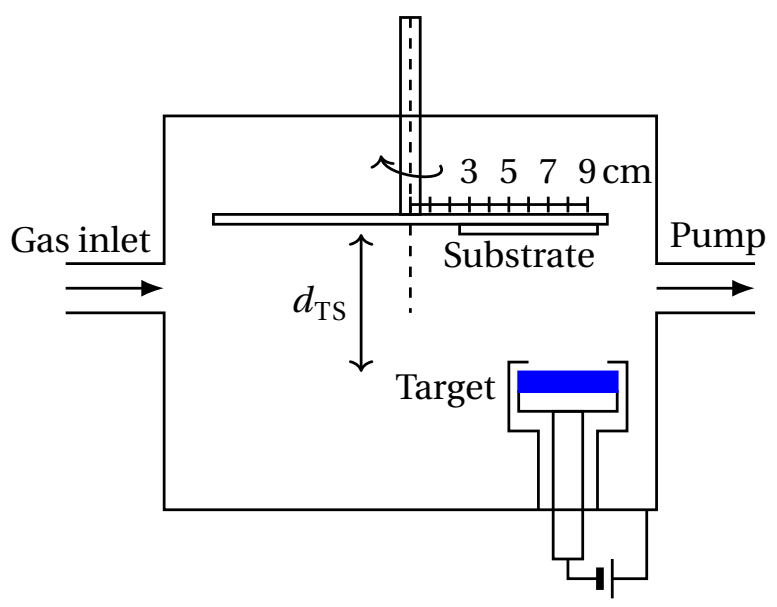

Figure 3.8: Experimental sputter setup for Papers 1 and $\mathbf{2}$

pump were used to reach a base pressure in the order of $10^{-3} \mathrm{~Pa}$. The depositions in Paper 1 and the depositions using HiPIMS in Paper 2 were done in a chamber that is equipped with three $5 \mathrm{~cm}$ magnetrons and a rotating substrate holder. A schematic drawing of this chamber is shown in Figure 3.8. The three magnetrons are placed symmetrically around the centre of the chamber in a distance of $8 \mathrm{~cm}$. For clarity, only one of the magnetrons is shown in the figure. Substrates are usually fixed on the sample holder using a polyimide tape. The substrates can be placed at different lateral positions as indicated in Figure 3.8. The vertical distance between the target and the substrate $d_{\text {TS }}$ can be adjusted by moving the magnetron. The substrate holder can be connected to a radio frequency (RF) power supply, in order to plasma etch the substrates. This plasma etching can be used to clean the surface of the substrates from contamination. The volume of the chamber is 451 .

For Paper 3 a different deposition chamber was used, that is equipped with a rotating substrate heater with a diameter of $15 \mathrm{~cm}$. The chamber has a volum of $30 \mathrm{l}$ and is equipped with 2 magnetrons. These magnetrons were placed at a distance of $6 \mathrm{~cm}$ from the centre of the chamber.

For Papers 1, 2 and 3, the plasma was generated by an Advanced Energy Pinnacle Plus pulsed DC power supply, connected to a Melec Spik 2000A HiPIMS pulsing unit. For the HiPIMS experiments, the discharge current waveforms could be measured using a Tektronix TDS 2024B 
oscilloscope with a Pearson Current Monitor model 110. For the DC experiments, the Advanced Energy Pinnacle Plus was used in constant current mode.

For Paper 4, a $70 \mathrm{l}$ chamber was used with a single magnetron placed in the centre of the chamber. The substrates were placed at a distance of $11 \mathrm{~cm}$ from the target on a static substrate holder. The plasma was generated by using an Ionautics HiPSTER 1 pulsing unit, that is charged by a Technix SR1KV DC power supply. 


\section{Chapter 4}

\section{Characterization methods}

The various characterization methods that were used in this work in order to evaluate the optical, electrical and structural properties of the AZO thin films will be presented in this chapter.

\subsection{Spectrophotometry}

The optical transmittance and reflectance spectra in the infrared, visible and the UV range can be obtained by spectrophotometry. In a spectrophotometer, light is directed through a sample and the change in intensity between the incident and transmitted light or the incident and reflected light can be measured. The light is created by a lamp and then a certain wavelength is selected using a monochromator. A common setup is a double beam setup. The light beam is split into two components. One beam is directed towards the sample, while the other one is used as a reference. The fraction of the intensity of the sample beam over the intensity of the reference beam gives the measured signal.

The transmittance $T$ is defined as the ratio of intensities of the transmitted light $I_{\mathrm{t}}$ and the incident light $I_{0}$. The specular reflectance $R$ is the ratio of intensities of the reflected light $I_{\mathrm{r}}$ and the incident light $I_{0}$. Light can also be reflected or transmitted diffusely, leading to the optical scatter $S$, that is given by $S=I_{\mathrm{s}} / I_{0}$ with $I_{\mathrm{s}}$ the intensity of the scattered light. Additionally, light can be absorbed in the material and the absorptance $A$ can be defined accordingly. Due to energy conservation the different intensities add up to the incident intensity [143, pp. 71-73]:

$$
I_{\mathrm{t}}+I_{\mathrm{r}}+I_{\mathrm{s}}+I_{\mathrm{a}}=I_{0} .
$$


Therefore, the sum of transmittance, specular reflectance, scatter and absorptance must be equal to one.

$$
T+R+S+A=1 .
$$

The transmittance and specular reflectance of a sample can be easily measured with a spectrophotometer. In order to measure the optical scatter, an integration sphere is necessary, that collects all the light that is reflected or transmitted onto a detector. Most of the thin films investigated in this work are homogeneous and have relatively flat surfaces, so the scatter can be neglected [143, p. 110]. Only for the films in Paper 4 an integration sphere was used.

In order to measure the transmittance of the film several methods are available. It is possible to use the substrate as a reference. In this case, the measured transmittance would directly correspond to the transmittance of the film. However, possible effects of the interface between the substrate and the film are neglected. It is also possible to only use air as a reference and to leave the reference sample holder empty. In this case, the transmittance of the substrate can be measured in a separate measurement as $T_{\mathrm{S}}$. The transmittance of the film $T_{\mathrm{F}}$ is then approximated from the measured transmittance $T$ as

$$
T_{\mathrm{F}}=\frac{T}{\sqrt{T_{\mathrm{S}}}} .
$$

To understand this equation, the interactions of light with interfaces have to be taken into account [144]. These interactions can be described by Fresnel's formulae [143, pp. 76-83]. These formulae describe a system where light is arriving on an interface between a medium with complex refractive index $N_{1}$ and a medium with complex refractive index $N_{2}$. For normal incidence, Fresnel's coefficients $r$ and $t$ are given by

$$
r=\frac{N_{1}-N_{2}}{N_{1}+N_{2}}
$$

and

$$
t=\frac{2 N_{1}}{N_{1}+N_{2}} .
$$

The reflectance $R$ is related to the Fresnel coefficient $r$ by

$$
R=|r|^{2}
$$




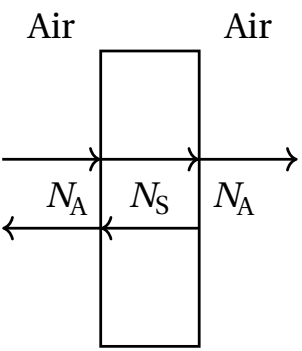

(a) Substrate

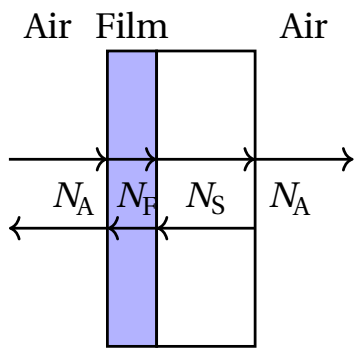

(b) Thin film on substrate

Figure 4.1: Light traversing different media

and the transmittance $T$ is then given by

$$
T=1-R=\frac{N_{2}}{N_{1}}|t|^{2} .
$$

When light traverses a substrate, it passes two interfaces. The first interface is between air and the substrate and the second interface is between the substrate and air. Such a system is shown in Figure 4.1a. The transmittance of the substrate is therefore given by

$$
T_{\mathrm{S}}=T_{\mathrm{AS}} T_{\mathrm{SA}}=\frac{16 N_{\mathrm{A}}^{2} N_{\mathrm{S}}^{2}}{\left(N_{\mathrm{A}}+N_{\mathrm{S}}\right)^{4}} .
$$

Similarly, if light traverses only a thin film, its transmittance $T_{\mathrm{F}}$ is given by

$$
T_{\mathrm{F}}=T_{\mathrm{AF}} T_{\mathrm{FA}}=\frac{16 N_{\mathrm{A}}^{2} N_{\mathrm{F}}^{2}}{\left(N_{\mathrm{A}}+N_{\mathrm{F}}\right)^{4}} .
$$

The total transmittance of the system with a film on a substrate as shown in Figure $4.1 \mathrm{~b}$ is given by

$$
T_{\text {total }}=T_{\mathrm{AF}} T_{\mathrm{FS}} T_{\mathrm{SA}}=\frac{64 N_{\mathrm{A}}^{2} N_{\mathrm{F}}^{2} N_{\mathrm{S}}^{2}}{\left(N_{\mathrm{A}}+N_{\mathrm{F}}\right)^{2} \times\left(N_{\mathrm{F}}+N_{\mathrm{S}}\right)^{2} \times\left(N_{\mathrm{S}}+N_{\mathrm{A}}\right)^{2}} .
$$

By combining Equations 4.8, 4.9 and 4.10 a more exact expression than Equation 4.3 can be found:

$$
T_{\mathrm{F}}=\frac{T}{\sqrt{T_{\mathrm{S}}}} \frac{N_{\mathrm{A}}\left(N_{\mathrm{F}}+N_{\mathrm{S}}\right)^{2}}{N_{\mathrm{S}}\left(N_{\mathrm{A}}+N_{\mathrm{F}}\right)^{2}} .
$$


Inserting typical values $\left(N_{\mathrm{A}}=1, N_{\mathrm{S}}=1.5\right.$ and $\left.N_{\mathrm{F}}=2\right)$ in the correction factor in Equation 4.11 results in a factor of 0.91, which is close to 1 . If one would use $T_{\text {total }} / T_{\mathrm{S}}$ to calculate the transmittance of the film $T_{\mathrm{F}}$, a different correction factor would have to be used:

$$
T_{\mathrm{F}}=\frac{T}{T_{\mathrm{S}}} \frac{4 N_{\mathrm{A}}^{2}\left(N_{\mathrm{F}}+N_{\mathrm{S}}\right)^{2}}{\left(N_{\mathrm{A}}+N_{\mathrm{S}}\right)^{2}\left(N_{\mathrm{A}}+N_{\mathrm{F}}\right)^{2}} .
$$

Inserting the same values as above for the refractive indices results in a factor of 0.87 , which is farther away from 1 . Accordingly, the approximation in Equation 4.3 is slightly better adapted for the materials used in this work. However, this approximation does not take into account multiple reflections at the interfaces and the resulting interference phenomena. Also, the absorption within the media is neglected. To take all these effects into account, a more complex model needs to be used [143, p. 118].

From the transmittance $T$ the absorption coefficient $\alpha$ can be calculated according to the Beer-Lambert law [145, p. 776]:

$$
T=\frac{I}{I_{0}}=\mathrm{e}^{-\alpha t},
$$

with $I$ the intensity of the transmitted light, $I_{0}$ the intensity of the incident light and $t$ the thickness of the film. Accordingly, the absorption coefficient $\alpha$ is given by

$$
\alpha=\frac{1}{t} \ln \frac{1}{T} .
$$

If some of the incident light is reflected at the interface, the reflectance $R$ has to be taken into account in the calculation of the absorption coefficient. The initial intensity in the Beer-Lambert law is now $I^{\prime}=I_{0}(1-R)$ and Equation 4.14 becomes

$$
\alpha=\frac{1}{d} \ln \frac{1-R}{T} .
$$

To determine the band gap from the absorption spectrum at energies above the band gap, the Tauc method can be used [146]. The Tauc method assumes that the absorption coefficient $\alpha$ and the band gap energy $E_{\mathrm{g}}$ are related by

$$
(\alpha h v)^{1 / n}=A\left(h v-E_{\mathrm{g}}\right),
$$




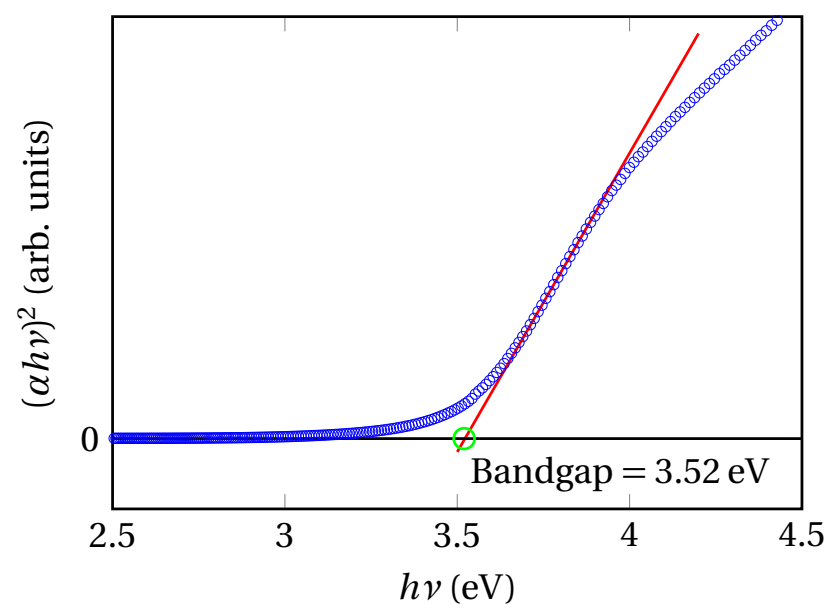

Figure 4.2: Example of a Tauc plot

with $h$ Planck's constant, $v$ the frequency and $A$ a proportionality constant [147]. The exponent $1 / n$ is equal to 2 for direct transitions and equal to $1 / 2$ for indirect transitions [17, p. 180]. To determine the band gap of a direct band gap material such as $\mathrm{ZnO}$ it is possible to $\operatorname{plot}(\alpha h v)^{2}$ as a function of $h v$ and extrapolate the linear part of the curve to the point where $(\alpha h v)^{2}$ is zero. This method is shown in Figure 4.2.

The spectrophotometer used in Papers 1, 2 and 3 is a Cary 5000 UV-Vis-NIR spectrophotometer. This spectrophotometer is equipped with two different light sources and allows measurements in the range between 200 and $3300 \mathrm{~nm}$. For Paper 4, a Perkin Elmer Lambda 950 $\mathrm{UV} /$ Vis spectrophotometer was used. It is equipped with an integration sphere, in order to be able to measure the specular and the diffuse transmittance. The measurement range is between 250 and $2200 \mathrm{~nm}$.

\subsection{Photoluminescence spectroscopy}

In photoluminescence spectroscopy (PL) a sample is irradiated with light of a certain wavelength to excite electrons in the material, which leads to emission of light of other wavelengths. The spectrum of this emitted light is measured. The excitation source can be a laser or a lamp where a certain wavelength is selected using a monochromator. A typical experimental setup is shown in Figure 4.3. The light that is emitted from 


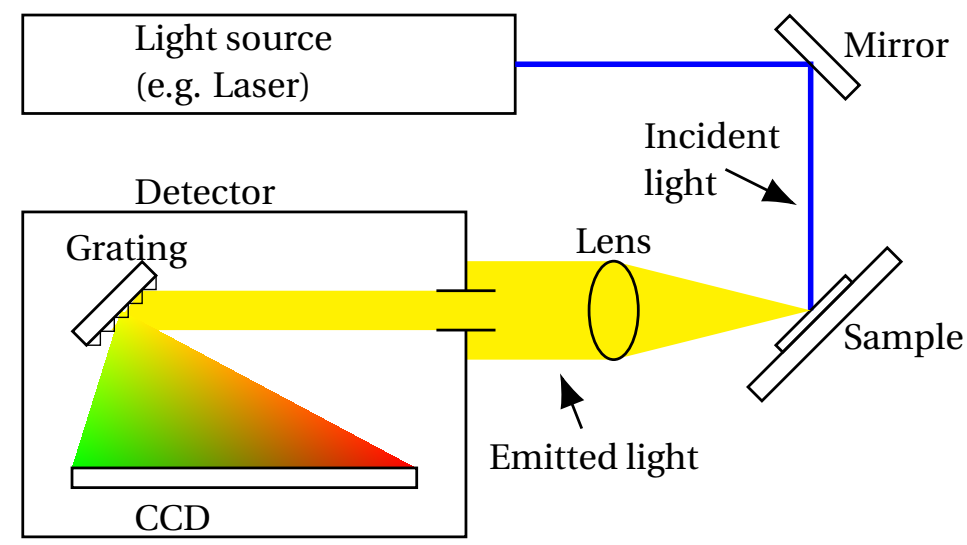

Figure 4.3: Photoluminescence spectroscopy setup

the sample enters the detector and is diffracted using a grating. The intensity of the light is then measured as a function of the wavelength using a line CCD (charge coupled device) detector.

Photoluminescence spectroscopy is useful to obtain information about the band structure and defect states of a material. An example of a typical PL spectrum of $\mathrm{ZnO}$ thin films is shown in Figure 4.4 for an excitation at $325 \mathrm{~nm}$. In $\mathrm{ZnO}$ there are generally two contributions observed if the material is excited with an energy above the band gap. The first contribution corresponds roughly to the energy of the band gap corrected by the exciton binding energy. The second contribution can be found in the visible range and corresponds to different defect states within the band gap of $\mathrm{ZnO}$. Using a deconvolution of the defect emission, information about the different types of defects in the material can be obtained [148].

The PL setup used in this work uses a Horiba iHR320 spectrometer. This spectrometer is equipped with a Horiba Syncerity multichannel CCD detector. A $266 \mathrm{~nm}$ CryLas FQCW266-50 laser was used as the excitation light source. In order to avoid parasitic light from the laser being measured, several filters were used. For measuring the part of the spectrum at low wavelengths, a $325 \mathrm{~nm}$ edge filter was used. In order to avoid the second order of the excitation wavelength appearing in the PL spectra, a $400 \mathrm{~nm}$ edge filter was used to record the part of the spectrum at larger wavelengths. 


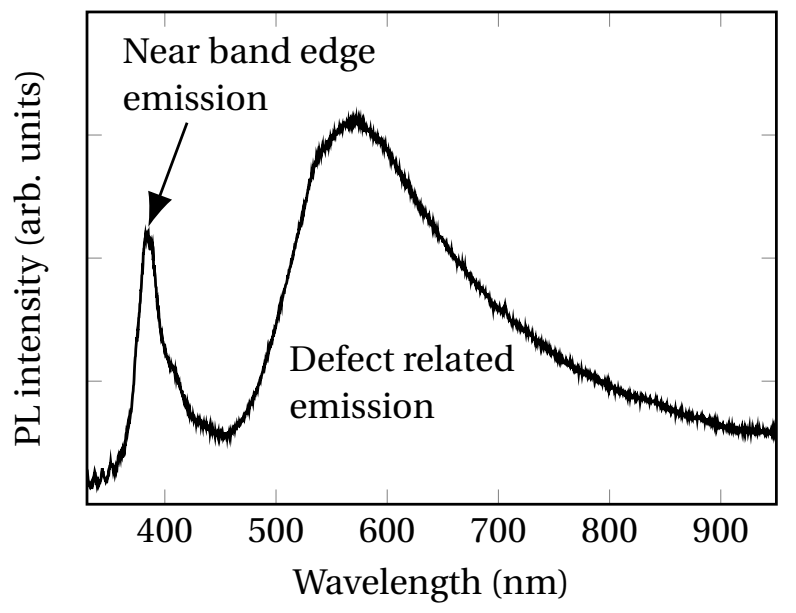

Figure 4.4: Typical PL spectrum of a $\mathrm{ZnO}$ thin film excited at $325 \mathrm{~nm}$

\subsection{Electrical characterization}

The sheet resistance $R_{\mathrm{S}}$ of thin films is defined by $R_{\mathrm{S}}=\rho / t$, with $\rho$ the resistivity and $t$ the thickness. The sheet resistance is generally given in the unit $\Omega$ per square $(\Omega /$ sq or $\Omega / \square)$. $R_{\mathrm{S}}$ can be measured using the 4-point probe method [72, pp. 453-455]. The film is contacted by four probes in a linear configuration as shown in Figure 4.5a. Through the outer contacts a current is applied, and the resulting voltage is measured at the inner contacts. The measured value has to be multiplied with a correction factor due to the contact geometry and the geometry of the sample. For a linear contact configuration the correction factor is equal to $\pi / \ln (2)=4.53$ if the sample is much larger than the spacing between the contacts. Otherwise, a smaller correction factor has to be applied [149].

An alternative configuration is the Van der Pauw configuration [150]. The film needs to be contacted in four points $A, B, C$, and $D$. Ideally, the sample should have a square shape and the contacts should be placed in the corners. This configuration is shown in Figure 4.5b. The current $I$ and the voltage $V$ need to be measured for different configurations. The resistivity $\rho$ is then calculated from

$$
\exp \left(-\frac{\pi t}{\rho} \frac{V_{C D}}{I_{A B}}\right)+\exp \left(-\frac{\pi t}{\rho} \frac{V_{D A}}{I_{B C}}\right)=1 .
$$




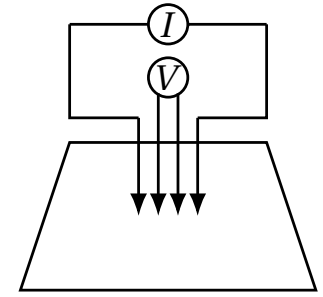

(a) Linear configuration

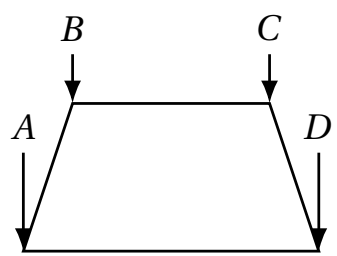

(b) Van der Pauw configuration

Figure 4.5: Contact configurations for 4-point probe measurements [72, p. 454]

It is also possible to perform Hall effect measurements using the Van der Pauw configuration [150]. In this case a magnetic field $B$ is applied perpendicular to the film surface. If a current $I$ is passed through opposing corners of the sample (e.g. $A$ and $C$ ), the Hall voltage $V_{\mathrm{H}}$ can be measured through the other two corners (e.g. $B$ and $D$ ). The Hall mobility $\mu_{\mathrm{H}}$ is then calculated using

$$
\mu_{\mathrm{H}}=\frac{t}{B} \frac{V_{\mathrm{H}}}{I \rho} .
$$

With the known resistivity and mobility the charge carrier concentration $n$ can be calculated according to $n=1 /(\rho e \mu)$ with $e$ being the electron charge. The Hall effect setup used in this work is an Ecopia HMS 5000 setup, that uses a magnetic field of $0.57 \mathrm{~T}$.

\subsection{X-ray diffraction}

In X-ray diffraction (XRD) the sample is irradiated with X-rays of a certain wavelength $\lambda$ in a certain angle $\theta$. The diffracted $X$-rays are measured as a function of the diffraction angle. This gives crystallographic information about the sample. The diffraction angle $2 \theta$ is related to the distances between planes of the crystal lattice $d_{h k l}$ by Bragg's law [151, p. 192]:

$$
2 d_{h k l} \sin \theta=n \lambda,
$$

with $n$ the order of diffraction. With a known wavelength of the X-rays (typically $\mathrm{Cu} \mathrm{K} \alpha, \lambda=1.5406 \AA$ ) the distance $d_{h k l}$ can be calculated from 


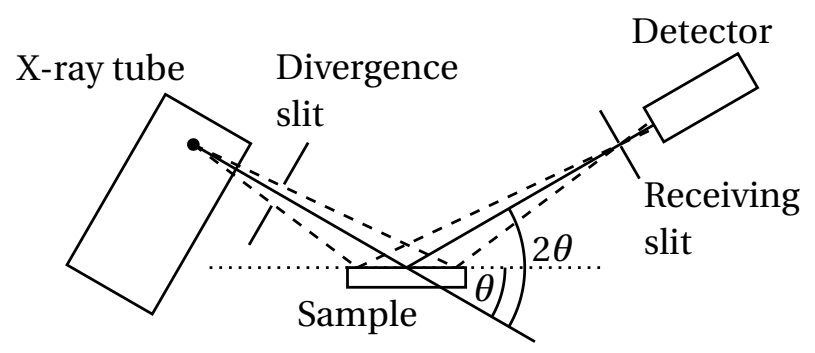

Figure 4.6: Schematic representation of the Bragg-Brentano geometry used in XRD [152, p. 15]

each peak in the diffraction pattern. The indices $h k l$ are the Miller indices, that indicate the crystallographic plane.

There are several different geometries that are used in XRD. The Bragg-Brentano geometry is commonly used for $\theta / 2 \theta$ scans [152, p. 15]. This geometry is schematically shown in Figure 4.6. In this case, the angle between the incident $\mathrm{X}$-rays and the sample surface $\theta$ is varied and the angle between the detector and the incident $\mathrm{X}$-rays is accordingly varied to keep it as $2 \theta$. Using a $\theta / 2 \theta$ scan only the planes in the film that are parallel to the surface are probed. For the case of a textured thin film only few peaks will be visible because the planes that are parallel to the surface belong to the same family of planes. An alternative to the Bragg-Brentano geometry is the parallel beam configuration, which makes the diffractometer less sensitive to a misalignment of the sample height [153].

The width of a diffraction peak is broadened due to several effects. The first effect is the broadening due to instrumental settings, such as the emission characteristics of the X-ray source or the characteristics of the used X-ray optics [152, p. 97]. The second effect is the broadening due to microstrains. Microstrains are local distortions of the crystal lattice, such as dislocations. These distortions cause variations in the lattice parameter and therefore a broadening of the diffraction peak [152, p. 85]. The third contribution to peak broadening is due to the finite crystallite size. Smaller crystallite sizes lead to broader peaks. Analyzing the peak broadening is especially useful in the case of nanoparticles, where the 
particle size $D$ can be estimated by the Scherrer equation

$$
D=\frac{K \lambda}{\beta \cos \theta},
$$

with $\beta$ the full width at half maximum (FWHM) and $K$ a constant, that can be related to the shape of the crystallite [154]. A typical value for $K$ is around 0.9. In the case of thin films the Scherrer equation can only be used to estimate the size of coherently scattering domains, which does not correspond to the grain size. In any case, the Scherrer equation gives only a lower bound for the crystallite size or coherence length, as the contributions of the instrumental broadening and especially the microstrains are difficult to take into account.

One way to solve this problem is the method by de Keijser et al. [155]. In this method the peak is fitted by a Voigt function, which is a convolution of a Gaussian and a Lorentzian function. The broadening due to the size can be assumed to follow a Lorentzian function and the microstrain and instrumental broadening follow a Gaussian function. This allows to insert the width of the Lorentzian component into Equation 4.20 to calculate an estimate for the crystallite size. The instrumental broadening should be determined by measuring a standard sample of a material of high crystalline quality using the same diffractometer settings. Assuming that the instrumental broadening follows a Gaussian function, the broadening due to microstrains $\beta_{\text {strain }}$ can be calculated as

$$
\beta_{\text {strain }}=\sqrt{\beta_{\text {Gaussian }}^{2}-\beta_{\text {instr }}^{2}},
$$

with $\beta_{\text {Gaussian }}$ the width of the Gaussian component and $\beta_{\text {instr }}$ the width due to instrumental broadening [152, p. 101].

Several diffractometers were used in this work. For most of the samples an AXS Bruker D8 Advance with a $\mathrm{Cu}$ anode was used. This diffractometer uses the Bragg-Brentano geometry and is equipped with an automatic sample loading system. Such as system allows to measure several samples in a batch measurement. Another diffractometer was a PANalytical X'pert with a $\mathrm{Cu}$ anode using a parallel beam geometry.

\subsection{Scanning electron microscopy}

A scanning electron microscope (SEM) can be used to investigate the surface morphology and the chemical composition of a sample. In SEM, 


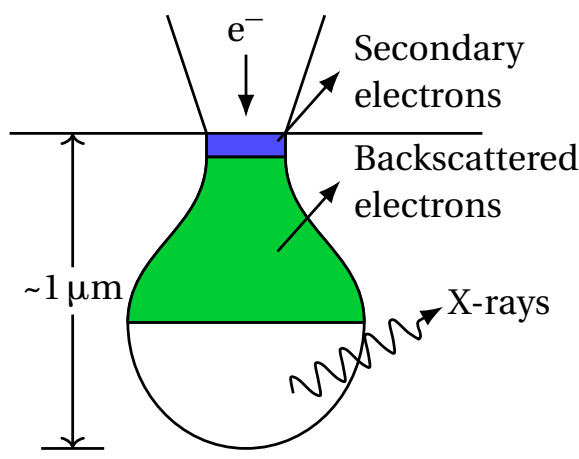

Figure 4.7: Schematic of the interaction of the primary electron beam with the sample surface in SEM [72, p. 267]

an electron beam is accelerated by a voltage of a few $\mathrm{kV}$ to several tens of $\mathrm{kV}$. The beam is then focussed on a small spot on the sample and scanned across the surface of the sample [72, p. 266]. The interaction of the electrons with the sample leads to several detectable signals such as secondary electrons, backscattered electrons and X-rays. These interactions are schematically shown in Figure 4.7.

Secondary electrons are generated when the incoming primary electrons ionize atoms in the sample. Secondary electrons have low energy, so only those originating from close to the surface can escape the sample. Therefore, secondary electrons show the surface morphology [72, p. 267].

Backscattered electrons are primary electrons that undergo elastic collisions with the atoms of the sample. As the backscattering probability increases with the mass of the scattering atoms, heavier atoms will lead to a higher intensity of backscattered electrons. These electrons therefore include information about the chemical contrast [72, p. 268].

The emitted X-rays can be analyzed by energy dispersive spectroscopy (EDS) or wavelength dispersive spectroscopy (WDS) [72, p. 269]. The energy of the X-rays is element specific, so it is possible to study the chemical composition of the sample using EDS or WDS. The X-rays are emitted from a certain interaction volume, that depends on the energy of the incident electrons and the chemical composition of the sample. The quantification of a EDS or WDS spectrum assumes a homogeneous composition of the sample within the interaction volume. In the case of 
thin films, a problem can arise if the interaction volume is larger then the thickness of the films.

The SEMs used in this work are a Philips XL30 and a LEO 1550 Gemini. Both of these microscopes use a field-emission gun (FEG) as their electron source. A FEG uses the high electric field that can form at sharp tips of a material to emit electrons [156, p. 74]. Both microscopes are equipped with detectors for secondary electrons as well as EDS systems. Additionally, they are equipped with in-lens detectors. Such a detector is placed inside the final lens of the microscope and allows for a higher resolution than a conventional secondary electron detector [157]. The Philips XL30 is also equipped with a backscattered electron detector. This detector can be used to measure the thickness of the films in crosssectional cuts of the sample as the chemical contrast between the film and the sample is visible.

\subsection{Transmission electron microscopy}

With transmission electron microscopy (TEM) thin foils of a sample can be investigated at high resolution. In TEM, electrons are accelerated with an acceleration voltage of $200-300 \mathrm{kV}$. The electron beam is then condensed using electromagnetic lenses and traverses the sample [156, p. 142]. The electrons have different interactions with the sample and the transmitted electrons are used to create a magnified image of the specimen on a screen with the help of several electromagnetic lenses. In the sample, a part of the electrons are transmitted without interaction, while another part is scattered. The elastically scattered electrons are diffracted by the lattice planes in the case of crystalline samples. On the other hand, there are also inelastic collisions, where the electrons lose some of their energy. These inelastic collisions can cause the emission of X-rays from the sample, which can be analyzed by EDX.

A TEM has two basic modes, which are the image mode and the diffraction mode. It is possible to choose between those modes by changing the focal point of one of the lenses. A simplified scheme of the two modes is shown in Figure 4.8 [156, p. 153]. In diffraction mode (Figure 4.8a), an image of the back-focal plane of the objective lens is projected on the screen [156, p. 152]. This way, the diffracted beams are separated from the direct beam. In case of a crystalline sample, the diffracted beams form spots that correspond to the lattice planes of the sample in recip- 


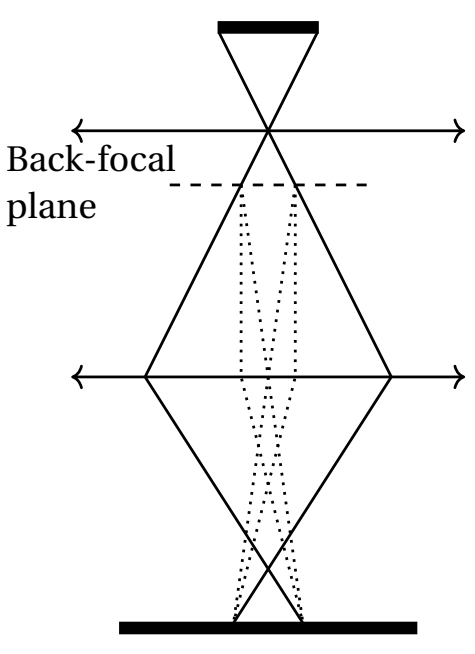

(a) Diffraction mode

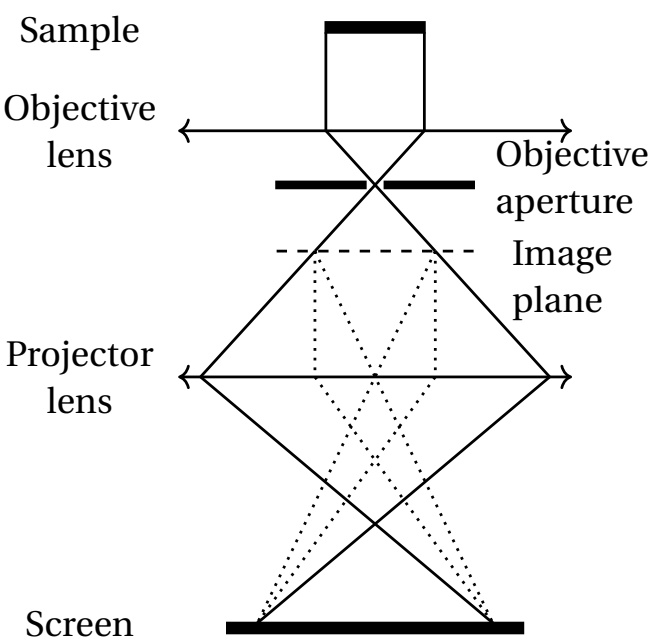

(b) Image mode

Figure 4.8: Simplified schematic representation of the two basic operating modes of a TEM [156, p. 153]

rocal space. This allows to obtain information about the crystal structure of the sample. It is also possible to obtain crystallographic information about a sample by using a fast Fourier transform (FFT) of a high resolution TEM (HRTEM) image. In image mode (Figure 4.8b), the image plane of the objective lens is projected onto the screen. In this mode it is possible to create bright field and dark field images [156, p. 155]. To choose between bright field and dark field images, an aperture has to be inserted in the back-focal plane of the objective lens. By selecting only the direct beam, a bright field image is created. For a dark field image, one of the diffracted beam spots has to be selected with the objective aperture.

There are several possible ways to prepare a sample for TEM investigation. The simplest way is to chip off material from the thin film using a diamond tip onto a carbon grid. However, this method does not always work well, in which case a more sophisticated method is needed. Cross-sectional samples can be prepared by cutting the sample, and then polishing it mechanically to reduce the thickness. After the mechanical polishing, ion-milling is used to sputter away more material, until 
a hole appears. At the edge of this hole, the sample is thin enough to be investigated by TEM. Another way is to use a focused ion beam (FIB) to cut out a thin foil from the sample. A FIB is an addition to a conventional SEM, that allows to precisely sputter away atoms from certain places on the sample. Another possibility for the preparation of TEM samples is to deposit a thin film directly onto a TEM grid.

\subsection{Secondary ion mass spectrometry}

Secondary ion mass spectrometry (SIMS) can be used to analyze the chemical composition profile of a thin film. It uses a primary ion beam to bombard the sample and sputter atoms and ions from the sample surface. The sputtered secondary ions can then be analyzed in a mass spectrometer. A schematic presentation of the SIMS method is shown in Figure 4.9.

As primary ions $\mathrm{Ar}^{+}, \mathrm{Cs}^{+}$or $\mathrm{O}_{2}^{-}$with energies between $2-15 \mathrm{keV}$ are typically used [72, p. 298]. The secondary ion yield for a given element is influenced by a multitude of parameters, such as the type of projectile and the target material. Different projectiles influence the work function of the material in different ways, which can introduce large changes in the secondary ion yield. For a quantitative analysis of the composition using SIMS it is therefore necessary to use standards of the same ele-

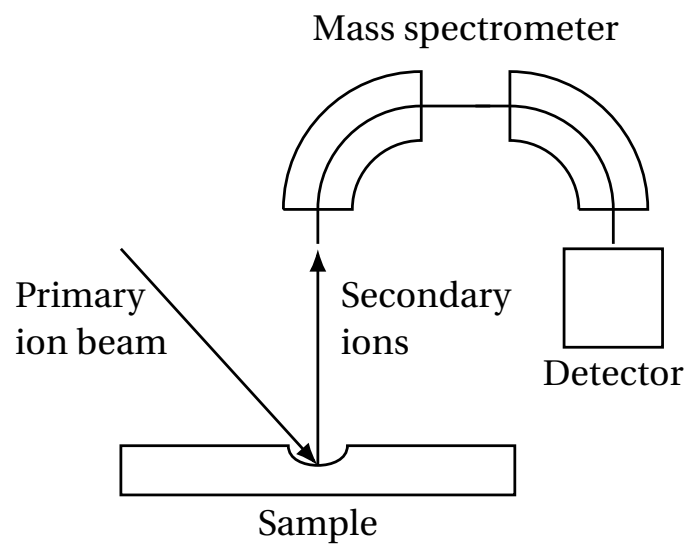

Figure 4.9: Schematic representation of a SIMS experiment [72, p. 298] 
ments and matrices as the sample [72, p. 297]. As the sample surface is being sputtered during the analysis, the sputtering time is proportional to the analysis depth. This allows to obtain depth profiles of the chemical composition [72, p. 299]. In this work a CAMECA IMS $7 \mathrm{f}$ spectrometer is used with $\mathrm{Cs}^{+}$as primary ions.

\subsection{Rutherford backscattering spectrometry}

In Rutherford backscattering spectrometry (RBS), a sample is irradiated by fast ions of low mass and the energy of the backscattered ions is measured [72, pp. 289-296]. This technique allows to obtain information about the chemical composition of the sample. When the fast ions bombard the sample, a small portion of them can collide elastically with the nuclei of the target atoms and can be backscattered. Due to the elastic collision the projectile ions lose some of their kinetic energy. The energy $E_{1}$ of the projectile with mass $m_{\mathrm{P}}$ and initial energy $E_{0}$ after the collision with the target nucleus of mass $m_{\mathrm{T}}$ is given by

$$
E_{1}=E_{0} \cdot\left[\frac{\sqrt{1-\left[\frac{m_{\mathrm{P}}}{m_{\mathrm{T}}} \cdot \sin \theta\right]^{2}}+\frac{m_{\mathrm{P}}}{m_{\mathrm{T}}} \cdot \cos \theta}{1+\frac{m_{\mathrm{P}}}{m_{\mathrm{T}}}}\right]^{2},
$$

with $\theta$ the scattering angle. As this energy loss depends on the mass of the target atoms, it contains information about the chemical composition of the sample.

RBS also provides information about the composition profile along the sample depth. When the bombarding ions penetrate into the sample, they lose energy due to excitation of electrons and ionization of atoms within the sample. This energy loss can be considered to be continuous with the sample depth, meaning that ions backscattered deeper within the sample have a lower energy [72, p. 289].

As projectile ions typically $\mathrm{He}^{+}$ions are used. The ions are accelerated to an energy of several $\mathrm{MeV}$ using linear accelerators. The ion beam can be focussed on the substrate. A detector is placed close to the incoming ion beam, to measure the energy of the backscattered ions at a scattering angle close to $180^{\circ}$. The setup is schematically shown in Figure 4.10. In this work, the RBS setup of the ACACIA platform at the ICube laboratory in Strasbourg was used. In this setup, $\mathrm{He}^{+}$ions are accelerated to $1.5 \mathrm{MeV}$ using a Van de Graaff accelerator. 


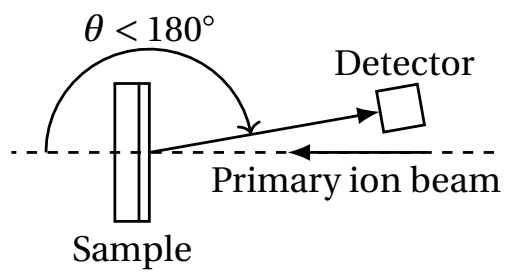

Figure 4.10: Schematic representation of the RBS measurement setup [72, p. 290]

\subsection{X-ray photoelectron spectroscopy}

$\mathrm{X}$-ray photoelectron spectroscopy (XPS) is a technique that is used for the analysis of the chemical composition of a sample. In XPS, the sample is irradiated by X-rays and the energy of the emitted photoelectrons is analyzed. Only photoelectrons created close to the surface $(\sim 15 \AA)$ can escape the material, which means that XPS is a surface sensitive technique [72, p. 275]. As an X-ray source usually $\mathrm{Mg}$ or $\mathrm{Al}$ anodes are used [72, p. 286]. In this work, $\mathrm{Al} \mathrm{K \alpha}(1486.6 \mathrm{eV})$ radiation was used. The kinetic energy of the photoelectron $E_{\text {kin }}$ is related to the energy of the incident photon $h v$ and the binding energy of the electron in the material $E_{\mathrm{B}}$ via

$$
E_{\mathrm{B}}=h v-E_{\mathrm{kin}} .
$$

As the binding energy is element specific XPS allows the determination of the chemical composition of the sample [72, p. 282]. The binding energy of a certain element can be shifted by a few $\mathrm{eV}$ due to the chemical bonding [72, p. 287]. By analyzing these shifts, the bonding state of atoms can be determined. A schematic representation of a typical XPS setup is shown in Figure 4.11. The energy of the electrons is analyzed by a hemispherical analyzer [158, pp. 37-39]. The analyzer consists of two concentric hemispheres with a potential difference between them. For a given potential difference only electrons with a specific energy can reach the other end of the analyzer. Between the sample and the analyzer there is a series of lenses to decrease the energy of the electrons and therefore improve the energy resolution of the analyzer. The analyzer used in this work was a Omicrometer EA 125.

As explained above, XPS is a surface sensitive technique. To obtain information about the bulk of the sample, it is possible to sputter away 


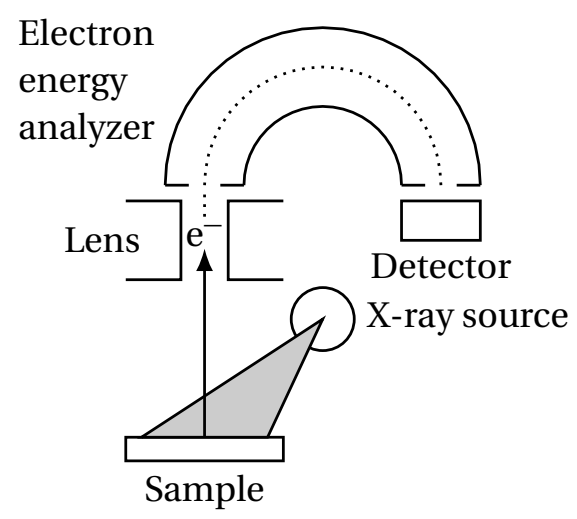

Figure 4.11: Schematic representation of a typical XPS setup [158, p. 51]

atoms from the surface of the sample using an ion gun [158, pp. 93-103]. $\mathrm{Ar}^{+}$ions with an energy of a few hundreds or thousands of $\mathrm{eV}$ are typically used in this case. After a first analysis, the sample is bombarded for a certain time and then analyzed again. This cycle is then repeated, until the final sample depth is reached. The ion bombardment can induce problems, such as preferential sputtering, which will alter the chemical composition of the surface. 


\section{Chapter 5}

\section{Summary of the results}

In this chapter, the results of the work in this thesis are summarized. In Paper 1, the deposition of AZO films using reactive HiPIMS is investigated at room temperature. The electrical, optical and structural properties of the films are compared to those of a film deposited using reactive DC magnetron sputtering. In Paper 2, the stability of AZO films towards ambient moisture has been investigated and a low temperature annealing of the films to improve their electrical properties is proposed. In Paper 3, the effect of the deposition temperature on the properties of the AZO films in case of reactive HiPIMS is studied. Finally, nanostructured AZO films have been deposited on flexible substrates in Paper 4.

\section{Paper 1: Room temperature deposition of homogeneous, highly transparent and conductive Al-doped ZnO films by reactive high power impulse magnetron sputtering}

In this study, AZO films have been deposited using reactive HiPIMS at room temperature. The properties of these films have been investigated and compared to the properties of AZO films deposited using DC sputtering in the same chamber under similar conditions. The AZO films have been deposited using three different discharge voltages between 540 and $570 \mathrm{~V}$. The best films were deposited using HiPIMS at the highest discharge voltage of $570 \mathrm{~V}$. In this case, an optimum resistivity of $4 \times 10^{-4} \Omega \mathrm{cm}$ was found. The charge carrier concentration reached values of up to $11 \times 10^{20} \mathrm{~cm}^{-3}$. This suggests, that ionized im- 
purity scattering is the dominant scattering mechanism in the columnar films.

The evolution of the properties between the different samples can be summarized as follows. When going from DC to HiPIMS, and with increasing discharge voltage in the case of HiPIMS, the resistivity of the films and the transmittance in the near infrared decrease, the band gap increases and the crystalline quality decreases. These results suggest, that the films become increasingly substoichiometric. Additionally, the electrical and optical properties show the lowest lateral variation in the case of the HiPIMS deposited film at $570 \mathrm{~V}$. The lateral variation of the electrical properties is believed to be related to the oxygen ion bombardment as outlined in section 3.7.

Additional AZO films were deposited using reactive HiPIMS with pulse lengths between 80 and $120 \mu \mathrm{s}$. The optical and structural properties of these films show, that the films become more substoichiometric with increasing pulse width and therefore increasing ion dose per pulse. These results, together with the low oxygen ion bombardment, suggest that the process is shifted towards the metallic mode, because of the increased instantaneous sputter rate, that could hinder the formation of an oxide layer at the target surface.

From the ion dose per pulse and the racetrack profile, the local distribution of the sputter rate across the racetrack was estimated as outlined in the supplementary material of Paper 1. At the centre of the racetrack, the number of sputtered atoms is estimated to be in the same order of magnitude as the surface atom density in $\mathrm{ZnO}$. This supports the model of the partial removal of oxygen at the centre of the racetrack in HiPIMS. Additionally, the normalized deposition rate was found to be higher in the case of HiPIMS than in DC sputtering.

\section{Paper 2: Restoring the properties of transparent Al-doped $\mathrm{ZnO}$ thin film electrodes exposed to ambient air}

In the second paper, AZO films deposited using both HiPIMS and DC sputtering with different process conditions have been annealed at low temperatures between 160 and $180^{\circ} \mathrm{C}$ in $\mathrm{N}_{2}$ after an aging process in ambient air. As the electrical properties of AZO are known to degrade 
upon exposure to humidity, the proposed annealing process allowed to improve and partially restore the electrical properties. The degradation of the electrical properties has been related to the absorption of water and the formation of hydroxyl groups by various authors [159-161]. These hydroxyl groups act as traps for charge carriers and can therefore decrease the charge carrier concentration and the mobility.

In this work, the evolution of the sheet resistance and the transmittance spectra was followed in situ during the annealing. The results are interpreted as a diffusion process, related to the decomposition of hydroxyl groups and the out-diffusion of water. A simplified diffusion model was fitted to the evolution of the sheet resistance with the annealing time. The starting point of this model was adapted from the diffusion equation for the desorption from a membrane (Equation 4.17 in [162, p. 47]). This allowed to obtain an effective diffusion coefficient, that was found to have the highest value for the film deposited at the highest pressure. As a higher deposition pressure is generally related to a less dense microstructure of the films, the results suggest that grain boundaries serve as diffusion paths for the water molecules. Additional evidence for the removal of hydrogen from the films was obtained by SIMS, as well as XPS. The XPS results for the O 1s core level peak show that the amount of hydroxyl groups decreases after annealing.

\section{Paper 3: Effect of substrate temperature on the deposition of Al-Doped ZnO thin films using high power impulse magnetron sputtering}

In the third paper, $\mathrm{AZO}$ films have been deposited at substrate temperatures between room temperature and $600{ }^{\circ} \mathrm{C}$ using reactive HiPIMS. As described in section 3.7, the substrate temperature plays an important role for the properties of AZO films. In this study, the electrical properties were found to improve up to the highest tested temperature of $600^{\circ} \mathrm{C}$ with a minimum resistivity of $3 \times 10^{-4} \Omega \mathrm{cm}$. The improvement in the resistivity of the films can be mostly related to an increase in the charge carrier mobility, due to an improved crystalline quality at high substrate temperature.

In the literature, optimum substrate temperatures for AZO deposition by reactive DC sputtering are usually reported to lie between 200 
and $350^{\circ} \mathrm{C}$ [5]. The bombardment of the growing film with negative oxygen ions is believed to cause the deactivation of charge carriers due to the formation of insulating secondary phases [8, 9, 63]. The formation of secondary phases has been reported to increase at high substrate temperatures due to the preferential desorption of $\mathrm{Zn}$ [63]. The results of Paper 1 have shown that the detrimental effects of negative oxygen bombardment can be reduced in the case of HiPIMS, which can explain why there is no degradation of the electrical properties at high substrate temperature in this study.

Additionally, the effect of aging the films in ambient moisture similar to the procedure described in Paper 2 has been studied. Only the films deposited at room temperature showed a significant degradation of the properties after 9 months. Films deposited at substrate temperatures of $200^{\circ} \mathrm{C}$ and above are more stable with time. This can be related to the improved crystalline quality of the films, that makes it more difficult for water to diffuse into the films.

\section{Paper 4: Improved electrical reliability of flexible transparent electrodes based on bottom-up nanostructured Al-doped ZnO thin films}

The results of Paper 1 have shown that HiPIMS is a suitable technique to deposit transparent conductive AZO films at room temperature. Therefore, it is interesting to deposit AZO films on flexible polymer substrates such as polyethylene terephthalate (PET) using this technique, as polymer substrates are sensitive towards high temperatures. Additionally, the deposited AZO films consisted of a porous array of nanorods on top of a dense seed layer of around $100 \mathrm{~nm}$ thickness. This special nanostructure allowed to improve the electrical reliability of the films upon bending.

The sheet resistance of the films was measured after successive bending with a decreasing bending radius. The resistance was found to increase with decreasing bending radius, however, the onset of the decrease was shifted towards lower bending radius with increasing film thickness. Additionally, the magnitude of the change in sheet resistance decreased with the film thickness. This can be explained by the nanostructure of the films. When the sample is flat, the nanorods are in lateral contact with each other, ensuring the conductivity in the film. When 
the sample is bent, the nanorods can separate without breaking and can go back to their initial orientation after bending. This interpretation is supported by the absence of long cracks in the films perpendicular to the bending direction.

The seed layer showed a high compressive stress of nearly -3 GPa for the films deposited on PET, while for the films deposited on Si, the compressive stress is only about -1 GPa. The high compressive stress in the seed layer in the case of deposition on PET can be related to the difference in the thermal expansion coefficient of PET and AZO. The nanorod layer on top of the seed layer is growing with the same low compressive stress of about $-1 \mathrm{GPa}$ on both types of substrates. This compressive stress is close to the compressive stress found in the AZO films deposited at room temperature and at $200^{\circ} \mathrm{C}$ in Paper 3 .

The formation of the nanostructure of the AZO films in this study can be explained by a combination of an atomic shadowing effect and a limited diffusion of the adatoms due to a relatively high growth rate. The atomic shadowing effect is known to lead to such porous structures in the case of sputter deposition at oblique angles [163]. The growth rate in this work was about $40 \mathrm{~nm} / \mathrm{min}$, which is still higher than the highest growth rate in the case of Paper $3\left(35 \mathrm{~nm} / \mathrm{min}\right.$ at $\left.500^{\circ} \mathrm{C}\right)$. Considering the low substrate temperature in this study, the high growth rate could prevent the diffusion of adatoms between the grains. The segregation of secondary phases at the grain boundaries could also hinder lateral grain growth. 


\section{Chapter 6}

\section{Contributions and future work}

The main contributions of this thesis to the field, in the author's opinion, are the following:

- The possibility to deposit highly conductive AZO films with a good homogeneity of the properties using reactive HiPIMS at room temperature is demonstrated. The improvement in the homogeneity can be related to a shift of the process conditions towards the metallic mode as compared to DC sputtering.

- A low temperature annealing method is proposed to restore the electrical properties of AZO films after exposure to ambient moisture. The improvement of the electrical properties can be related to the out-diffusion of water.

- The effect of high substrate temperature on the properties of AZO films provides further evidence for the decreased oxygen bombardment in the case of reactive HiPIMS.

- The deposition of nanostructured, transparent and conducting films on flexible substrates using reactive HiPIMS was shown. Using such nanostructured films can improve the electrical reliability of the films in flexible devices. 
Based on the results of this thesis, potential future work is presented in the following:

- There is still a large unexplored parameter space in reactive HiPIMS of AZO. More specifically, the influence of short $(20 \mu \mathrm{s})$ or long pulses $(\sim 200 \mu \mathrm{s})$, as well as the influence of larger peak currents could be interesting to study.

- The reason for the increase in deposition rate with the substrate temperature as seen in Paper 3 needs clarification. More experiments are needed. For example, the experiments could be repeated while keeping the gas density constant.

- The porous nanostructure of the AZO films in Paper 4 should be further studied, as this structure might be interesting for other applications, such as gas sensors or solar cells, due to their increased surface to volume ratio. 


\section{Bibliography}

[1] R. G. Gordon, "Criteria for Choosing Transparent Conductors", MRS Bulletin 25, 52-57 (2000).

[2] P. D. C. King and T. D. Veal, "Conductivity in transparent oxide semiconductors", Journal of Physics: Condensed Matter 23, 334214 (2011).

[3] T. Minami, "Present status of transparent conducting oxide thin-film development for Indium-Tin-Oxide (ITO) substitutes", Thin Solid Films, 5th International Symposium on Transparent Oxide Thin Films for Electronics and Optics 516, 5822-5828 (2008).

[4] K. Ellmer, "Magnetron sputtering of transparent conductive zinc oxide: relation between the sputtering parameters and the electronic properties", Journal of Physics D: Applied Physics 33, R17 (2000).

[5] S. Cornelius and M. Vinnichenko, "Al in $\mathrm{ZnO}$ - From doping to alloying: An investigation of $\mathrm{Al}$ electrical activation in relation to structure and charge transport limits", Thin Solid Films, ZnO and Related Transparent Conductive Oxides 605, 20-29 (2016).

[6] K. Ellmer, A. Klein and B. Rech, eds., Transparent conductive zinc oxide: basics and applications in thin film solar cells, Springer series in materials science 104 (Springer, Berlin, 2008).

[7] D. S. Ginley, ed., Handbook of Transparent Conductors (Springer US, Boston, MA, 2011).

[8] D. Horwat, M. Jullien, F. Capon, J.-F. Pierson, J. Andersson and J. L. Endrino, "On the deactivation of the dopant and electronic structure in reactively sputtered transparent $\mathrm{Al}$-doped $\mathrm{ZnO}$ thin films", Journal of Physics D: Applied Physics 43, 132003 (2010). 
[9] A. Bikowski, T. Welzel and K. Ellmer, "The impact of negative oxygen ion bombardment on electronic and structural properties of magnetron sputtered ZnO:Al films", Applied Physics Letters 102, 242106 (2013).

[10] V. Kouznetsov, K. Macák, J. M. Schneider, U. Helmersson and I. Petrov, "A novel pulsed magnetron sputter technique utilizing very high target power densities", Surface and Coatings Technology 122, 290-293 (1999).

[11] H. Kawazoe, M. Yasukawa, H. Hyodo, M. Kurita, H. Yanagi and H. Hosono, "P-type electrical conduction in transparent thin films of $\mathrm{CuAlO}_{2}$ ”, Nature 389, 939-942 (1997).

[12] P. P. Edwards, A. Porch, M. O. Jones, D. V. Morgan and R. M. Perks, "Basic materials physics of transparent conducting oxides", Dalton Transactions, 2995-3002 (2004).

[13] S. M. Sze, Physics of semiconductor devices (Wiley-Interscience, New York, 1969).

[14] T. S. Moss, "The Interpretation of the Properties of Indium Antimonide", Proceedings of the Physical Society. Section B 67, 775 (1954).

[15] E. Burstein, "Anomalous Optical Absorption Limit in InSb", Physical Review 93, 632-633 (1954).

[16] M. Fox, Optical properties of solids, 2nd ed (Oxford University Press, Oxford ; New York, 2010).

[17] S. Adachi, Optical Properties of Crystalline and Amorphous Semiconductors (Springer US, Boston, MA, 1999).

[18] A. Bikowski and K. Ellmer, "Analytical model of electron transport in polycrystalline, degenerately doped $\mathrm{ZnO}$ films", Journal of Applied Physics 116, 143704 (2014).

[19] G. Masetti, M. Severi and S. Solmi, "Modeling of carrier mobility against carrier concentration in arsenic-, phosphorus-, and boron-doped silicon”, IEEE Transactions on Electron Devices 30, 764-769 (1983).

[20] K. Ellmer, "Resistivity of polycrystalline zinc oxide films: current status and physical limit", Journal of Physics D: Applied Physics 34, 3097 (2001). 
[21] K. Ellmer and R. Mientus, "Carrier transport in polycrystalline transparent conductive oxides: A comparative study of zinc oxide and indium oxide", Thin Solid Films 516, 4620-4627 (2008).

[22] J. Y. W. Seto, "The electrical properties of polycrystalline silicon films", Journal of Applied Physics 46, 5247-5254 (1975).

[23] N. W. Ashcroft and N. D. Mermin, Solid state physics (Holt, Rinehart and Winston, New York, 1976).

[24] A. Piegari and F. Flory, eds., Optical thin films and coatings: from materials to applications, Woodhead Publishing series in electronic and optical materials 49 (Woodhead Publishing, Cambridge, 2013).

[25] C. G. Granqvist, "Transparent conductors as solar energy materials: A panoramic review", Solar Energy Materials and Solar Cells 91, 1529-1598 (2007).

[26] K. L. Chopra, S. Major and D. K. Pandya, "Transparent conductors-A status review", Thin Solid Films 102, 1-46 (1983).

[27] I. Hamberg, J. S. E. M. Svensson, T. S. Eriksson, C.-G. Granqvist, P. Arrenius and F. Norin, "Radiative cooling and frost formation on surfaces with different thermal emittance: theoretical analysis and practical experience", Applied Optics 26, 2131-2136 (1987).

[28] K. Ellmer, "Past achievements and future challenges in the development of optically transparent electrodes", Nature Photonics 6, 809-817 (2012).

[29] J. J. Vos, "Colorimetric and photometric properties of a $2^{\circ}$ fundamental observer", Color Research \& Application 3, 125-128 (1978).

[30] D. Myers, S. Kurtz, K. Emery, C. Whitaker and T. Townsend, "Outdoor meteorological broadband and spectral conditions for evaluating photovoltaic modules", in Conference Record of the Twenty-Eighth IEEE Photovoltaic Specialists Conference - 2000 (2000), pp. 1202-1205.

[31] U. Betz, M. Kharrazi Olsson, J. Marthy, M. F. Escolá and F. Atamny, "Thin films engineering of indium tin oxide: Large area flat panel displays application", Surface and Coatings Technology 200, 5751-5759 (2006). 
[32] E. Fortunato, A. Pimentel, A. Gonçalves, A. Marques and R. Martins, "High mobility amorphous/nanocrystalline indium zinc oxide deposited at room temperature”, Thin Solid Films 502, 104-107 (2006).

[33] A. Facchetti and T. J. Marks, eds., Transparent electronics: from synthesis to applications (Wiley, Chichester, U.K, 2010).

[34] B. Rech and H. Wagner, "Potential of amorphous silicon for solar cells", Applied Physics A 69, 155-167 (1999).

[35] K. Ramanathan, M. A. Contreras, C. L. Perkins, S. Asher, F. S. Hasoon, J. Keane, D. Young, M. Romero, W. Metzger, R. Noufi, J. Ward and A. Duda, "Properties of 19.2\% efficiency $\mathrm{ZnO} / \mathrm{CdS} / \mathrm{CuInGaSe}{ }_{2}$ thin-film solar cells", Progress in Photovoltaics: Research and Applications 11, 225-230 (2003).

[36] A. Gupta and A. D. Compaan, "All-sputtered 14\% CdS/CdTe thin-film solar cell with ZnO:Al transparent conducting oxide", Applied Physics Letters 85, 684-686 (2004).

[37] J. S. E. M. Svensson and C. G. Granqvist, "Electrochromic coatings for windows””, Solar Energy Materials 12, 391-402 (1985).

[38] D. B. Fraser and H. D. Cook, "Highly Conductive, Transparent Films of Sputtered $\operatorname{In}_{2-x} \mathrm{Sn}_{x} \mathrm{O}_{3-y}$ ", Journal of The Electrochemical Society 119, 1368-1374 (1972).

[39] G. Haacke, "New figure of merit for transparent conductors", Journal of Applied Physics 47, 4086-4089 (1976).

[40] R. G. Gordon, "Preparation and Properties of Transparent Conductors”, MRS Online Proceedings Library Archive 426, 419-429 (1996).

[41] K. Nomura, H. Ohta, A. Takagi, T. Kamiya, M. Hirano and H. Hosono, "Room-temperature fabrication of transparent flexible thin-film transistors using amorphous oxide semiconductors", Nature 432, 488-492 (2004).

[42] E. Fortunato, P. Barquinha and R. Martins, "Oxide Semiconductor Thin-Film Transistors: A Review of Recent Advances”, Advanced Materials 24, 2945-2986 (2012). 
[43] T. Smijs and Pavel, "Titanium dioxide and zinc oxide nanoparticles in sunscreens: focus on their safety and effectiveness", Nanotechnology, Science and Applications, 95 (2011).

[44] A. Janotti and C. G. V. d. Walle, "Fundamentals of zinc oxide as a semiconductor", Reports on Progress in Physics 72, 126501 (2009).

[45] Z. L. Wang, "Zinc oxide nanostructures: growth, properties and applications”, Journal of Physics: Condensed Matter 16, R829 (2004).

[46] S. Pearton, W. Heo, M. Ivill, D. Norton and T. Steiner, "Dilute magnetic semiconducting oxides”, Semiconductor Science and Technology 19, R59-R74 (2004).

[47] Ü. Özgür, Y. I. Alivov, C. Liu, A. Teke, M. A. Reshchikov, S. Doğan, V. Avrutin, S.-J. Cho and H. Morkoç, "A comprehensive review of ZnO materials and devices”, Journal of Applied Physics 98, 041301 (2005).

[48] H. Morkoç and Ü. Özgür, Zinc oxide: fundamentals, materials and device technology (Wiley-VCH, Weinheim, 2009).

[49] Y. Kajikawa, "Texture development of non-epitaxial polycrystalline ZnO films", Journal of Crystal Growth 289, 387-394 (2006).

[50] C. Jagadish and S. J. Pearton, eds., Zinc oxide bulk, thin films and nanostructures: processing, properties and applications (Elsevier, Amsterdam ; Boston, 2006).

[51] C. Klingshirn, "ZnO: From basics towards applications”, physica status solidi (b) 244, 3027-3073 (2007).

[52] P. Y. Yu and M. Cardona, Fundamentals of Semiconductors, Graduate Texts in Physics (Springer Berlin Heidelberg, Berlin, Heidelberg, 2010).

[53] L. Schmidt-Mende and J. L. MacManus-Driscoll, “ZnO nanostructures, defects, and devices”, Materials Today 10, 40-48 (2007). 
[54] K. E. Knutsen, A. Galeckas, A. Zubiaga, F. Tuomisto, G. C. Farlow, B. G. Svensson and A. Y. Kuznetsov, "Zinc vacancy and oxygen interstitial in $\mathrm{ZnO}$ revealed by sequential annealing and electron irradiation”, Physical Review B 86, 121203 (2012).

[55] K. Ellmer and A. Bikowski, "Intrinsic and extrinsic doping of $\mathrm{ZnO}$ and ZnO alloys", Journal of Physics D: Applied Physics 49, 413002 (2016).

[56] C. G. Van de Walle, "Defect analysis and engineering in $\mathrm{ZnO",}$ Physica B: Condensed Matter, International Conference on Defects in Semiconductors 308, 899-903 (2001).

[57] H. Sato, T. Minami and S. Takata, "Highly transparent and conductive group IV impurity-doped $\mathrm{ZnO}$ thin films prepared by radio frequency magnetron sputtering", Journal of Vacuum Science \& Technology A: Vacuum, Surfaces, and Films 11, 2975-2979 (1993).

[58] J. Hu and R. G. Gordon, "Textured fluorine-doped $\mathrm{ZnO}$ films by atmospheric pressure chemical vapor deposition and their use in amorphous silicon solar cells", Solar Cells 30, 437-450 (1991).

[59] J. Clatot, M. Nistor and A. Rougier, "Influence of Si concentration on electrical and optical properties of room temperature $\mathrm{ZnO}: \mathrm{Si}$ thin films", Thin Solid Films 531, 197-202 (2013).

[60] M.-C. Lin, Y.-J. Chang, M.-J. Chen and C.-J. Chu, "Characteristics of Zr-Doped ZnO Thin Films Grown by Atomic Layer Deposition", Journal of The Electrochemical Society 158, D395-D398 (2011).

[61] S. Yoshioka, F. Oba, R. Huang, I. Tanaka, T. Mizoguchi and T. Yamamoto, "Atomic structures of supersaturated $\mathrm{ZnO}-\mathrm{Al}_{2} \mathrm{O}_{3}$ solid solutions”, Journal of Applied Physics 103, 014309 (2008).

[62] K. Shirouzu, T. Ohkusa, M. Hotta, N. Enomoto and J. Hojo, "Distribution and Solubility Limit of $\mathrm{Al}$ in $\mathrm{Al}_{2} \mathrm{O}_{3}$-Doped $\mathrm{ZnO}$ Sintered Body", Journal of the Ceramic Society of Japan 115, 254-258 (2007). 
[63] M. Vinnichenko, R. Gago, S. Cornelius, N. Shevchenko, A. Rogozin, A. Kolitsch, F. Munnik and W. Möller, "Establishing the mechanism of thermally induced degradation of $\mathrm{ZnO}: \mathrm{Al}$ electrical properties using synchrotron radiation”, Applied Physics Letters 96, 141907 (2010).

[64] D. Inamdar, C. Agashe, P. Kadam and S. Mahamuni, "Doping optimization and surface modification of aluminum doped zinc oxide films as transparent conductive coating", Thin Solid Films 520, 3871-3877 (2012).

[65] F. A. Garcés, N. Budini, J. A. Schmidt and R. D. Arce, "Highly doped ZnO films deposited by spray-pyrolysis. Design parameters for optoelectronic applications", Thin Solid Films, $\mathrm{ZnO}$ and Related Transparent Conductive Oxides 605, 149-156 (2016).

[66] K. E. Lee, M. Wang, E. J. Kim and S. H. Hahn, "Structural, electrical and optical properties of sol-gel AZO thin films", Current Applied Physics 9, 683-687 (2009).

[67] L. Znaidi, T. Touam, D. Vrel, N. Souded, S. B. Yahia, O. Brinza, A. Fischer and A. Boudrioua, "AZO Thin Films by Sol-Gel Process for Integrated Optics”, Coatings 3, 126-139 (2013).

[68] C. J. Brinker and G. W. Scherer, Sol-gel science: the physics and chemistry of sol-gel processing (Academic Press, Boston, 1990).

[69] O. Baka, A. Azizi, S. Velumani, G. Schmerber and A. Dinia, "Effect of Al concentrations on the electrodeposition and properties of transparent Al-doped $\mathrm{ZnO}$ thin films", Journal of Materials Science: Materials in Electronics 25, 1761-1769 (2014).

[70] H. E. Belghiti, T. Pauporté and D. Lincot, "Mechanistic study of ZnO nanorod array electrodeposition", physica status solidi (a) 205, 2360-2364 (2008).

[71] V.-A. Antohe, M. Mickan, F. Henry, R. Delamare, L. Gence and L. Piraux, "Self-seeded electrochemical growth of $\mathrm{ZnO}$ nanorods using textured glass/Al-doped ZnO substrates", Applied Surface Science 313, 607-614 (2014).

[72] M. Ohring, The materials science of thin films (Academic Press, Boston, 1992). 
[73] C. H. Lee and D. W. Kim, "Preparation of Al doped ZnO thin films by MOCVD using ultrasonic atomization”, Journal of Electroceramics 33, 12-16 (2014).

[74] A. Martín, J. P. Espinós, A. Justo, J. P. Holgado, F. Yubero and A. R. González-Elipe, "Preparation of transparent and conductive Al-doped ZnO thin films by ECR plasma enhanced CVD”, Surface and Coatings Technology, Proceedings of Symposium C on Protective Coatings and Thin Films 151, 289-293 (2002).

[75] J. Hu and R. G. Gordon, "Textured aluminum-doped zinc oxide thin films from atmospheric pressure chemical-vapor deposition", Journal of Applied Physics 71, 880-890 (1992).

[76] Y. Geng, L. Guo, S.-S. Xu, Q.-Q. Sun, S.-J. Ding, H.-L. Lu and D. W. Zhang, "Influence of Al Doping on the Properties of ZnO Thin Films Grown by Atomic Layer Deposition", The Journal of Physical Chemistry C 115, 12317-12321 (2011).

[77] I. Volintiru, M. Creatore, B. J. Kniknie, C. I. M. A. Spee and M. C. M. v. d. Sanden, "Evolution of the electrical and structural properties during the growth of $\mathrm{Al}$ doped $\mathrm{ZnO}$ films by remote plasma-enhanced metalorganic chemical vapor deposition", Journal of Applied Physics 102, 043709 (2007).

[78] V. Miikkulainen, M. Leskelä, M. Ritala and R. L. Puurunen, "Crystallinity of inorganic films grown by atomic layer deposition: Overview and general trends", Journal of Applied Physics 113, 021301 (2013).

[79] K. S. Sree Harsha, Principles of physical vapor deposition of thin films, 1st ed (Elsevier, Amsterdam ; Boston, 2006).

[80] C. Periasamy and P. Chakrabarti, "Tailoring the Structural and Optoelectronic Properties of Al-Doped Nanocrystalline $\mathrm{ZnO}$ Thin Films", Journal of Electronic Materials 40, 259-266 (2011).

[81] D. R. Sahu, S.-Y. Lin and J.-L. Huang, "Improved properties of Al-doped $\mathrm{ZnO}$ film by electron beam evaporation technique", Microelectronics Journal, 2005 Workshop on Thermal Investigations of ICs and Systems (THERMINIC) 38, 245-250 (2007). 
[82] A. Anders, S. H. Lim, K. M. Yu, J. Andersson, J. Rosén, M. McFarland and J. Brown, "High quality ZnO:Al transparent conducting oxide films synthesized by pulsed filtered cathodic arc deposition", Thin Solid Films 518, 3313-3319 (2010).

[83] H. Liu, V. Avrutin, N. Izyumskaya, ü. Özgür and H. Morkoç, "Transparent conducting oxides for electrode applications in light emitting and absorbing devices", Superlattices and Microstructures 48, 458-484 (2010).

[84] H. Agura, A. Suzuki, T. Matsushita, T. Aoki and M. Okuda, "Low resistivity transparent conducting Al-doped $\mathrm{ZnO}$ films prepared by pulsed laser deposition", Thin Solid Films, Proceedings of the 3rd International Symposium on Transparent Oxide Thin films for Electronics and Optics 445, 263-267 (2003).

[85] A. Anders, "A review comparing cathodic arcs and high power impulse magnetron sputtering (HiPIMS)", Surface and Coatings Technology, 25 years of TiAlN hard coatings in research and industry 257, 308-325 (2014).

[86] A. Fridman, Plasma Chemistry (Cambridge University Press, Leiden, 2008).

[87] R. F. Bunshah, ed., Handbook of deposition technologies for films and coatings: science, technology, and applications, 2nd ed, Materials science and process technology series (Noyes Publications, Park Ridge, N.J, 1994).

[88] F. F. Chen, Introduction to plasma physics and controlled fusion, 2nd ed (Plenum Press, New York, 1984).

[89] D. Depla, Magnetrons, reactive gases and sputtering (2014).

[90] M. W. Thompson, "II. The energy spectrum of ejected atoms during the high energy sputtering of gold", Philosophical Magazine 18, 377-414 (1968).

[91] K. Ellmer and T. Welzel, "Reactive magnetron sputtering of transparent conductive oxide thin films: Role of energetic particle (ion) bombardment", Journal of Materials Research 27, 765-779 (2012). 
[92] J. A. Thornton, "Magnetron sputtering: basic physics and application to cylindrical magnetrons", Journal of Vacuum Science \& Technology 15, 171-177 (1978).

[93] R. A. Baragiola, E. V. Alonso, J. Ferron and A. Oliva-Florio, "Ion-induced electron emission from clean metals", Surface Science 90, 240-255 (1979).

[94] D. Depla, S. Mahieu and R. De Gryse, "Magnetron sputter deposition: Linking discharge voltage with target properties", Thin Solid Films 517, 2825-2839 (2009).

[95] A. Anders, J. Andersson and A. Ehiasarian, "High power impulse magnetron sputtering: Current-voltage-time characteristics indicate the onset of sustained self-sputtering", Journal of Applied Physics 102, 113303 (2007).

[96] J. T. Gudmundsson, N. Brenning, D. Lundin and U. Helmersson, "High power impulse magnetron sputtering discharge", Journal of Vacuum Science \& Technology A 30, 030801 (2012).

[97] P. J. Kelly and R. D. Arnell, "Magnetron sputtering: a review of recent developments and applications", Vacuum 56, 159-172 (2000).

[98] D. Depla, S. Mahieu, R. Hull, R. M. Osgood, J. Parisi and H. Warlimont, eds., Reactive Sputter Deposition, Vol. 109, Springer Series in Materials Science (Springer Berlin Heidelberg, Berlin, Heidelberg, 2008).

[99] D. Depla, S. Heirwegh, S. Mahieu and R. D. Gryse, "Towards a more complete model for reactive magnetron sputtering", Journal of Physics D: Applied Physics 40, 1957-1965 (2007).

[100] S. Berg and T. Nyberg, "Fundamental understanding and modeling of reactive sputtering processes", Thin Solid Films 476, 215-230 (2005).

[101] S. Berg, H.-O. Blom, T. Larsson and C. Nender, "Modeling of reactive sputtering of compound materials", Journal of Vacuum Science \& Technology A 5, 202-207 (1987).

[102] W. D. Sproul, D. J. Christie and D. C. Carter, "Control of reactive sputtering processes”, Thin Solid Films 491, 1-17 (2005). 
[103] D. Depla, S. Heirwegh, S. Mahieu, J. Haemers and R. De Gryse, "Understanding the discharge voltage behavior during reactive sputtering of oxides", Journal of Applied Physics 101, 013301 (2007).

[104] S. Bugaev, N. Koval, N. Sochugov and A. Zakharov, "Investigation of a high-current pulsed magnetron discharge initiated in the low-pressure diffuse arc plasma", in , XVIIth International Symposium on Discharges and Electrical Insulation in Vacuum, 1996. Proceedings. ISDEIV, Vol. 2 (July 1996), 1074-1076 vol.2.

[105] K. Sarakinos, J. Alami and S. Konstantinidis, "High power pulsed magnetron sputtering: A review on scientific and engineering state of the art", Surface and Coatings Technology 204, 1661-1684 (2010).

[106] A. Anders, "Tutorial: Reactive high power impulse magnetron sputtering (R-HiPIMS)”, Journal of Applied Physics 121, 171101 (2017).

[107] A. Anders, "Discharge physics of high power impulse magnetron sputtering", Surface and Coatings Technology 205, S1-S9 (2011).

[108] D. J. Christie, "Target material pathways model for high power pulsed magnetron sputtering", Journal of Vacuum Science \& Technology A 23, 330-335 (2005).

[109] J. Vlček and K. Burcalová, "A phenomenological equilibrium model applicable to high-power pulsed magnetron sputtering", Plasma Sources Science and Technology 19, 065010 (2010).

[110] A. Anders, J. Čapek, M. Hála and L. Martinu, "The 'recycling trap': a generalized explanation of discharge runaway in high-power impulse magnetron sputtering", Journal of Physics D: Applied Physics 45, 012003 (2012).

[111] N. Brenning, C. Huo, D. Lundin, M. A. Raadu, C. Vitelaru, G. D. Stancu, T. Minea and U. Helmersson, "Understanding deposition rate loss in high power impulse magnetron sputtering: I. Ionization-driven electric fields", Plasma Sources Science and Technology 21, 025005 (2012).

[112] D. Horwat and A. Anders, "Compression and strong rarefaction in high power impulse magnetron sputtering discharges", Journal of Applied Physics 108, 123306 (2010). 
[113] A. Anders, P. Ni and A. Rauch, "Drifting localization of ionization runaway: Unraveling the nature of anomalous transport in high power impulse magnetron sputtering", Journal of Applied Physics 111, 053304 (2012).

[114] M. A. Raadu, I. Axnäs, J. T. Gudmundsson, C. Huo and N. Brenning, "An ionization region model for high-power impulse magnetron sputtering discharges", Plasma Sources Science and Technology 20, 065007 (2011).

[115] M. Aiempanakit, A. Aijaz, D. Lundin, U. Helmersson and T. Kubart, "Understanding the discharge current behavior in reactive high power impulse magnetron sputtering of oxides", Journal of Applied Physics 113, 133302 (2013).

[116] T. Shimizu, M. Villamayor, D. Lundin and U. Helmersson, "Process stabilization by peak current regulation in reactive high-power impulse magnetron sputtering of hafnium nitride", Journal of Physics D: Applied Physics 49, 065202 (2016).

[117] J. T. Gudmundsson, D. Lundin, N. Brenning, M. A. Raadu, C. Huo and T. M. Minea, "An ionization region model of the reactive $\mathrm{Ar} / \mathrm{O}_{2}$ high power impulse magnetron sputtering discharge", Plasma Sources Science and Technology 25, 065004 (2016).

[118] E. Wallin and U. Helmersson, "Hysteresis-free reactive high power impulse magnetron sputtering”, Thin Solid Films 516, 6398-6401 (2008).

[119] M. Hála, J. Čapek, O. Zabeida, J. E. Klemberg-Sapieha and L. Martinu, "Hysteresis-free deposition of niobium oxide films by HiPIMS using different pulse management strategies", Journal of Physics D: Applied Physics 45, 055204 (2012).

[120] K. Strijckmans, F. Moens and D. Depla, "Perspective: Is there a hysteresis during reactive High Power Impulse Magnetron Sputtering (R-HiPIMS)?", Journal of Applied Physics 121, 080901 (2017).

[121] J. A. Thornton, "High Rate Thick Film Growth", Annual Review of Materials Science 7, 239-260 (1977).

[122] A. Anders, "A structure zone diagram including plasma-based deposition and ion etching", Thin Solid Films 518, 4087-4090 (2010). 
[123] D. Depla and W. P. Leroy, "Magnetron sputter deposition as visualized by Monte Carlo modeling”, Thin Solid Films 520, 6337-6354 (2012).

[124] J. A. Thornton, "Influence of apparatus geometry and deposition conditions on the structure and topography of thick sputtered coatings", Journal of Vacuum Science \& Technology 11, 666-670 (1974).

[125] P. B. Barna and M. Adamik, "Fundamental structure forming phenomena of polycrystalline films and the structure zone models", Thin Solid Films 317, 27-33 (1998).

[126] P. B. Barna and M. Adamik, "Growth Mechanisms of Polycrystalline Thin Films", in Science and Technology of Thin Films, edited by F. C. Matacotta and G. Ottaviani (World Scientific, Oct. 1995).

[127] S. Mahieu, P. Ghekiere, D. Depla and R. De Gryse, "Biaxial alignment in sputter deposited thin films", Thin Solid Films 515, 1229-1249 (2006).

[128] H. Sato, T. Minami, S. Takata, T. Mouri and N. Ogawa, "Highly conductive and transparent $\mathrm{ZnO}$ :Al thin films prepared on high-temperature substrates by d.c. magnetron sputtering", Thin Solid Films 220, 327-332 (1992).

[129] S. Cornelius, M. Vinnichenko, N. Shevchenko, A. Rogozin, A. Kolitsch and W. Möller, "Achieving high free electron mobility in $\mathrm{ZnO}$ :Al thin films grown by reactive pulsed magnetron sputtering", Applied Physics Letters 94, 042103 (2009).

[130] C. Agashe, O. Kluth, J. Hüpkes, U. Zastrow, B. Rech and M. Wuttig, "Efforts to improve carrier mobility in radio frequency sputtered aluminum doped zinc oxide films", Journal of Applied Physics 95, 1911-1917 (2004).

[131] C. May, R. Menner, J. Strümpfel, M. Oertel and B. Sprecher, "Deposition of TCO films by reactive magnetron sputtering from metallic Zn:Al alloy targets", Surface and Coatings Technology, Proceedings of Frontiers of Surface Engineering 169-170, 512-516 (2003). 
[132] K. Tominaga, K. Kuroda and O. Tada, "Radiation Effect due to Energetic Oxygen Atoms on Conductive Al-Doped ZnO Films", Japanese Journal of Applied Physics 27, 1176 (1988).

[133] D. Horwat and A. Billard, "Effects of substrate position and oxygen gas flow rate on the properties of $\mathrm{ZnO}$ : $\mathrm{Al}$ films prepared by reactive co-sputtering", Thin Solid Films 515, 5444-5448 (2007).

[134] T. Minami, H. Nanto and S. Takata, "Highly conductive and transparent zinc oxide films prepared by rf magnetron sputtering under an applied external magnetic field", Applied Physics Letters 41, 958-960 (1982).

[135] S. Brehme, F. Fenske, W. Fuhs, E. Nebauer, M. Poschenrieder, B. Selle and I. Sieber, "Free-carrier plasma resonance effects and electron transport in reactively sputtered degenerate $\mathrm{ZnO}: \mathrm{Al}$ films", Thin Solid Films 342, 167-173 (1999).

[136] S. Konstantinidis, A. Hemberg, J. P. Dauchot and M. Hecq, "Deposition of zinc oxide layers by high-power impulse magnetron sputtering”, Journal of Vacuum Science \& Technology B: Microelectronics and Nanometer Structures 25, L19 (2007).

[137] F. Ruske, A. Pflug, V. Sittinger, W. Werner, B. Szyszka and D. Christie, "Reactive deposition of aluminium-doped zinc oxide thin films using high power pulsed magnetron sputtering", Thin Solid Films 516, 4472-4477 (2008).

[138] D. J. Christie, F. Tomasel, W. D. Sproul and D. C. Carter, "Power supply with arc handling for high peak power magnetron sputtering", Journal of Vacuum Science \& Technology A: Vacuum, Surfaces, and Films 22, 1415-1419 (2004).

[139] V. Sittinger, F. Ruske, W. Werner, C. Jacobs, B. Szyszka and D. Christie, "High power pulsed magnetron sputtering of transparent conducting oxides", Thin Solid Films 516, 5847-5859 (2008).

[140] V. Sittinger, O. Lenck, M. Vergöhl, B. Szyszka and G. Bräuer, "Applications of HIPIMS metal oxides", Thin Solid Films 548, 18-26 (2013). 
[141] V. Tiron, L. Sirghi and G. Popa, "Control of aluminum doping of ZnO:Al thin films obtained by high-power impulse magnetron sputtering”, Thin Solid Films 520, 4305-4309 (2012).

[142] A. Anders and J. Brown, "A Plasma Lens for Magnetron Sputtering”, IEEE Transactions on Plasma Science 39, 2528-2529 (2011).

[143] O. Stenzel, The Physics of Thin Film Optical Spectra, Vol. 44, Springer Series in Surface Sciences (Springer-Verlag, Berlin/Heidelberg, 2005).

[144] C. Celindano, "Croissance et propriétés de pérovskites en couches minces pour le solaire photovoltaïque", Master thesis (Université de Lorraine, Nancy, 2016).

[145] H. G. Tompkins and E. A. Irene, eds., Handbook of ellipsometry (William Andrew Pub. ; Springer, Norwich, NY : Heidelberg, Germany, 2005).

[146] J. Tauc, R. Grigorovici and A. Vancu, "Optical Properties and Electronic Structure of Amorphous Germanium”, physica status solidi (b) 15, 627-637 (1966).

[147] B. D. Viezbicke, S. Patel, B. E. Davis and D. P. Birnie, "Evaluation of the Tauc method for optical absorption edge determination: $\mathrm{ZnO}$ thin films as a model system", physica status solidi (b) 252, 1700-1710 (2015).

[148] W. Chamorro, D. Horwat, P. Pigeat, P. Miska, S. Migot, F. Soldera, P. Boulet and F. Mücklich, "Near-room temperature single-domain epitaxy of reactively sputtered ZnO films", Journal of Physics D: Applied Physics 46, 235107 (2013).

[149] F. M. Smits, "Measurement of Sheet Resistivities with the Four-Point Probe”, Bell System Technical Journal 37, 711-718 (1958).

[150] Van der Pauw, L.J., "A method of measuring specific resistivity and hall effect of discs of arbitrary shape", Philips Research Reports 13, 1-9 (1958). 
[151] C. Hammond, The basics of crystallography and diffraction, 3rd ed, International Union of Crystallography texts on crystallography 12 (Oxford University Press, Oxford ; New York, 2009).

[152] M. Birkholz, P. F. Fewster and C. Genzel, Thin film analysis by $X$-ray scattering (Wiley-VCH, Weinheim, 2006).

[153] M. Wohlschlögel, T. U. Schülli, B. Lantz and U. Welzel, "Application of a single-reflection collimating multilayer optic for $\mathrm{X}$-ray diffraction experiments employing parallel-beam geometry", Journal of Applied Crystallography 41, 124-133 (2008).

[154] A. L. Patterson, “The Scherrer Formula for X-Ray Particle Size Determination”, Physical Review 56, 978-982 (1939).

[155] T. H. de Keijser, J. I. Langford, E. J. Mittemeijer and A. B. P. Vogels, "Use of the Voigt function in a single-line method for the analysis of X-ray diffraction line broadening”, Journal of Applied Crystallography 15, 308-314 (1982).

[156] D. B. Williams and C. B. Carter, Transmission electron microscopy: a textbook for materials science, 2nd ed (Springer, New York, 2008).

[157] B. J. Griffin, "A comparison of conventional Everhart-Thornley style and in-lens secondary electron detectors-a further variable in scanning electron microscopy", Scanning 33, 162-173 (2011).

[158] J. F. Watts and J. Wolstenholme, An introduction to surface analysis by XPS and AES (J. Wiley, Chichester, West Sussex, England ; New York, 2003).

[159] T. Tohsophon, J. Hüpkes, S. Calnan, W. Reetz, B. Rech, W. Beyer and N. Sirikulrat, "Damp heat stability and annealing behavior of aluminum doped zinc oxide films prepared by magnetron sputtering", Thin Solid Films 511-512, 673-677 (2006).

[160] J. Hüpkes, J. Owen, M. Wimmer, F. Ruske, D. Greiner, R. Klenk, U. Zastrow and J. Hotovy, "Damp heat stable doped zinc oxide films”, Thin Solid Films 555, 48-52 (2014). 
[161] J. I. Kim, W. Lee, T. Hwang, J. Kim, S.-Y. Lee, S. Kang, H. Choi, S. Hong, H. H. Park, T. Moon and B. Park, "Quantitative analyses of damp-heat-induced degradation in transparent conducting oxides", Solar Energy Materials and Solar Cells 122, 282-286 (2014).

[162] J. Crank, The mathematics of diffusion, 2d ed (Clarendon Press, Oxford, [Eng], 1975).

[163] J. C. Sit, D. Vick, K. Robbie and M. J. Brett, “Thin Film Microstructure Control Using Glancing Angle Deposition by Sputtering”, Journal of Materials Research 14, 1197-1199 (1999). 


\section{Papers}

The papers associated with this thesis have been removed for copyright reasons. For more details about these see:

http:// urn.kb.se/ resolve?urn=urn:nbn:se:liu:diva-142925 